\title{
Initial Borehole Accelerometer Array Observations Near the North Portal of the ESF
}

Final

$08 / 17 / 2005$

\begin{abstract}
Prepared by the Nevada Seismological Laboratory for the U.S. DOE/UCCSN Cooperative Agreement Number DE-FC28-98NV12081
\end{abstract}

Task Title: $\quad$ Southern Great Basin Seismic Network Operations

Task Number: ORD-FY04-006:

Document ID: TR-04-001, Rev. 0

Originator:

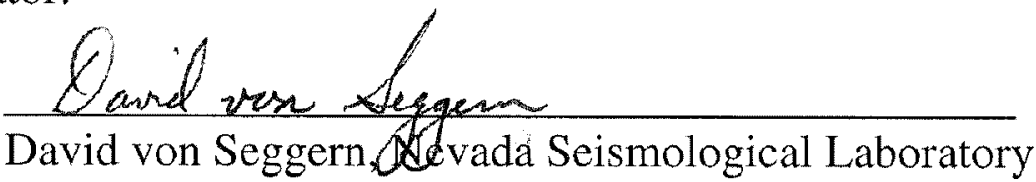

Note: In order to print the figure captions on pp. 38-87, you must set in the print dialogue box the option to print "Document and Markups" (or "document and Comments", depending on the Acrobat version).

Approvals:

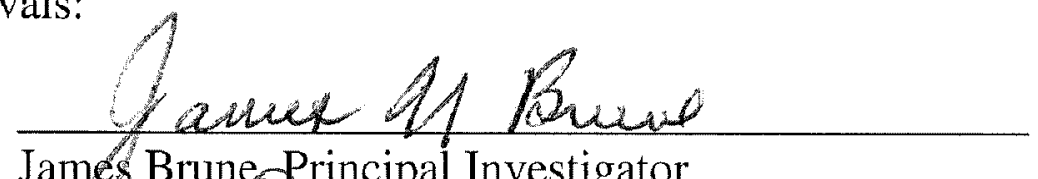

James Brune, Principal Investigator

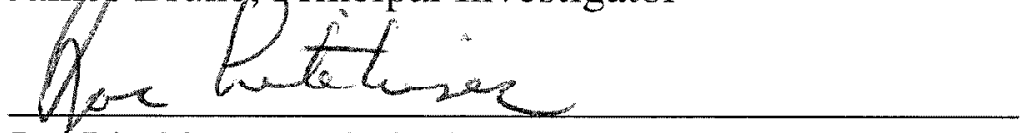

Joe Litehiser, Technical Reviewer

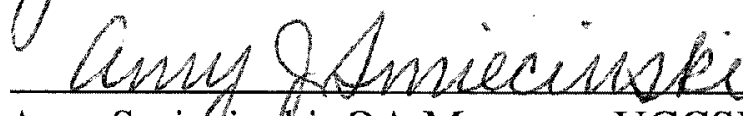

Amy Smiecinski, QA Manager, UCCSN

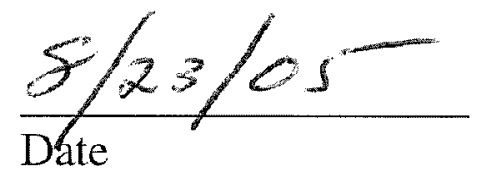

$8-19-05$

Date

$\frac{8-26-05}{\text { Date }}$ 


\section{TABLE OF CONTENTS}

List of Figures $\quad 3$

List of Tables

$\begin{array}{lr}\text { Abstract } & 6\end{array}$

1. Introduction $\quad 8$

2. Installation of the Array 10

3. Calibration of Instruments 12

4. PGA/PGV Results 14

$\begin{array}{lr}\text { 5. Spectral Observations } & 18\end{array}$

6. Relationship to Known Site Geology 20

7. Signal Correlation Among Boreholes 22

8. Transfer Functions for Deep to Surface Signals 25

9. Relationship to PSHA Predictions 29

10. Conclusions 32

$\begin{array}{ll}\text { References } & 35\end{array}$

Appendices

1. PGA Values for 8 Events in 2003

2. PGV Values for 8 Events in 2003 


\section{List of Figures (figures placed at end of report)}

1. Map of the pad at the north portal of the ESF. The borehole locations are shown, with the three having accelerometers circled. This figure is taken exactly from Luebbers et al. (2002), Figure 2, except for the added circles.

2. Ground-motion data flow from the accelerometers on the ESF pad to recording on hard disk at NSL.

3. Accelerometer recordings of an M 2.5 earthquake on day 304 in Rock Valley (Table 3), approximately $26 \mathrm{~km}$ from the ESF north portal. The recordings are grouped by borehole on three pages. (Q data in TDA \# 006DV.003)

4. PGA values for usable signals in 2003 . Values are grouped by component $(\mathrm{Z}, \mathrm{N}, \mathrm{E})$ on three pages. (Q data in TDA \# 006DV.007 -- derived from TDA \# 006DV.003)

5. PGA ratios (surface-to-midhole and surface-to-deep) for usable signals in 2003. Ratios are computed from the data displayed in Figure 4 and grouped by component $(Z, N, E)$ on three pages. (Q data in TDA \# 006DV.007 -- derived from TDA \# 006DV.003)

6. Averages of PGA ratios over available events $(\mathrm{s}=$ surface, $\mathrm{m}=$ midhole, $\mathrm{d}=\mathrm{deep})$. Ratios are computed from the data displayed in Figure 4. (Q data in TDA \#006DV.007 -- derived from TDA \# 006DV.003)

7. Velocity traces of an M 2.5 earthquake on day 304 in Rock Valley (Table 3), integrated from the accelerometer recordings shown in Figure 3. The traces are grouped by borehole on three pages. (Q data in TDA \# 006DV.003)

8. PGV values for usable signals in 2003 . Values are grouped by component $(\mathrm{Z}, \mathrm{N}, \mathrm{E})$ on three pages. (Q data in 006DV.007 -- derived from TDA \# 006DV.003)

9. Accelerometer spectra of the day 304 earthquake in Rock Valley (see Figure 3 for time series). The spectra are grouped by sensor on nine pages. (Q data derived from TDA \# 006DV.003 with program SAC)

10. Spectral ratios for spectra shown in Figure 9. The ratios are surface/deep, surface/midhole, and midhole/deep for each borehole. (Q data derived from TDA \# 006DV.003 with program $\mathrm{SAC})$

11. Acceleration response spectra (Sa) for the surface accelerograms of the day 304 earthquake in Rock Valley (see Figure 3 for time series). A 5\% damping constant is assumed. The spectra are grouped by borehole on three pages. (non-Q: not to be used for quality-affecting work; source data from TDA \# 006DV.003) 
12. A geologic cross-section through boreholes RF16 and RF13. This figure is taken exactly from Luebbers et al. (2002), Figure 226. (DTN's GS020383114233.003, MO0008GSC00286.000)

13. A geologic cross-section through boreholes RF13 and RF15. This figure is taken exactly from Luebbers et al. (2002), Figure 225. (DTN's GS020383114233.003, MO0008GSC00286.000)

14. Ratio of RF13 and RF16 PGA's to those of RF15, the reference site. Ratios are computed from the data displayed in Figure 4 and grouped by component (Z,N,E) on three pages. (Q data in TDA \# 006.DV.007 -- derived from TDA \# 006DV.003)

15. Geometry of signal propagation across the ESF pad for the Rock Valley earthquake on day 304. The projection is UTM.

16. $\mathrm{P}$ waves of the earthquake on day 304 in Rock Valley (Table 3). The recordings are at 200 sps; 60-cycle noise is clear on the surface accelerometer recordings. (Q data in TDA \# 006DV.003)

17. Correlation coefficients of the $\mathrm{P}$ waves among the three boreholes for different lowpass cutoff frequencies. "s"= surface, "m"= midhole, and "d"= deep. Only coefficients among recordings at similar depth (s,m,d) were computed. (Q data derived from TDA \# 006DV.003 with program SAC)

18. Actual P-wave transfer functions at the three boreholes determined from the signals recorded on day 304 in Rock Valley (Table 3). The transfer functions are the ratios of surface to deep spectra. (Q data derived from TDA \# 006DV.003 with program SAC)

19. Computed P-wave transfer functions at the three boreholes. A simple 1-D model with vertically propagating waves was assumed at each borehole. (non-Q: not to be used for quality-affecting work; source data from 006DV.003)

20. Observed peak horizontal accelerations recorded at the surface accelerometer at borehole RF15 (the "reference" site) versus extrapolations of the PSHA equations (CRWMS M\&O, 1998). (Observed data points are Q data in TDA \# 006.DV.007 -- derived from TDA \# 006DV.003; PSHA extrapolations are non-QA. Not to be used for quality-affecting work.) 


\section{List of Tables (tables placed inline)}

1. Parameters for Boreholes on the Pad for the Waste Handling Buildings (non-Q)

2. Emplacement Depths for Accelerometers (Q)

3. Events Selected for Analysis of PGA in the Borehole Array (non-Q)

4. Data Availability for the Events Selected for Analysis

5. Layered Earth Models for the Three Boreholes (non-Q) 


\begin{abstract}
This report addresses observed ground motions at the site of the proposed surface facilities associated with the designated repository for high-level nuclear waste at Yucca Mountain, Nevada. In 2003 an accelerometer array was installed at three boreholes on the pad of the north portal of the ESF (Exploratory Studies Facility) at Yucca Mountain, Nevada, by the Nevada Seismological Laboratory (NSL). These boreholes, roughly $150 \mathrm{~m}$ apart and initially used for extensive geological and geophysical surveys, were ideal locations to measure the subsurface ground motions at the proposed site of surface facilities such as the Waste Handling Building. Such measurements will impact the design of the facilities. Accelerometer emplacement depths of approximately $15 \mathrm{~m}$ from the surface and then at the bottom of the boreholes, roughly $100 \mathrm{~m}$, were chosen. Accelerometers were also placed at the surface next to the boreholes, for a total of nine accelerometers, all three-component. Data recording was accomplished with onsite recorders, with the onsite data transmitted to a central computer at a trailer on the pad. All requirements were met to qualify these data as "Q". Due to the lack of significant recordings during 2003, several low signal-to-noise (S/N) quality events were chosen for processing. The maximum horizontal peak ground acceleration (PGA) recorded at the pad was approximately 1 $\mathrm{cm} / \mathrm{s}^{2}$ in 2003 ; the corresponding peak ground velocity $(\mathrm{PGV})$ was approximately $0.01 \mathrm{~cm} / \mathrm{s}$. PGA and PGV were obtained at all nine accelerometers for most of these events, and spectra were computed. Ground motion amplitudes varied significantly across the boreholes. Higher ground amplifications were observed at the surface for the two boreholes that penetrated a thick amount $(\sim 30 \mathrm{~m})$ of fill and Quaternary alluvium compared to the one that had less than $2 \mathrm{~m}$ of such. Additionally, surface-to-deep recordings showed as much as a factor of five amplification at these two boreholes. Signal correlation with inter-borehole distance agrees with basic
\end{abstract}


scattering theory, and the recorded signals across the wavefront correlate more strongly than those along the propagation path. Transfer functions computed from layered models for each borehole reflect some of the actual signal attributes fairly well, but many more signals need to be recorded and used to provide a good basis of comparison. 


\section{Introduction}

The north portal area of the ESF at Yucca Mountain has an extensive built-up pad of leveled rock and dirt material. Much of this area is proposed to be the site of a complex called the Surface Facilities Area (SFA) where high-level waste would be finally prepared for storage underground. During 1998-2000, 16 holes were drilled on this pad as part of an extensive geotechnical program to characterize the site (Luebbers et al., 2002). The program included measuring shear-wave velocity in several ways.

Table 1. Parameters for Boreholes on the Pad for the Waste Handling Buildings (non-Q: not to be used for quality-affecting work)

\begin{tabular}{|c|c|c|c|c|}
\hline Borehole & $\begin{array}{l}\text { Steel } \\
\text { Surface } \\
\text { Casing } \\
\text { Depth } \\
\text { (ft) }\end{array}$ & $\begin{array}{c}\text { 8-1/2" } \\
\text { Diameter } \\
\text { Drilled } \\
\text { Depth (ft) }\end{array}$ & $\begin{array}{c}\text { Grouted } \\
\text { PVC } \\
\text { Casing } \\
\text { Depth } \\
\text { (ft) }\end{array}$ & $\begin{array}{l}\text { PVC Casing } \\
\text { Diameter }\end{array}$ \\
\hline UE-25 RF\#13 & 5.0 & 350.0 & 350.0 & 3.5" O.D. x 3.042" I.D. \\
\hline UE-25 RF\#14 & 4.7 & 550.2 & 550.0 & 4.5" O.D. x 3.786" I.D. \\
\hline UE-25 RF\#15 & 4.6 & 330.0 & 323.6 & 4.5" O.D. x 3.786" I.D. \\
\hline UE-25 RF\#16 & 4.9 & 452.8 & 451.4 & 4.5" O.D. x 3.786" I.D. \\
\hline UE-25 RF\#17 & 4.9 & 667.8 & 656.0 & 4.5" O.D. x 3.786" I.D. \\
\hline UE-25 RF\#18 & 4.7 & 493.6 & 492.4 & 4.5" O.D. x 3.786" I.D. \\
\hline UE-25 RF\#19 & 4.8 & 645.2 & 645.7 & 4.5" O.D. x 3.786" I.D. \\
\hline UE-25 RF\#20 & 4.7 & 160.0 & 159.7 & 4.5" O.D. x 3.786" I.D. \\
\hline UE-25 RF\#21 & 5.0 & 192.2 & 192.0 & 4.5" O.D. x 3.786" I.D. \\
\hline UE-25 RF\#22 & 5.0 & 540.6 & 511.4 & 4.5" O.D. x 3.786" I.D. \\
\hline UE-25 RF\#23 & 5.0 & 159.1 & 159.0 & 4.5" O.D. x 3.786" I.D. \\
\hline UE-25 RF\#24 & 4.9 & 268.0 & 266.1 & 4.5" O.D. x 3.786" I.D. \\
\hline UE-25 RF\#25 & 4.9 & 159.0 & 158.5 & 4.5" O.D. x 3.786" I.D. \\
\hline UE-25 RF\#26 & 4.9 & 264.9 & 259.9 & 4.5" O.D. x 3.786" I.D. \\
\hline UE-25 RF\#28 & 4.9 & 99.8 & 98.0 & 4.5" O.D. x 3.786" I.D. \\
\hline UE-25 RF\#29 & 4.5 & 429.9 & 409.7 & 4.5" O.D. x 3.786" I.D. \\
\hline
\end{tabular}

In order to provide basic ground motion data to evaluate site response effects at the SFA, it was decided in early 2002 to install accelerometers in three of these boreholes and at the surface next 
to the holes. This work was performed by the NSL. Boreholes RF13, RF15, and RF16 were chosen for reasons of accessibility, of line-of-site to a central recording structure, and of variation in subsurface character. The boreholes are shown in Figure 1, which is a map of the pad at the north portal of the ESF; the boreholes with accelerometer installations are circled. Data for all the boreholes are shown in Table 1 (taken from Luebbers et al.). The distances

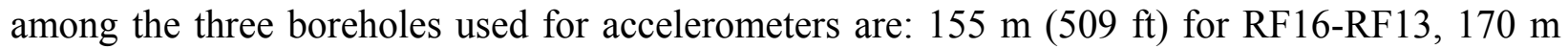
(558 ft) for RF13-RF15, and $223 \mathrm{~m} \mathrm{(732} \mathrm{ft)} \mathrm{for} \mathrm{RF15-RF16.} \mathrm{It} \mathrm{was} \mathrm{decided} \mathrm{to} \mathrm{place}$ accelerometers at the borehole bottoms to baseline the incoming wavefield and also at shallow depths to provide readings in the upper part of the consolidated rock. The emplacement depths of the six accelerometers in the three holes are shown in Table 2. These depths were measured by the procedure documented in IPR-021.

Table 2. Emplacement Depths for Accelerometers (Q)

\begin{tabular}{|l|l|l|}
\hline Borehole & $\begin{array}{l}\text { Midhole emplacement depth } \\
\text { in feet }(\mathrm{m})\end{array}$ & $\begin{array}{l}\text { Deep emplacement } \\
\text { depth in feet }(\mathrm{m})\end{array}$ \\
\hline RF13 & $30(9.1)$ & $350(106.7)$ \\
\hline RF15 & $50(15.2)$ & $324(98.8)$ \\
\hline RF16 & $50(15.2)$ & $451(137.5)$ \\
\hline
\end{tabular}

The surface accelerometers are 3-component Episensor models from Kinemetrics, Inc. The downhole accelerometers are Hyposensor models from Kinemetrics, Inc., a version of the Episensor designed for shallow borehole deployments. These accelerometers have linear response from $\mathrm{DC}$ to $200 \mathrm{~Hz}$ and a dynamic range of $140 \mathrm{~dB}$. The output levels of these sensors can be set by the user; for this project, they were set at $2 \mathrm{~g}$ at full scale of $20 \mathrm{v}$, or $10 \mathrm{v} / \mathrm{g}$. 
Hereafter, the sensor positions will be referred to as "surface", "midhole", or "deep" although "midhole" is really very shallow. This allows for further contraction occasionally to "s", "m", or "d".

\section{Installation of the Array}

The installation of the accelerometers was governed by IPR-021 (Installation, Operation, and Maintenance of the Yucca Mountain Borehole Strong Motion Network). Details of the preinstallation and installation are given in Scientific Notebook UCCSN-UNR-039 (Development of Seismic Data Collection in the ESF Tunnel and on the WHB Pad). Prior to installation, the three boreholes were examined for water accumulation. All three boreholes had significant water and were pumped dry (156 feet from RF13, 207 feet from RF15, and 11 feet from RF16). Due to the cost and difficulty of providing $\mathrm{A} / \mathrm{C}$ power to the borehole locations, it was decided to power the accelerometers and their recording equipment with solar panels. A concrete pad (6 ft x $5 \mathrm{ft})$ was poured at each borehole to accommodate the solar panels, the storage batteries, and the electronic equipment. Another pad ( $4 \mathrm{ft} \times 4 \mathrm{ft}$, with 6 'inch depth) was poured to hold the surface accelerometer.

Surface sensors were oriented with a compass, leveled, and bolted to the concrete pads. For the downhole accelerometers, locking mechanisms were specially fabricated to hold the Hyposensors in position once they had been lowered to the proper depths. The robustness of this locking mechanism to $2 \mathrm{~g}$ of acceleration was lab-tested by locking the accelerometers in PVC pipe and shaking it. A digital compass was attached to the locking frame for the deep accelerometers, and these instruments were rotated by the cable to approximately attain the 
correct orientation prior to locking. The midhole borehole instruments did not require this step due to the short length over which they were lowered into the hole. The orientation is only approximate, but probably accurate to within $10^{\circ}$; and it is intended that observations over some undetermined period of time will confirm the orientation to within $10^{\circ}$ or better. Attaining exact $\mathrm{N}-\mathrm{S}$ and E-W orientation was not part of the project specification because the main interest was recording horizontal ground motions, regardless of direction.

Installation of the accelerometers was completed on 18 March 2003. The recording equipment was then installed and connected to the central recording site on the pad. A schematic of the recording setup is shown in Figure 2. The data loggers chosen were Q330 models from Kinemetrics, Inc. These recorders handle up to six input channels with 24-bit A/D conversion. Data are initially sampled at a high rate of 1000 sps; after this it can be downsampled to various rates for recording, and 200 sps was chosen for this project. Taking advantage of the 6-channel capability, only two Q330's were installed at each borehole; one records the surface and deep accelerometers while the other records the midhole borehole accelerometer. An onsite backup capability was also installed in the form of "Baler-14" disk devices from Kinemetrics. These 20GB disk units are set to record continuously in FIFO style, one per Q330, in order that data are preserved in the case of failure of transmission links to the central recording site on the pad, of software/hardware problems with the Sun computer at the central site, or of power outages at the central site. The disk units provide almost a month of backup data for the 6-channel recorders and more for the 3-channel ones. Recording was initiated for all the boreholes on 18 March 2003. 
The digitized data are relayed to the central recording site on the pad with spread-spectrum BreezeCOM radios manufactured by Alvarion. There it is cabled into one of the Ethernet cards of the Sun computer. This card supports a "private" network consisting of the Q330's, the radios, and the Sun computer. The Sun is reachable from the outside through its other Ethernet card, but only through a firewall requiring UNIX "ssh" access. NSL personnel are able to log onto the computer and review data files remotely, with "tcp" file transfer available. The data are collected centrally on the pad in the Antelope software system (BRTT, Inc.) through the program Q3302ORB (STN \# UCCSN-004, V4.5), which receives the digital data packets off the private network and puts them into the Antelope system. Q3302ORB controls the Q330 units insofar as setting sample rates, station and channel names, types of auxiliary data to record (for example, temperature), and telemetry-related parameters. Antelope archives the data in daily files for each station-component; data are continuous in these 27 separate files.

\subsection{Calibration of Instruments}

Quality Assurance (QA) requirements state that instruments used in data collection for the Yucca Mountain Project must be fully calibrated. In this case, we performed an extensive "calibrationfor-use" on both the sensors and the data loggers. These calibration procedures are documented in IPR-021 and will only be summarized here. Actual results of the procedures were recorded in Scientific Notebook UCCSN-UNR-039 (Development of Seismic Data Collection in the ESF Tunnel and on the ESF Pad).

The calibration of the sensors consisted of: 
* With the sensors mounted on a tilt-table, they were rotated through $15^{\circ}$ increments starting from vertical through a full $180^{\circ}$. Output was compared to theoretical outputs calculated from the geometry. This was repeated for all three components of the sensor.

* The sensors were placed next to a standard seismometer to compare the noise floor.

* Monochromatic signals at frequencies from $0.1 \mathrm{~Hz}$ to $50 \mathrm{~Hz}$ were applied to the calibration coils to test the constancy of the response of the sensors to varying frequency.

The calibration of the data loggers consisted of:

* Monochromatic signals from $0.2 \mathrm{~Hz}$ to $20 \mathrm{~Hz}$ of constant amplitude were input to the recorders to test the uniformity of output and to verify the manufacturer's specified gain (counts/v).

* Voltage steps of various amplitudes were input to test the linearity of the response.

* Signals were input to both the Q330 and to an independent digital recorder, manufactured by RefTek, Inc.; and then the recorded data were compared to confirm that the Q330 timing was correct.

* Simultaneity of sampling was tested by applying a single step signal to all channels at once.

These tests were all passed and documented prior to the instruments being taken to the recording site. A procedure for checking that the instruments remain within certain tolerances was specified in IPR-021. In this procedure, a step of voltage is applied to the calibration circuit by the Q330 unit itself. The actual voltage step change on the calibration line is measured with a calibrated voltage meter. The output of the Q330 is then examined after its recording by the 
Antelope system. The value of the step in counts on the recording must agree to within $5 \%$ of that which is predicted by taking into account the constants of the sensor's calibration circuit and output circuit and the constant counts/volt of the data logger. Details of the calculation are given in IPR-021. This system check is repeated at intervals of two months and is done on all three components of all nine sensors. The first complete system check was made on 17 April 2003, with results showing everything in tolerance. Since this date, no components have been found to be out of tolerance throughout 2003, except for a period of time when a substitute recorder was used for the midhole accelerometer at RF-16 (calibration status was not determined).

\section{PGA/PGV Results}

This section treats PGA and PGV observations made from available recordings in 2003. PGA and PGV are basic inputs to seismic design and were treated extensively in the PSHA (Probabilistic Seismic Hazard Analysis) study for Yucca Mountain (CRWMS M\&O, 1998). In order to preserve significant ground-motion data from the borehole sensors, the hypocenter lists formed by NSL for Nevada seismic activity and by other regional networks outside Nevada are reviewed daily for events that may have usable signals at the borehole array. In addition, 24hour plots of seismic activity are examined daily for several stations of the Southern Great Basin Digital Seismic Network (SGBDSN). Since the borehole array was installed and thereafter through the end of calendar year 2003, there was not any significant seismic activity in the vicinity of Yucca Mountain. Therefore, only eight events have been selected to report on here; and none of them have excellent signal-to-noise $(\mathrm{S} / \mathrm{N})$ ratios. The date, time, magnitude, and distance to the ESF pad of the events are compiled in Table 3; these data were taken from available preliminary locations made at the NSL and are non-Q. Although non-Q data, the 
locations are reliable and are fairly accurate due to the size of the events, as indicated by the number of observations (“\#obs”) and the standard deviations of the errors (“major minor depth"). Epicentral errors are very likely less than $2-3 \mathrm{~km}$, quite small in comparison to the calculated distances (70 to $198 \mathrm{~km}$ ) from the events to the borehole recording site. Thus there will be no impact on the data analysis here due to errors in distance or azimuth calculated between the pad and the epicenters.

The events are again listed in Table 4 along with a notation indicating the data status at each of the nine sensors. Some Q330 problems prevented full recording, across all nine sensors, of some of these events; and one unit at RF16S was temporarily replaced in late 2003, resulting in some non-Q data due to its not being calibrated ("UC" in Table 4). Such problems are associated with the startup phase and, as of early 2004, they are solved. For some of the events, signal quality was so poor at certain sensors that the recordings were simply not usable. Only data tagged as "OK" in Table 4 is used in this report.

Table 3: Events Selected for Analysis of PGA in the Borehole Array (non-Q: not to be used for quality-affecting work; TDA \#006DV.008)

\begin{tabular}{|c|c|c|c|c|c|c|c|c|c|c|c|}
\hline $\begin{array}{l}\text { julia } \\
\text { day }\end{array}$ & date & $\begin{array}{r}\text { time } \\
\text { UTC }\end{array}$ & lat. & lon. & $\begin{array}{l}\text { depth } \\
(\mathrm{km})\end{array}$ & ML & \#obs & $\begin{array}{r}\text { standa } \\
\text { major } \\
(\mathrm{km})\end{array}$ & $\begin{array}{l}\text { rd devi } \\
\text { minor } \\
(\mathrm{km})\end{array}$ & $\begin{array}{l}\text { iation } \\
\text { depth } \\
(\mathrm{km})\end{array}$ & $\begin{array}{c}\text { distance } \\
\text { to site } \\
(\mathrm{km})\end{array}$ \\
\hline 080 & $3 / 21 / 2003$ & $18: 46: 34$ & 36.658 & -117.174 & 9.0 & 3.44 & 40 & 0.77 & 0.59 & 1.65 & 70.0 \\
\hline 120 & $4 / 30 / 2003$ & $16: 19: 33$ & 36.677 & -117.191 & 6.4 & 3.06 & 33 & 0.95 & 0.79 & 2.01 & 70.9 \\
\hline 144 & $5 / 24 / 2003$ & $16: 16: 26$ & 36.709 & -116.303 & 11.2 & 2.23 & 44 & 0.59 & 0.55 & $\odot .80$ & 19.2 \\
\hline 194 & $7 / 13 / 2003$ & $20: 44: 25$ & 36.853 & -116.088 & 9.2 & 2.45 & 34 & 0.65 & 0.53 & 1.53 & 30.0 \\
\hline $3 \odot 4$ & $10 / 31 / 2003$ & $13: 57: \odot 4$ & 36.701 & -116.206 & 9.2 & 2.47 & 50 & 0.57 & 0.51 & 0.85 & 25.7 \\
\hline $319 a$ & $11 / 15 / 2003$ & $20: 11: 59$ & 38.221 & -117.873 & 8.7 & 4.47 & 38 & 1.37 & 0.75 & 1.20 & 198.5 \\
\hline $319 b$ & $11 / 15 / 2003$ & $21: 19: 36$ & 38.218 & -117.869 & 6.4 & 4.47 & 27 & 1.97 & 0.98 & 4.44 & 198.1 \\
\hline 354 & $12 / 20 / 2003$ & $16: 35: 23$ & 37.200 & -117.869 & 8.9 & 4.15 & 31 & 1.74 & 0.70 & 3.85 & 133.7 \\
\hline
\end{tabular}


Table 4: Data Availability for the Events Selected for Analysis

\begin{tabular}{|lccccccccc|}
\hline jdate & RF13_s & RF13_m & RF13_d & RF15_s & RF15_m & RF15_d & RF16_s & RF16_m & RF16_d \\
\hline 080 & OK & OK & NG & OK & OK & OK & OK & OK & ND \\
\hline 120 & OK & OK & NG & NG & OK & OK & NG & NG & NG \\
\hline 144 & OK & OK & OK & OK & OK & OK & OK & OK & OK \\
\hline 194 & ND & OK & ND & OK & OK & OK & OK & OK & OK \\
\hline 304 & OK & OK & OK & OK & OK & OK & OK & OK & OK \\
\hline $319 a$ & OK & OK & OK & OK & OK & OK & OK & UC & OK \\
\hline $319 b$ & OK & OK & OK & OK & OK & OK & OK & UC & OK \\
\hline 354 & OK & OK & OK & NG & OK & OK & OK & OK & OK \\
\hline
\end{tabular}

$\mathrm{OK}=$ data are usable

$N G=$ data are too noisy

$\mathrm{ND}=$ no data recorded

$\mathrm{UC}=$ uncalibrated status

$\mathrm{s}=$ surface sensor

$\mathrm{m}=$ midhole sensor

$\mathrm{d}=$ deep sensor

Only recording of the events on days 144 and 304 is complete for all sensors. The accelerograms for the event on day 304 are plotted in Figure 3 for all the sensors in order to show an example of the quality of recordings. For those events and sensors labeled as "OK" in Table 4, the PGA (peak ground acceleration) was taken from the raw recordings on each component, after mean removal, using the SAC program (STN \# 10085-00.46). The actual PGA values are tabulated in Appendix 1.

The graphical presentations of these PGA values in $\mathrm{cm} / \mathrm{s}^{2}$ are shown in Figure 4 for each component. Clearly the amplitudes decrease from the surface down to the deep sensor locations. RF16 has the largest surface amplitudes in almost all cases while RF15 generally shows the smallest surface amplitudes. Amplitudes on horizontal components are generally larger than those on the vertical components for the same event, with some horizontal amplitudes over twice as large as the vertical ones. The ratios of surface amplitudes to those in the midhole and deep locations are shown in Figure 5 for the three components. The vertical amplification at 
RF16 (surface over deep) is usually at least a factor of 5, with one value ( $\mathrm{N}$ component for event on day 080 ) equal to 15 . Horizontal component amplifications at RF16 are generally much less. Vertical and horizontal amplifications (surface to deep) at the other two boreholes are generally less than a factor of 5 .

Amplification between the midhole borehole sensor PGA values and those at the surface are generally in the range of 1 to 3 , with only a few exceptions. The averages of these ratios, over all available events in each case, are shown in Figure 6. The components $\mathrm{Z}, \mathrm{N}$, and $\mathrm{E}$ track one another well. Borehole RF16 here is definitely seen to have the highest amplifications from the deep sensor to the surface sensor and also from the midhole ("mid") borehole sensor to the surface sensor. RF13 and RF15 have very similar average ratios.

Velocity traces were computed from the acceleration traces for all the events of Table 3 using program SAC (STN \# 10085-00.46). The mean and trend of the acceleration traces were removed prior to integration in the time domain. As an example, the velocity traces for the day 304 event are shown in Figure 7, corresponding to the acceleration traces in Figure 3. From the velocity traces, the peak ground velocity (PGV) values were determined for the three components of motion (Appendix 2). The results are plotted in $\mathrm{cm} / \mathrm{s}$ in Figure 8 for all three components. Actual PGV values are tabulated in Appendix 2. Similar to the pattern for PGA values, the surface PGV values at RF16 are usually the largest of the three surface accelerometers. PGV's at the deep accelerometers are factors of two to ten less than those at the surface, similar to the PGA observations. 


\section{Spectral Observations}

Beyond simply PGA and PGV, more detailed information can be extracted from the signals in the spectral domain, provided that $\mathrm{S} / \mathrm{N}$ remains greater than one over a sufficiently broad bandwidth. Spectral estimates of ground motion were also treated in the PSHA study (CRWMS M\&O, 1998). The Fourier amplitude spectra of the usable signals listed in Table 4 were computed with program SAC (STN \# 10085-00.46). Prior to the spectral computation, the signals were windowed from a few seconds prior to the $\mathrm{P}$ arrival through the S-wave coda, demeaned, and tapered with a Hanning half-window for $5 \%$ of the window length on each end. The spectra for the event on day 304, for which recording was complete, are shown in Figure 9 (the corresponding time series are shown in Figure 3). The amplitude spectra scaling is in units of $\left(\mathrm{cm} / \mathrm{s}^{2}\right)-\mathrm{s}$, equivalent to $\mathrm{cm} / \mathrm{s}$. Noise spectra were examined for noise windows just prior to the signal. The noise spectra were generally flat (white noise) with maximum values at $10^{-3}$ $\left(\mathrm{cm} / \mathrm{s}^{2}\right)$-s or less at nearly all frequencies at all sensors. Thus very little, if any, signal energy lies above the noise for frequencies higher than $50 \mathrm{~Hz}$. Similarly, signal spectra at less than $1 \mathrm{~Hz}$ are not reliable. In general, for any given borehole, the spectral amplitudes at the surface exceed those at the midhole sensor by a factor of two or more while the ratios for surface-to-deep sensors are roughly in the range of 5 to 10.

Due to the fact that $\mathrm{S} / \mathrm{N}$ ratios are different for the eight events treated here and that these ratios vary across the spectra of any particular event, an average for the ratio of surface-to-midhole and surface-to-deep spectral amplitudes was not computed over all the events. The spectral ratios for the event on day 304 were computed as representative though and are shown in Figure 10. There 
are nine plots, three for each borehole. For a given borehole, the ratios of surface/deep, surface/midhole, and midhole/deep amplitudes are shown for all three components of motion. The surface/deep spectral ratios generally reflect the PGA ratios shown in Figure 6. Except for the horizontal components at RF16, the surface/midhole ratios are near unity below approximately $10 \mathrm{~Hz}$. Corresponding surface/deep ratios at these lower frequencies are factors of two or more. At high frequencies $(>40 \mathrm{~Hz})$, the surface amplitudes are still significantly amplified in comparison to the deep ones; however, most of the amplification appears to be in the shallow layers as the midhole/deep ratios are near unity at these high frequencies.

A type of spectrum which is of interest to engineering seismologists is the acceleration response spectrum, usually termed $S a$. This spectrum shows, at a given frequency $\mathrm{f}_{0}$, the peak response of a damped one-degree-of-freedom oscillator, with natural frequency $f_{0}$, to an input taken to be an actual observed accelerogram. The Sa can be computed for Z, N, and E components of motion. It can be computed for a range of frequencies, hence "spectrum", and for any given damping coefficient. The most commonly chosen damping is $0.05(5 \%)$, and that was assumed here. The $S a$ is intended to show the maximum response of typical structures, with varying $\mathrm{f}_{0}$, to specific ground motion measured as acceleration.

Using the actual surface accelerograms of the earthquake on day 304 (Table 3), the response spectra were computed for the range of $0-50 \mathrm{~Hz}$ for all three components of motion using an unqualified MatLab program called response_spectrum.m. The computed response spectra for the surface stations at the three boreholes are shown in Figure 11; note the change in scale for the RF16 plot. The amplitudes of RF13 and RF16 Sa relative to RF15 Sa show the same character 
as seen previously in Figure 9 for the ordinary spectra. RF16 shows amplitudes on the horizontal components 2 to 4 times greater than those of RF15 in the range of 8 to $15 \mathrm{~Hz}$. RF13 shows lesser amplifications relative to RF15, roughly a factor of two. Below $8 \mathrm{~Hz}$ the amplification factors drop rapidly to approximately unity. Note that the peaks in these response spectra, in the $5-15 \mathrm{~Hz}$ range, are controlled by the small magnitude of the earthquake; they would be expected to shift to lower frequencies for larger magnitudes.

\section{Relationship to Known Site Geology}

It is important to relate the results so far to the known subsurface conditions at the borehole sites. Some confirmation of the pattern of variability seen for the time-domain and spectral-domain amplitudes should exist when known geologic parameters are used for prediction. Downhole velocity surveys (Luebbers et al., 2002) measured both compressional-wave and shear-wave velocity profiles in the boreholes. Cuttings logs, also reported in Luebbers et al., defined the stratigraphic profile. The stratigraphy in each borehole was used to develop a 3-D model of the entire SFA. Important to the current study are the cross-sections developed between the boreholes RF16-RF13 and RF13-RF15, shown in Figures 12 and 13, respectively. The borehole locations were previously shown in map view in Figure 1. Figures 12 and 13 show that RF16 has somewhat less thickness of fill and alluvium (23 m)than RF13 (30 m). Figure 13 shows that borehole RF15 penetrates the subsurface where not only the fill material is nearly absent but where the Quaternary alluvium layer (Qal) is very thin compared to RF13. On this evidence alone, one might expect surface recordings made at RF15 to have smaller amplitudes than at either RF13 or RF16, in agreement with observations shown here in previous figures. In 
addition, RF13 penetrates a high-angle normal fault, offsetting the strata by 30 to $40 \mathrm{~m}$; this fault dips to the north and trends roughly east-west. Neither RF15 nor RF16 penetrate any faults.

In this analysis, RF15 is considered as a reference site for computing the amplification at the other two boreholes because of its near absence of fill and alluvium. Figure 14 shows the ratios of surface PGA's (RF13/RF15 and RF16/RF15) for each event and for all three components of motion. For the $\mathrm{Z}$ component, the amplification factor is roughly between one and two, with RF16 showing the higher ratios. For the horizontal components, this factor of one to two is generally true for the RF13/RF15 ratios; but the RF16/RF15 ratios are significantly higher, nearly five for the event on day 080 (Table 3).

A common measure used in engineering seismology is called $V_{30}$, the average velocity in the first 30 meters (100 feet) of the subsurface. $V_{30}$ was introduced by Boore et al. (1994) and presented again in Boore et al. (1997) as a simple parameter that correlates with the amplification of PGA or PGV for varying subsurface composition. Here, we are merely concerned with the relative amplitudes among RF13, RF15, and RF16. For any two observations (1 and 2) made at approximately the same distance from a common seismic event, equation 1 in Boore et al. (1997) reduces to

$$
\mathrm{A}_{1} / \mathrm{A}_{2}=\left(\mathrm{V}_{1} / \mathrm{V}_{2}\right)^{\mathrm{b}}
$$

where $b$ is a coefficient determined by regression on actual ground motions. This coefficient is always negative; a value of -0.4 to -0.6 is shown in Boore et al. (1997) for the band of frequencies having dominant amplitude in the observed acceleration spectra of this study (Figure 9). From this, a value of $b=-1 / 2$ is assumed. Actual $V_{30}$ values for the three boreholes are easily 
obtainable from figures of $\mathrm{S}$ travel time $\left(\mathrm{T}_{\mathrm{S}}\right)$ versus depth in the downhole velocity surveys published in Luebbers et al. (2002). For RF13, RF15, and RF16, Figures VIII-1, VIII-3, and VIII-4 of that report were used to estimate times at $100 \mathrm{ft}(30 \mathrm{~m}) 30$ because the graphs were plotted in units of feet. Then $V_{30}$ was computed as $T_{S} / 30.5$. The results for RF13, RF15, and RF 16 are $524 \mathrm{~m} / \mathrm{s}, 716 \mathrm{~m} / \mathrm{s}$, and $478 \mathrm{~m} / \mathrm{s}$, respectively.

As expected from known geology, RF15 has the highest $\mathrm{V}_{30}$; however, while near the upper end, this value still lies in the range 360 to $760 \mathrm{~m} / \mathrm{s}$ for site class "C" (FEMA, 1994). The other two boreholes also would fall in this class, although in the lower half of the range. Using the formula above with $b=-1 / 2$ for the $A_{1} / A_{2}$ amplitude ratio, one gets amplification factors of roughly 1.2 for both RF13/RF15 and RF16/RF15, taking RF15 to be the "reference", or \#2, site. In examining the observed surface PGA ratios of Figure 14, the 1.2 factor seems somewhat below the observed RF13/RF15 ratios and significantly less than the observed RF16/RF15 ratios, especially the horizontal ones that are as large as four or more. Part of the explanation at RF16 may be that low $\mathrm{S}$ velocities persist much deeper than at RF15 (Luebbers et al., 2002, Figures VII-3 and VII-4) and influence $\mathrm{V}_{30}$.

\section{Signal Correlation Among Boreholes}

It is important to define the signal variability for ground motions, even when observed at closely spaced sites such as at the SFA. Signal variability statistics indicate the degree of representativeness of isolated measurements and therefore help to establish the degree of confidence one has in extrapolating the measurements from one or more sites to the entire SFA. This section examines the signal variability among the three boreholes. 
The signal correlation among the three borehole sites was studied using again the day 304 earthquake signals (Figure 3). From Table 1, the epicentral distance is $25.7 \mathrm{~km}$; the back azimuth (borehole to epicenter) was computed to be $131^{\circ}$, nearly perpendicular to the profile from RF16 to RF13, and therefore in line with the propagation from either of these boreholes to RF15. The geometry of the wavefront relative to the boreholes is shown in Figure 15. This geometry then allows for relating signal correlation to raypath direction. Chernov (1960) predicted that waveforms recorded at sites perpendicular to the wavefront should decorrelate more rapidly than waveforms recorded at sites parallel with it.

The P waves on the vertical component were windowed from the original recordings in SAC (STN 10085-00.46) and are shown in Figure 16. High-frequency (60 cycles/s) power noise clearly affects the surface recordings. The correlation coefficients of the $\mathrm{P}$ waves were measured in SAC using a 4-s window centered on the first arrival; this window was tapered symmetrically from the center to a value of zero on the ends using a Hanning weighting function. Several filters were applied to the $\mathrm{P}$ waves prior to computation of the correlation coefficients. These filters were Butterworth bandpass with 8 poles; the frequency bands were: 0-2, 1-4, 2-8, 5-15, 10-40, $25-75 \mathrm{~Hz}$. The raw, unfiltered traces were also used in computing the correlation coefficients.

The maxima of the correlation traces near lag zero were determined in SAC, but checked manually to make sure that the measured maximum occurred within one-half cycle of the zero lag. The resulting correlation coefficients are plotted in Figure 17. The results for the raw, unfiltered recordings are simply plotted at $100 \mathrm{~Hz}$ although they cover the entire band; and, 
although connecting lines are shown, there is no implied continuation to $100 \mathrm{~Hz}$. The $\mathrm{S} / \mathrm{N}$ ratios on the recorded waveforms decrease rapidly below $2 \mathrm{~Hz}$ (see Figure 9), thus explaining the lower correlations seen at $1 \mathrm{~Hz}$. If earthquakes with higher $\mathrm{S} / \mathrm{N}$ ratios were available, the correlation coefficients should peak at $1 \mathrm{~Hz}$. The correlations are highest for the 2-Hz center frequency and then taper off towards the higher center frequencies, as expected. Although the raw recordings are affected by the 60 -cycle power noise, they still show significant correlations (plotted at $100 \mathrm{~Hz}$ ). These results show that the correlations among signals at the deep accelerometers ("d") are apparently no better than that at the surface accelerometers ("s"), especially at $5 \mathrm{~Hz}$. This is contrary to intuition because one expects more scattering to affect the waves as they propagate through the upper layers below the ESF pad. The cause of the higher correlations near the surface may simply be random signal effects; results for one event here may not hold up in the analysis of many events.

Examining the curves in Figure 17, one sees that the correlation of the signals at the two sites parallel to the wavefront (RF13 and RF16 -- see Figure 13) is not discernibly different than either of the other two curves of correlations for the site pairs more perpendicular to the wavefront. Thus there is no support here for one of the predictions of the Chernov theory of wave scattering in a medium with random inhomogeneity. The overall pattern in Figure 17 of decreasing correlation with increasing frequency is in agreement with the Chernov theory which predicts

$$
\mathrm{C}=\exp \left(-\mathrm{x}^{2} / \mathrm{a}^{2}\right)
$$


where $\mathrm{C}$ is the correlation coefficient and $x$ is the distance. Although mostly applied in the distance domain, where $x$ varies, the equation can be turned around to let $a$ vary while $x$ is fixed as for the data in Figure 17. Let $a=b / f$ where $f$ is frequency; then the relation can be written as

$$
\mathrm{C}=\exp \left(-\mathrm{f}^{2} /(\mathrm{b} / \mathrm{x})^{2}\right]
$$

Absorbing $x$ into $b$ to give $b$, one gets

$$
\mathrm{C}=\exp \left(-\mathrm{f}^{2} / \mathrm{b}^{, 2}\right)
$$

This function goes to zero at some high frequency while the data used here apparently do not have a large sampling rate or sufficient $\mathrm{S} / \mathrm{N}$ to empirically show this. Clearly, some coherence persists in the signals even at high frequencies for the small separations in distance here. This may be expected if the signal wavelengths are much smaller than the size of the random inhomogeneities.

\section{Transfer Functions for Deep to Surface Signals}

The difference in the signals within one borehole location should reflect the viscoelastic properties of the stratigraphic column at that location. Using the velocity and density properties determined in a seismic velocity survey, one can use numerical methods to upward continue a signal recorded at the deep accelerometer to the surface where it is recorded by the midhole accelerometer. As one constraint on the model properties, travel-time differences between signals arriving at the deep and surface accelerometers should agree well with the downhole velocity survey results. Attenuation properties of the medium were not, however, part of the geotechnical program; and these are of considerable importance in modeling the signal propagation in near-surface layers of low rigidity. Starting values of the attenuation parameter $\mathrm{Q}$ can be roughly estimated from the velocities themselves, and then allowed to vary in the 
modeling. Values of the velocity and density samples for seven stratigraphic units, as shown in figures 33, 35, and 235 of Luebbers et al. (2002), were simply averaged by eye to get an estimate for each unit. The properties of the "fill" material are taken from the same report. The preliminary parameters of the constructed models are given in Table 5; these are non-Q data developed here simply for the exercise of computing transfer functions. The deep accelerometers reside at the bottom of each model. Below this point an infinite-thickness, halfspace layer is assumed with the same properties as the deepest layer. Note that the "fill" and "Tpki" layers are not present at the RF15 borehole.

Table 5. Layered Earth Models for the Three Boreholes (non-Q: not to be used for qualityaffecting work)

\begin{tabular}{|c|c|c|c|c|c|c|}
\hline \multicolumn{7}{|l|}{ RF13 } \\
\hline \multicolumn{2}{|c|}{ thickness } & $\mathrm{Vp}$ & Vs & Qp & Qs & $\rho$ \\
\hline & $\mathrm{m}$ & $\mathrm{m} / \mathrm{s}$ & $\mathrm{m} / \mathrm{s}$ & & & $\mathrm{gm} / \mathrm{cc}$ \\
\hline fill & 4 & 550 & 275 & 100 & 50 & 2.00 \\
\hline Qal & 26 & 1463 & 731 & 200 & 100 & 1.60 \\
\hline Tpki & 22 & 2042 & 1067 & 300 & 150 & 1.28 \\
\hline Tpcrn & 15 & 1981 & 975 & 300 & 150 & 1.89 \\
\hline Tpcpul & 4 & 2194 & 1128 & 300 & 150 & 2.09 \\
\hline Tpcpmn & 17 & 2835 & 1600 & 300 & 150 & 2.27 \\
\hline Tpcpll & 4 & 3109 & 1737 & 300 & 150 & 2.32 \\
\hline Tpcpln & 15 & 3444 & 1859 & 300 & 150 & 2.29 \\
\hline \multicolumn{7}{|c|}{ RF15 } \\
\hline \multicolumn{2}{|c|}{ thickness } & $\mathrm{Vp}$ & Vs & Qp & Qs & $\rho$ \\
\hline & $\mathrm{m}$ & $\mathrm{m} / \mathrm{s}$ & $\mathrm{m} / \mathrm{s}$ & & & $\mathrm{gm} / \mathrm{cc}$ \\
\hline fill & -- & -- & -- & -- & -- & -- \\
\hline Qal & 1 & 1463 & 731 & 200 & 100 & 1.60 \\
\hline Tpki & -- & -- & -- & -- & -- & -- \\
\hline Tpcrn & 22 & 1981 & 975 & 300 & 150 & 1.89 \\
\hline Tpcpul & 36 & 2194 & 1128 & 300 & 150 & 2.09 \\
\hline Tpcmn & 14 & 2835 & 1600 & 300 & 150 & 2.27 \\
\hline Tpcpll & 4 & 3109 & 1737 & 300 & 150 & 2.32 \\
\hline Tpcpln & 22 & 3444 & 1859 & 300 & 150 & 2.29 \\
\hline
\end{tabular}




$\begin{array}{lrrrrrl}\begin{array}{l}\text { RF16 } \\ \multicolumn{1}{l}{\text { thickness }}\end{array} & \begin{array}{r}\mathrm{Vp} \\ \mathrm{m} / \mathrm{s}\end{array} & \begin{array}{r}\mathrm{Vs} \\ \mathrm{m} / \mathrm{s}\end{array} & \mathrm{Qp} & \mathrm{Qs} & \rho \\ & \mathrm{m} & 7 & & & \text { gm/cc } \\ \text { fill } & 7 & 550 & 275 & 100 & 50 & 2.00 \\ \text { Qal } & 16 & 1463 & 731 & 200 & 100 & 1.60 \\ \text { Tpki } & 19 & 2042 & 1067 & 300 & 150 & 1.28 \\ \text { Tpcrn } & 26 & 1981 & 975 & 300 & 150 & 1.89 \\ \text { Tpcpul } & 42 & 2194 & 1128 & 300 & 150 & 2.09 \\ \text { Tpcpmn } & 13 & 2835 & 1600 & 300 & 150 & 2.27 \\ \text { Tpcpll } & 6 & 3109 & 1737 & 300 & 150 & 2.32 \\ \text { Tpcpln } & 9 & 3444 & 1859 & 300 & 150 & 2.29\end{array}$

A one-dimensional (plane-wave) modeling code called "stk4" was used in this exercise. This code is not qualified, and so the results from this exercise are simply for informative purposes. The $\mathrm{P}$ waves were chosen as the modeling target due to the fact that $\mathrm{S}$ waves do not have clear arrival times and undoubtedly, for the close distances shown in Table 3, include some surface waves. The actual transfer functions of the $\mathrm{P}$ waves at the three boreholes were computed in SAC from the $\mathrm{P}$ waves windowed to 4-s record centered on the first arrival. The 4-s windows were tapered with a full Hanning window centered on the first-arrival time. The spectra were computed and then smoothed with an 11-point operator prior to dividing the surface spectrum by the deep spectrum. The results for the three boreholes are shown in Figure 18. A large spike at $60 \mathrm{~Hz}$ is not shown in full in the RF15 case. The transfer function spectra are very erratic due to the division process and should be viewed with skepticism for details. Also, little or no amplitude above $50 \mathrm{~Hz}$ can be attributed to real signal, and the ratios at these high frequencies should be ignored.

The model parameters in Table 5 were then used to compute the top (surface) and bottom (deep) accelerometer responses to an impulsive $\mathrm{P}$ wave normally incident at the base of the layer stack. 
The actual propagation direction will be close enough to normal that the 1-D assumption should be applicable. The spectral domain results are shown in Figure 19, along with the transfer function obtained by dividing the surface response by the deep response. Note that the deep accelerometer's spectrum is highly scalloped, mostly a result of the P reflection at the surface with a reflection coefficient of -1 , causing perfect destructive interference at certain frequencies. For a single-layer model, the interval of the zeroes in the spectral domain are exactly predicted by $\cos (2 \pi T f)$ where $T$ is the one-way travel time through the layer and $f$ is the frequency. In a case with multiple layers, the formula prediction is only approximately seen in the waveform spectrum due to the many interacting reflections that effectively alter the zeroes in the spectrum. For the three models used at RF13, RF15, and RF16, the one-way times are $0.57 \mathrm{~s}, 0.41 \mathrm{~s}$, and $0.74 \mathrm{~s}$, respectively. Due to the zeroes, or near zeroes, in the deep spectrum, the transfer function has large spikes at the corresponding frequencies; this makes it somewhat difficult to interpret, but a line through the minima of the transfer function is a realistic guide to the true transfer function. Because the scattering is so severe, in reality the reflected $\mathrm{P}$ wave bears little resemblence to the upgoing wave. In this case, one might suggest that the "surface response", which is the ratio of surface to upgoing wave, is a better indicator of the actual phenomenon.

Comparing the actual (Figure 18) versus computed (Figure 19) transfer functions, one sees that the modeling predictions are roughly valid. In this comparison, frequencies above $50 \mathrm{~Hz}$ should be ignored due to the small $\mathrm{S} / \mathrm{N}$ ratios of the actual data at these frequencies. For RF13, the predictions are for transfer function ratios of roughly 2 to 4 over the band 1-50 $\mathrm{Hz}$ while the actual ratios fall into the range of 1 to 4 , but the erratic actual ratios are difficult to compare with the predictions. For RF15, the agreement of the prediction with actual is also good. Here both 
the predicted and actual transfer functions are somewhat flat over the band of 1-50 Hz, but the predicted ratios, roughly 1.5 at the minima, are smaller than the actual ratios if the actual transfer function were smoothed heavily. For RF16, the predicted transfer function reflects the actual one in that $1-25 \mathrm{~Hz}$ ratios are boosted and $30-50 \mathrm{~Hz}$ ones are much lower, and the ratios compare favorably overall. Because this is not a Q result and because of the lack of good signals to use, it does not seem worthwhile to pursue the modeling to obtain better agreement at this time. It has been shown that rough agreement can be obtained for the 1-D layered model predictions of the transfer functions and the actual ones at the three boreholes for $\mathrm{P}$ waves.

\section{Relationship to PSHA Results}

The results and discussion of this section are non-Q, for reasons which will become apparent. It is natural to ask to what degree are the observed ground motions reported here in agreement with predictions of ground motion in the vicinity of Yucca Mountain. The PSHA methodology is the preferred approach to predicting ground motions in engineering seismology, and a PSHA was performed for Yucca Mountain using multiple expert judgment by CRWMS M\&O (1998). In Figure 6-1 of that report, the Somerville median attenuation relationship is somewhat of aprediction average among the six experts for ground motion on the hanging wall of a M 6.5 normal fault, with perhaps $\pm 30 \%$ range in all the predictions. Therefore, for purposes of simple comparison with the actual PGA's observed at the boreholes, the Somerville regression coefficients $a_{i}$, listed in Appendix I of that report as "Horiz PGA", were used. The prediction equation is taken from equation 6-1a of the PSHA study; this equation is applicable to earthquakes for which $\mathrm{M}<6.25$ :

$$
\mu=a_{1}+a_{2}(M-6.25)+\left[a_{3}+a_{5}(M-6.25)\right] \ln \left[\left(R^{2}+a_{8}^{2}\right)^{1 / 2}\right]+a_{7} F
$$


where

$$
\begin{aligned}
& \mu=\ln (\mathrm{PGA}) \text { in } \mathrm{g} \\
& \mathrm{M}=\text { event magnitude } \\
& \mathrm{R}=\text { "rupture" distance }(\mathrm{km}) \\
& \mathrm{F}=0 \text { or } 1 \text { (a switch to give } \mathrm{a}_{7} \text { weight for normal faults) }
\end{aligned}
$$

The values of the Somerville coefficients for horizontal PGA are (Appendix I, CRWMS M\&O, 1998):

$$
\begin{aligned}
& \mathrm{a}_{1}=1.9958 \\
& \mathrm{a}_{2}=0.4419 \\
& \mathrm{a}_{3}=-1.4672 \\
& \mathrm{a}_{4}=\text { not used } \\
& \mathrm{a}_{5}=0.1873 \\
& \mathrm{a}_{6}=\text { not used for } \mathrm{M}<6.25 \\
& \mathrm{a}_{7}=0.0474 \\
& \mathrm{a}_{8}=\mathrm{z}=\text { focal depth of earthquake }(\mathrm{km})
\end{aligned}
$$

Although equation 6-1a in CRWMS M\&O (1998) contains two terms for weighting the hangingwall versus the footwall side of a normal fault, they are actually zero due to the relatively small magnitude of the events in Table 3 (see equation 6-2 of the same study) and so not used here. Due to the small area of the rupture plane for the earthquakes of Table $3\left(<1 \mathrm{~km}^{2}\right)$, the "rupture" distance is well approximated by the hypocentral distance. The term using $\mathrm{F}$ in the above is dropped due to lack of knowledge of the focal mechanisms; its value is only roughly 0.05 ( $\mathrm{a}_{7}$ coefficient). Using the Somerville coefficients and converting hypocentral distance to epicentral distance $r$, one gets:

$$
\mu=1.9958+0.4419(\mathrm{M}-6.25)+[-1.4672+0.1873(\mathrm{M}-6.25)]^{*} \ln \left[\left(\mathrm{R}^{2}+\mathrm{z}^{2}\right)^{1 / 2}\right]
$$

Using $980 \mathrm{~cm} / \mathrm{s}^{2}$ as the value of $g$ at the surface, conversion to acceleration $a$ in units of $\mathrm{cm} / \mathrm{s}^{2}$ gives: 


$$
\mathrm{a}=980 \exp (\mu)
$$

This expression was computed at coarse points of 10, 20, 50, 100, and $200 \mathrm{~km}$ for Figure 20. The actual PGA values (larger of the two horizontal values - Appendix 1 of this report) observed at the surface accelerometer for borehole RF15, the "reference" site in this study, are plotted on this figure for comparison. Two values are missing (days 120 and 354 -- see Table 4); and the values for the two earthquakes on day 319 , both M 4.5, are coincident.

The fit of the predictions to the actual data must be viewed in light of the fact that the PSHA study predicted the ground motion at repository level, with the overburden stripped off, representing a medium with a free surface at repository level (called "Point A" in CRWMS M\&O, 1998). Thus the free-surface effect is in both the actual and predicted points. But the "surface" shear velocity at Point A is given as $1900 \mathrm{~m} / \mathrm{s}$, considerably larger than the $\mathrm{V}_{30}$ of 716 $\mathrm{m} / \mathrm{s}$ at RF15 used in the current study. The PGA's for the three largest events (M 3.4, 4.5, and 4.5) lie approximately a half magnitude unit below the predictions; but the actual data for the lower magnitude events are much lower than the PSHA predictions, by almost an order of magnitude. The PSHA predictions were not meant to be extrapolated to $M<5$ (p. 5-22 in CRWMS M\&O, 1998). Clearly, downward-shifted prediction curves for $\mathrm{M}=3$ and $\mathrm{M}=2$ would agree with the data better. Actually, for small events, say $\mathrm{M}<3$, whose corner frequency is above $10 \mathrm{~Hz}$, the curves should separate by an order of magnitude for each unit decrease in $\mathrm{M}$; thus better agreement in Figure 20 could be attained merely by adjusting for this.

The sample is far too small to make inferences concerning the ground motion absolute values and attenuation relationship with any confidence. The signals used arrive at different azimuths 
from different source regions and have all the vagaries of source and path effects. $M_{L}$ residuals greater than 0.5 magnitude unit are common for the hypocenters of the seismic monitoring network around Yucca Mountain (von Seggern and Smith, 1997), and the data shown here may be simply anomalous.

\section{Conclusions}

An array of borehole accelerometers and surface accelerometers is now providing reliable $\mathrm{Q}$ data at the pad of the north portal to the ESF. Even though seismic activity in the vicinity of Yucca Mountain was low in 2003 and the largest acceleration recorded on the borehole array was only approximately $1 \mathrm{~cm} / \mathrm{s}^{2}$, a number of significant results could be extracted from the signals of eight earthquakes that had reasonably good $\mathrm{S} / \mathrm{N}$ ratios on the accelerometer recordings.

\subsection{Q Conclusions}

Intra-borehole PGA's and PGV's showed significantly higher amplitudes on the surface versus downhole recordings. Amplification of surface recordings over those at the bottom of the boreholes, 99 to $138 \mathrm{~m}$ deep, ranges generally from 2 to 5 , but the vertical amplification at one borehole, RF16, was observed to be 15 in one case. Amplification of surface recordings over those at shallow depth in the boreholes, 10 to $15 \mathrm{~m}$ deep, ranges generally between 1 and 3, with few exceptions. On average, the amplifications of $\mathrm{Z}, \mathrm{N}$, and $\mathrm{E}$ components track one another well. Spectral computations confirmed the amplifications seen in PGA and PGV values. The surface/midhole spectral ratios are generally near one for frequencies less than $10 \mathrm{~Hz}$ while the surface/deep spectral ratios in the same band are roughly two. Computed response spectra ( $S a)$ showed approximately the same character versus frequency as raw acceleration spectra. 
The geologic information developed in the previous geotechnical study at the boreholes agrees somewhat with the observations made here on seismic signals. The predictive $\mathrm{V}_{30}$ velocity indicates that RF15, with virtually no fill layer and without the shallow Quaternary alluvium layer at the other two boreholes, should have lower amplifications. However, the actual amplifications are significantly larger than the $\mathrm{V}_{30}$ analysis would predict (about 1.2); and so the remainder of the inter-borehole velocity differences is probably influencing the signals.

The signal correlation among the three boreholes was studied with short, 4-s, P-wave windows. This correlation is excellent in a bandwidth centered at $2 \mathrm{~Hz}$ but decreases rapidly as the frequency band moves to higher frequencies. Unexpectedly, it was found that the deep borehole signals decorrelated faster with increasing frequency than the surface signals; but this result is based on only one event.

\subsection{Non-Q Conclusions}

The transfer functions in the spectral domain for surface-to-deep recordings were computed for the $\mathrm{P}$ waves of one event. Using hypothetical earth models at each borehole developed from data in the geotechnical report, a theoretical transfer function was computed at each borehole. The theoretical and actual transfer functions agreed in a gross sense, with the low amplification (surface-to-deep) of borehole RF15 especially well modeled. Due to the lack of good signals in this study, no iterative modeling was done to provide the best attenuation values in the earth models. Actual recordings with good $\mathrm{S} / \mathrm{N}$ ratios up to and above $50 \mathrm{~Hz}$ will be required to 
separate true attenuation effects from simple elastic layering effects over the short vertical distances here $(\sim 100 \mathrm{~m})$.

An attempt was made to relate the peak acceleration observations of this study to predictions of the PSHA study for Yucca Mountain. Extrapolations of the PSHA curves to the small magnitudes here showed fair agreement for an event at M 3.4 and two more at M 4.5. PGA's for lower magnitude events ( $\sim$ M 2.0 to 2.5 ) were far below the extrapolated predictions though, and it must be recognized that the PSHA predictions were not intended to be applied to such small magnitudes. Inclusion of the effect of the source corner frequency could allow the PGA predictions of PSHA to more accurately fit the observed PGA values. The comparison is further hampered by the fact that the PSHA results were for a truly "hard-rock" site $(1900 \mathrm{~m} / \mathrm{s})$ while RF15 represents a much softer site $(716 \mathrm{~m} / \mathrm{s})$. 


\section{References}

Boore, D. M., W. B. Joyner, and T. E. Fumal (1994). Estimation of response spectra and peak accelerations from western North American earthquakes: An interim report, Part 2, U.S. Geol. Surv. Open-File Rept. 94-127, 40 pp.

Boore, D. M., W. B. Joyner, and T. E. Fumal (1997). Equations for estimating horizontal response spectra and peak accelerations from western North America earthquakes: A summary of recent work, Seism. Res. Lett., 68, 128-153.

Chernov, L. A., 1960. Wave Propagation in a Random Medium, translated by R. A. Silverman, McGraw-Hill, Inc.

CRWMS M\&O, 1998. Probabilistic seismic hazard analysis for fault motion displacements and vibratory ground motion at Yucca Mountain, Nevada: Final Report, Yucca Mountain Project, Las Vegas, Nevada (MOL \#19980619.0640).

Luebbers, M. J., I. G. Wong, and R. Lung, 2002. Geotechnical Data for a Potential Waste Handling Building and for Ground Motion Analyses for the Yucca Mountain Site Characterization Project (MOL \# 20021004.0078).

Von Seggern, D. H., and K. D. Smith, 1997. Seismicity in the vicinity of Yucca Mountain, Nevada, for the period 10/01/1995 to 09/30/1996 (MOL \#19981124.0334). 


\section{Appendix 1}

PGA Values $\left(\mathrm{cm} / \mathrm{s}^{2}\right)$ for 8 Events in 2003 - Q data submitted as TDA \# 006DV.007.

\section{$\mathrm{Z}$ component}

$\begin{array}{llllllllll}\text { jdate } & \text { RF13_S } & \text { RF13_m } & \text { RF13_d } & \text { RF15_s } & \text { RF15_m } & \text { RF15_d } & \text { RF16_s } & \text { RF16_m } & \text { RF16_d } \\ 080 & 0.208 & 0.153 & - & 0.196 & 0.141 & 0.057 & 0.279 & - & 0.052 \\ 120 & 0.129 & 0.090 & - & - & 0.071 & 0.031 & - & - & - \\ 144 & 0.277 & 0.158 & 0.079 & 0.192 & 0.120 & 0.049 & 0.315 & 0.142 & 0.061 \\ 194 & - & 0.191 & - & 0.266 & 0.202 & 0.068 & 0.507 & 0.200 & 0.090 \\ 304 & 0.164 & 0.128 & 0.052 & 0.127 & 0.099 & 0.038 & 0.228 & 0.083 & 0.041 \\ 319 \mathrm{a} & 0.051 & 0.049 & 0.029 & 0.074 & 0.060 & 0.029 & 0.153 & - & 0.022 \\ 319 \mathrm{~b} & 0.066 & 0.065 & 0.031 & 0.052 & 0.040 & 0.031 & 0.112 & - & 0.031 \\ 354 & 0.112 & 0.099 & 0.051 & - & 0.090 & 0.046 & 0.154 & 0.082 & 0.047\end{array}$

N component

$\begin{array}{llllllllll}\text { jdate } & \text { RF13_s } & \text { RF13_m } & \text { RF13_d } & \text { RF15_s } & \text { RF15_m } & \text { RF15_d } & \text { RF16_s } & \text { RF16_m } & \text { RF16_d } \\ 080 & 0.333 & 0.160 & - & 0.236 & 0.151 & 0.061 & 0.949 & - & 0.063 \\ 120 & 0.252 & 0.079 & - & - & 0.091 & 0.037 & - & - & - \\ 144 & 0.384 & 0.223 & 0.099 & 0.200 & 0.151 & 0.051 & 0.518 & 0.178 & 0.083 \\ 194 & - & 0.237 & - & 0.294 & 0.203 & 0.084 & 0.965 & 0.189 & 0.113 \\ 304 & 0.352 & 0.116 & 0.054 & 0.182 & 0.111 & 0.039 & 0.426 & 0.119 & 0.047 \\ 319 \mathrm{a} & 0.091 & 0.071 & 0.036 & 0.082 & 0.082 & 0.027 & 0.130 & - & 0.022 \\ 319 \mathrm{~b} & 0.098 & 0.076 & 0.043 & 0.073 & 0.071 & 0.024 & 0.112 & - & 0.027 \\ 354 & 0.153 & 0.121 & 0.077 & - & 0.107 & 0.063 & 0.240 & 0.105 & 0.048\end{array}$

\section{E component}

$\begin{array}{llllllllll}\text { jdate } & \text { RF13_s } & \text { RF13_m } & \text { RF13_d } & \text { RF15_s } & \text { RF15_m } & \text { RF15_d } & \text { RF16_s } & \text { RF16_m } & \text { RF16_d } \\ 080 & 0.373 & 0.178 & - & 0.177 & 0.185 & 0.085 & 0.821 & - & 0.065 \\ 120 & 0.195 & 0.102 & - & - & 0.114 & 0.042 & - & - & - \\ 144 & 0.342 & 0.198 & 0.105 & 0.226 & 0.142 & 0.071 & 0.410 & 0.146 & 0.103 \\ 194 & - & 0.199 & - & 0.294 & 0.239 & 0.097 & 0.582 & 0.131 & 0.126 \\ 304 & 0.240 & 0.126 & 0.072 & 0.177 & 0.126 & 0.070 & 0.361 & 0.100 & 0.055 \\ 319 \mathrm{a} & 0.090 & 0.076 & 0.039 & 0.109 & 0.093 & 0.039 & 0.303 & - & 0.022 \\ 319 \mathrm{~b} & 0.092 & 0.068 & 0.043 & 0.109 & 0.103 & 0.033 & 0.127 & - & 0.027 \\ 354 & 0.190 & 0.130 & 0.069 & - & 0.163 & 0.078 & 0.276 & 0.134 & 0.068\end{array}$

Notes:

"jdate" is julian day in 2003

“ _ " indicates unusable accelerogram (see Table 4 of text)

"s,m,d" suffices for borehole names stand for surface, midhole, and deep accelerometer locations 


\section{Appendix 2}

PGV Values $(\mathrm{cm} / \mathrm{s})$ for 8 Events in 2003 - Q data submitted as TDA \# 006DV.007.

\section{Z component}

$\begin{array}{llllllllll}\text { jdate } & \text { RF13_s } & \text { RF13_m } & \text { RF13_d } & \text { RF15_s } & \text { RF15_m } & \text { RF15_d } & \text { RF16_s } & \text { RF16_m } & \text { RF16_d } \\ 080 & 0.0042 & 0.0038 & - & 0.0030 & 0.0030 & 0.0016 & 0.0059 & - & 0.0013 \\ 120 & 0.0019 & 0.0018 & - & - & 0.0014 & 0.0008 & - & - & - \\ 144 & 0.0037 & 0.0032 & 0.0014 & 0.0028 & 0.0023 & 0.0011 & 0.0047 & 0.0034 & 0.0012 \\ 194 & - & 0.0032 & - & 0.0045 & 0.0037 & 0.0015 & 0.0067 & 0.0049 & 0.0015 \\ 304 & 0.0038 & 0.0034 & 0.0009 & 0.0025 & 0.0019 & 0.0013 & 0.0034 & 0.0023 & 0.0008 \\ 319 \mathrm{a} & 0.0028 & 0.0027 & 0.0016 & 0.0029 & 0.0028 & 0.0021 & 0.0031 & - & 0.0017 \\ 319 \mathrm{~b} & 0.0029 & 0.0028 & 0.0020 & 0.0025 & 0.0026 & 0.0022 & 0.0035 & - & 0.0021 \\ 354 & 0.0072 & 0.0072 & 0.0056 & - & 0.0062 & 0.0057 & 0.0069 & 0.0064 & 0.0055\end{array}$

N component

$\begin{array}{llllllllll}\text { jdate } & \text { RF13_s } & \text { RF13_m } & \text { RF13_d } & \text { RF15_s } & \text { RF15_m } & \text { RF15_d } & \text { RF16_s } & \text { RF16_m } & \text { RF16_d } \\ 080 & 0.005 \overline{7} & 0.0036 & - & 0.0044 & 0.0040 & 0.0020 & 0.0136 & - & 0.001 \overline{8} \\ 120 & 0.0039 & 0.0018 & - & - & 0.0017 & 0.0007 & - & - & - \\ 144 & 0.0112 & 0.0067 & 0.0028 & 0.0045 & 0.0045 & 0.0016 & 0.0095 & 0.0041 & 0.0018 \\ 194 & - & 0.0059 & - & 0.0055 & 0.0042 & 0.0013 & 0.0104 & 0.0033 & 0.0017 \\ 304 & 0.0049 & 0.0031 & 0.0017 & 0.0031 & 0.0029 & 0.0012 & 0.0071 & 0.0023 & 0.0010 \\ 319 \mathrm{a} & 0.0053 & 0.0048 & 0.0024 & 0.0044 & 0.0044 & 0.0022 & 0.0046 & - & 0.0018 \\ 319 \mathrm{~b} & 0.0061 & 0.0057 & 0.0028 & 0.0035 & 0.0042 & 0.0020 & 0.0053 & - & 0.0015 \\ 354 & 0.0103 & 0.0092 & 0.0047 & - & 0.0066 & 0.0039 & 0.0095 & 0.0069 & 0.0036\end{array}$

\section{E component}

$\begin{array}{llllllllll}\text { jdate } & \text { RF13_s } & \text { RF13_m } & \text { RF13_d } & \text { RF15_s } & \text { RF15_m } & \text { RF15_d } & \text { RF16_s } & \text { RF16_m } & \text { RF16_d } \\ 080 & 0.006 \overline{2} & 0.003 \overline{8} & - & 0.0064 & 0.0051 & 0.0028 & 0.0140 & - & 0.0020 \\ 120 & 0.0031 & 0.0022 & - & - & 0.0021 & 0.0008 & - & - & - \\ 144 & 0.0064 & 0.0059 & 0.0025 & 0.0053 & 0.0042 & 0.0027 & 0.0067 & 0.0041 & 0.0023 \\ 194 & - & 0.0040 & - & 0.0067 & 0.0053 & 0.0019 & 0.0094 & 0.0035 & 0.0018 \\ 304 & 0.0043 & 0.0032 & 0.0019 & 0.0035 & 0.0024 & 0.0017 & 0.0064 & 0.0019 & 0.0010 \\ 319 \mathrm{a} & 0.0056 & 0.0053 & 0.0023 & 0.0063 & 0.0059 & 0.0025 & 0.0051 & - & 0.0016 \\ 319 \mathrm{~b} & 0.0083 & 0.0081 & 0.0038 & 0.0052 & 0.0049 & 0.0026 & 0.0074 & - & 0.0021 \\ 354 & 0.0149 & 0.0142 & 0.0069 & - & 0.0139 & 0.0077 & 0.0148 & 0.0123 & 0.0059\end{array}$

Notes:

"jdate" is julian day in 2003

"-." indicates unusable accelerogram (see Table 4 of text)

"s,m,d" suffices on borehole names stand for surface, midhole, and deep accelerometer locations 


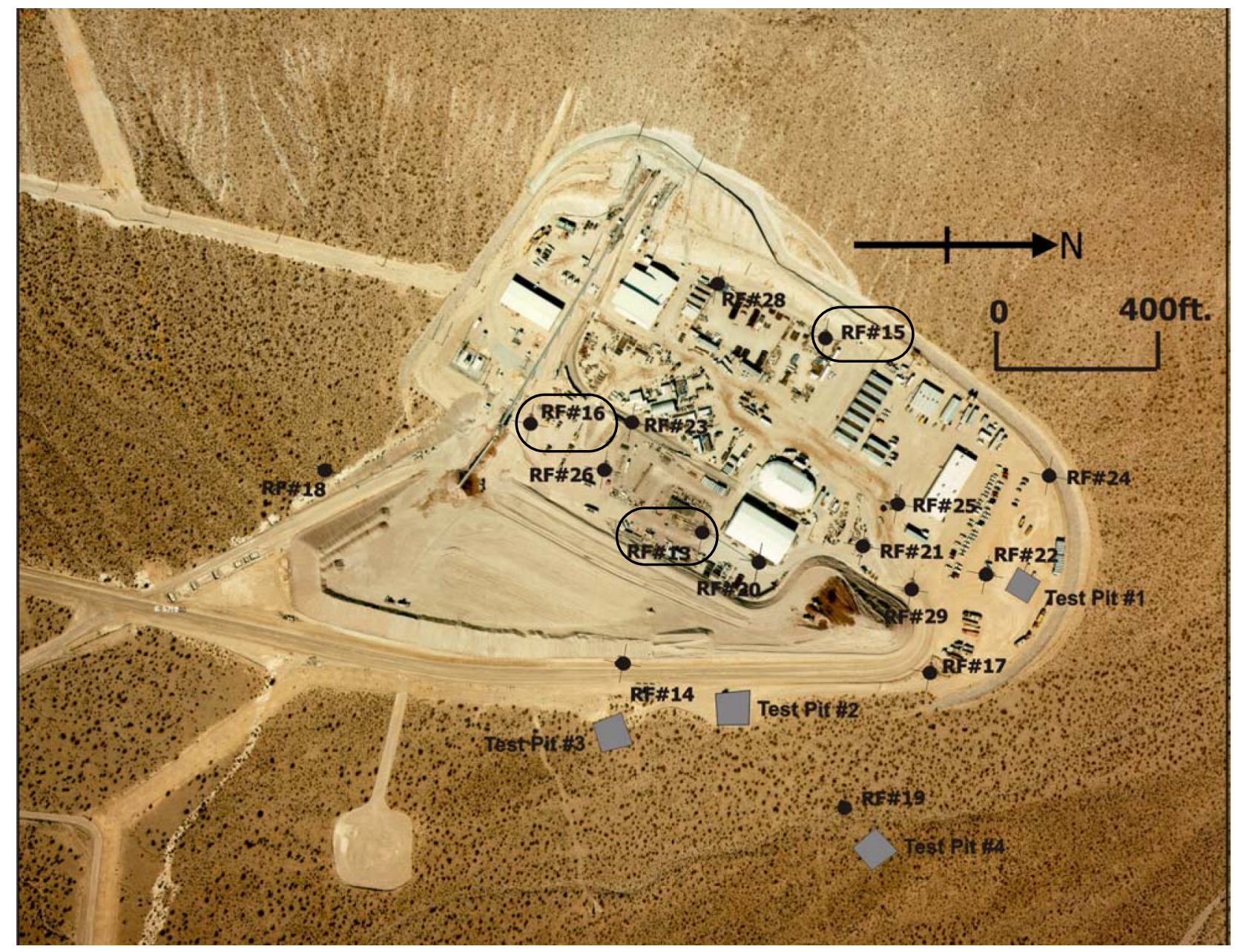

1. Map of the pad at the north portal of the ESF. The borehole locations are shown, with the three having accelerometers circled. This figure is taken exactly from Luebbers et al. (2002), Figure 2, except for the added circles. 


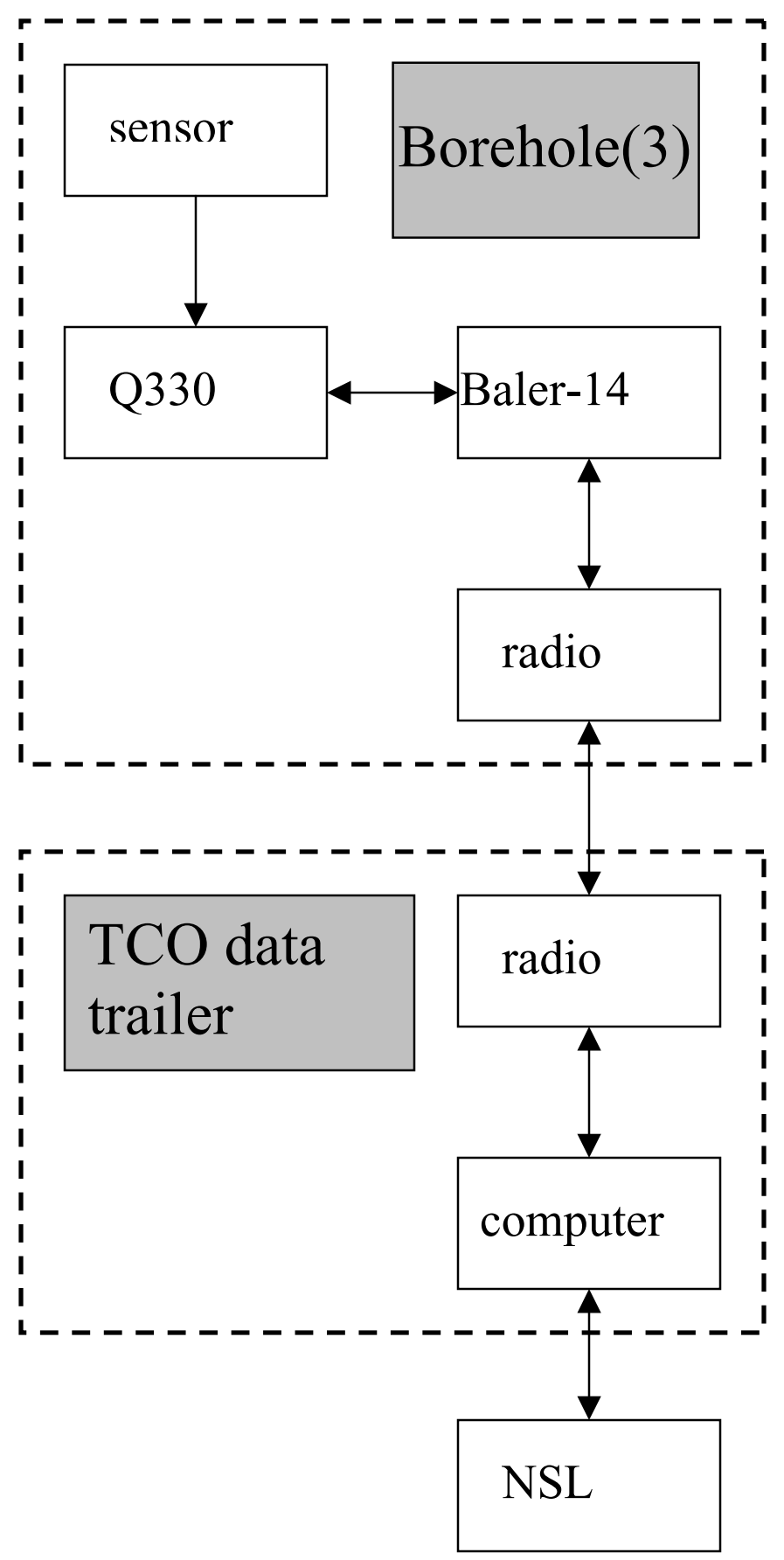

2. Ground-motion data flow from the accelerometers on the ESF pad to recording on hard disk at NSL. 

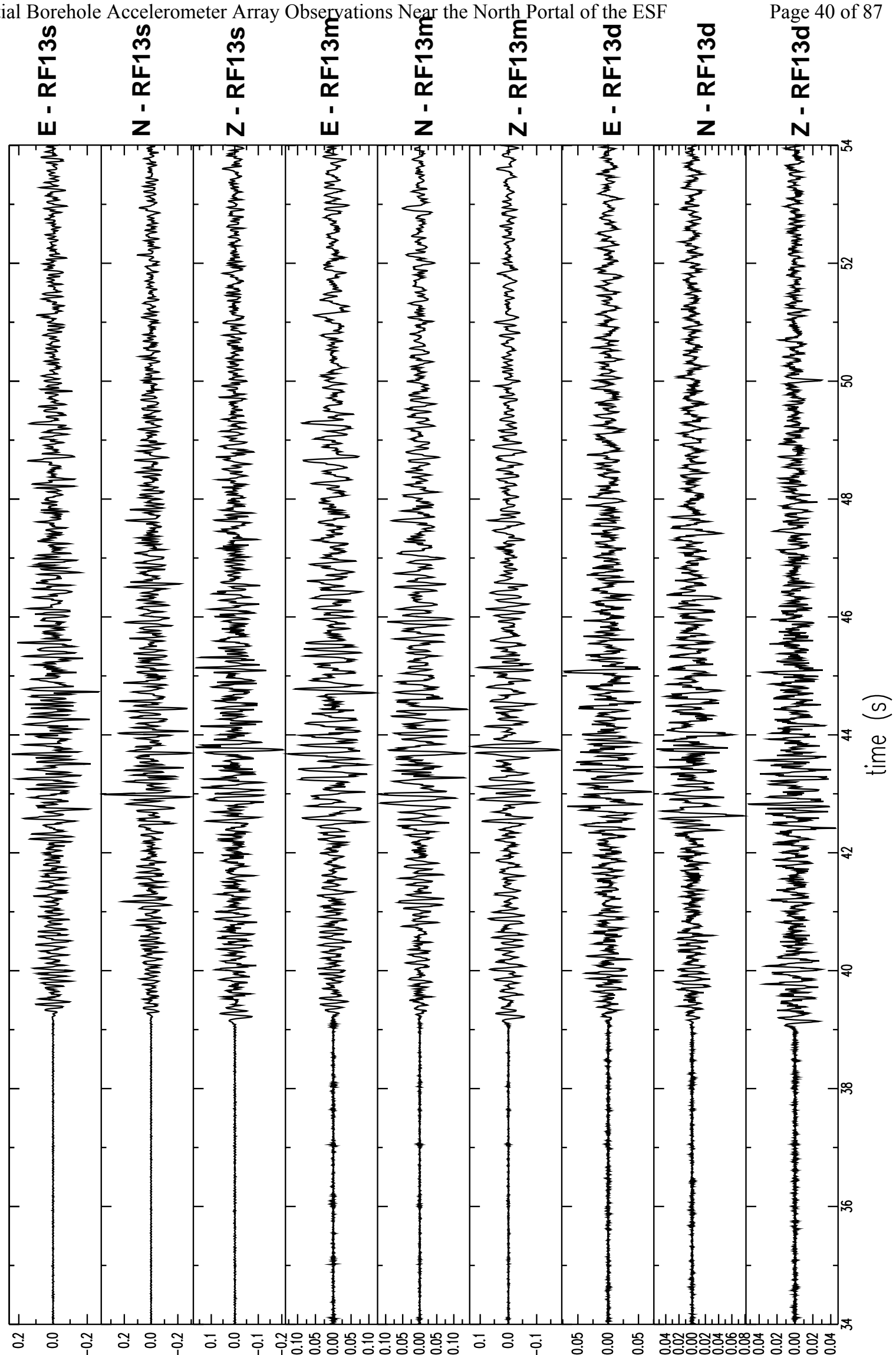

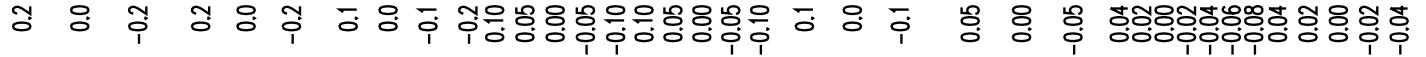

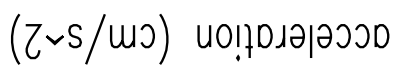

3a. Accelerometer recordings of an M 2.5 earthquake on day 304 in Rock Valley (Table 3), approximately $26 \mathrm{~km}$ from the ESF north portal. The recordings are grouped by borehole on three pages. (Q data in TDA \# 006DV.003.) 


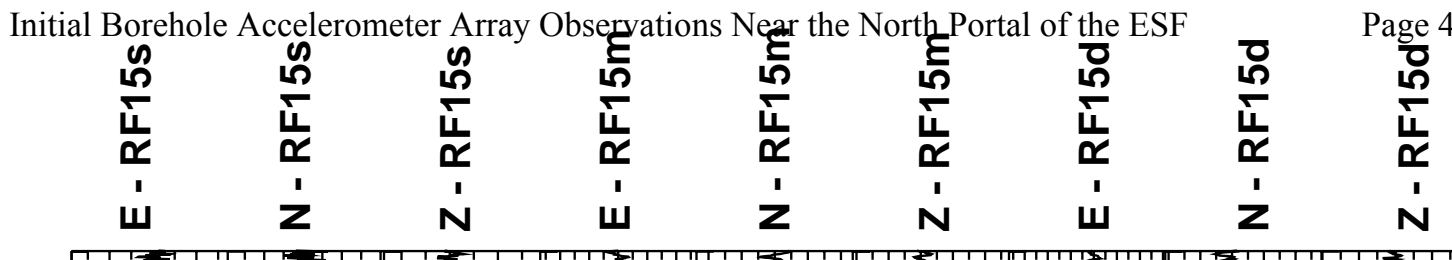

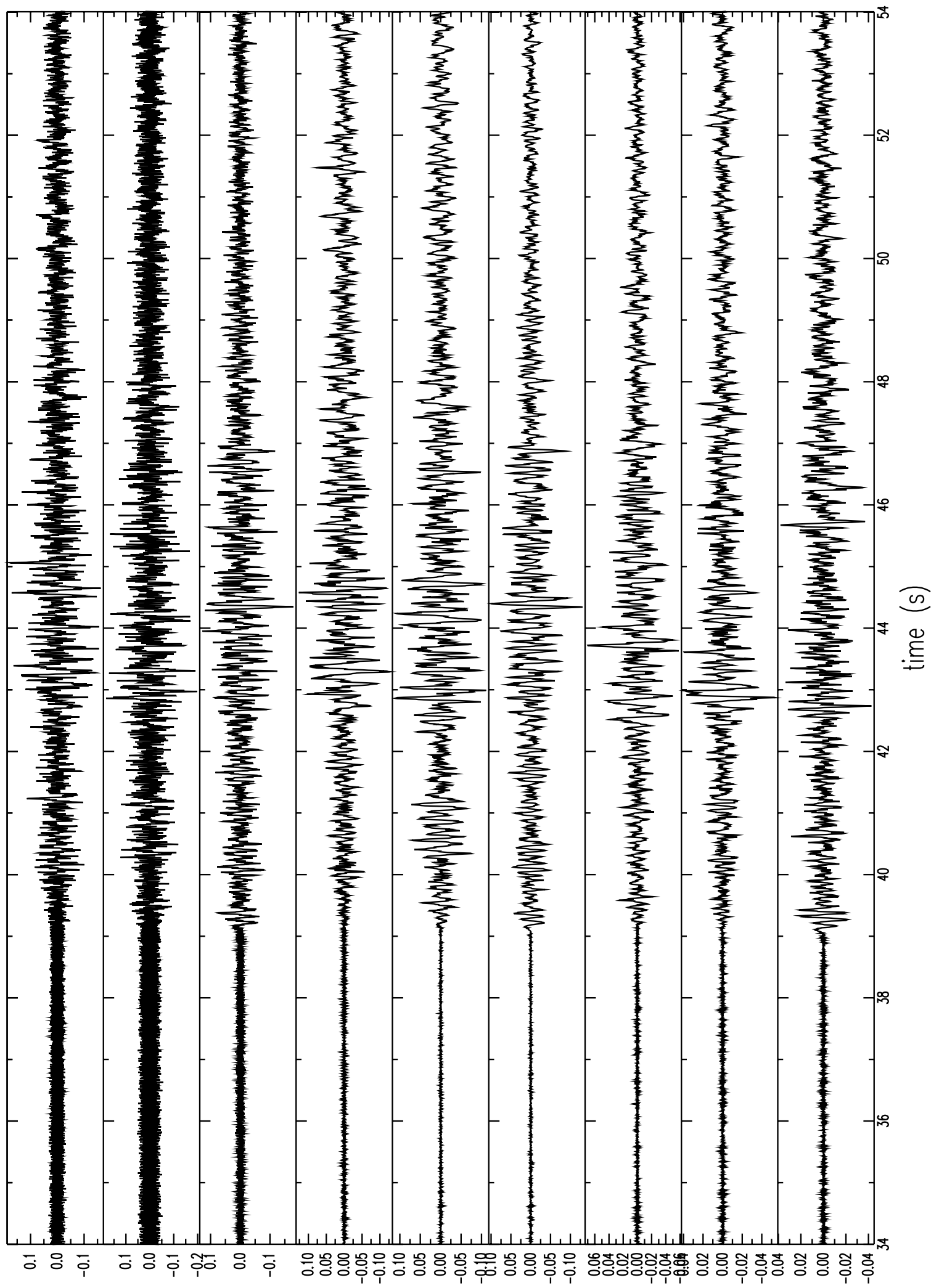

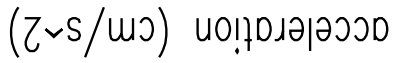

3b. Accelerometer recordings of an M 2.5 earthquake on day 304 in Rock Valley (Table 3), approximately $26 \mathrm{~km}$ from the ESF north portal. The recordings are grouped by borehole on three pages. (Q data in TDA \# 006DV.003.) 

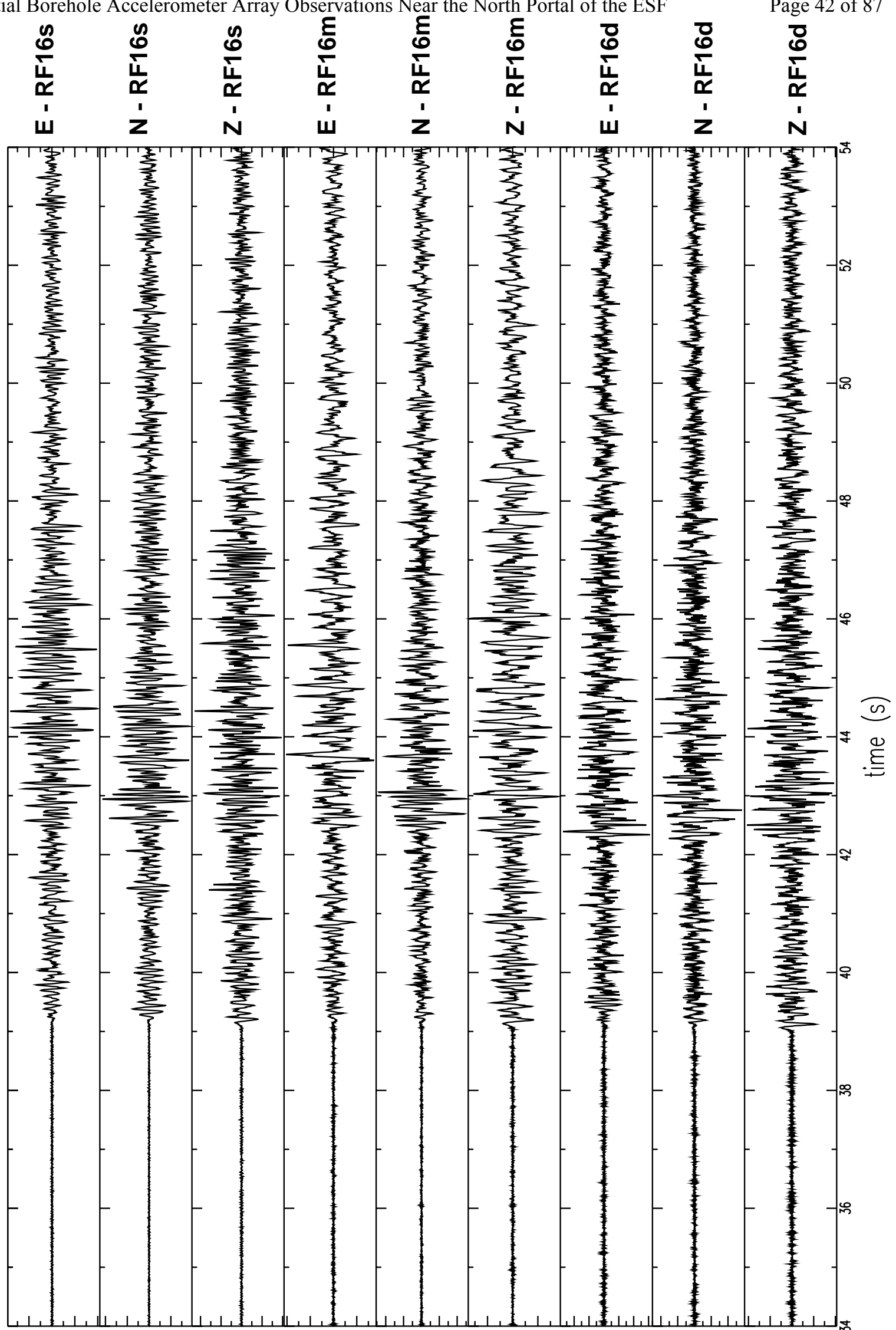

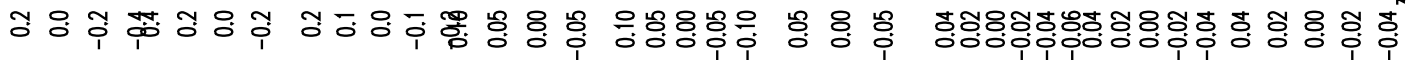

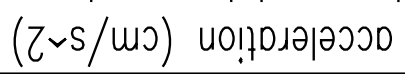

$3 c$. Accelerometer recordings of an M 2.5 earthquake on day 304 in Rock Valley (Table 3), approximately $26 \mathrm{~km}$ from the ESF north portal. The recordings are grouped by borehole on three pages. (Q data in TDA \# 006DV.003.) 


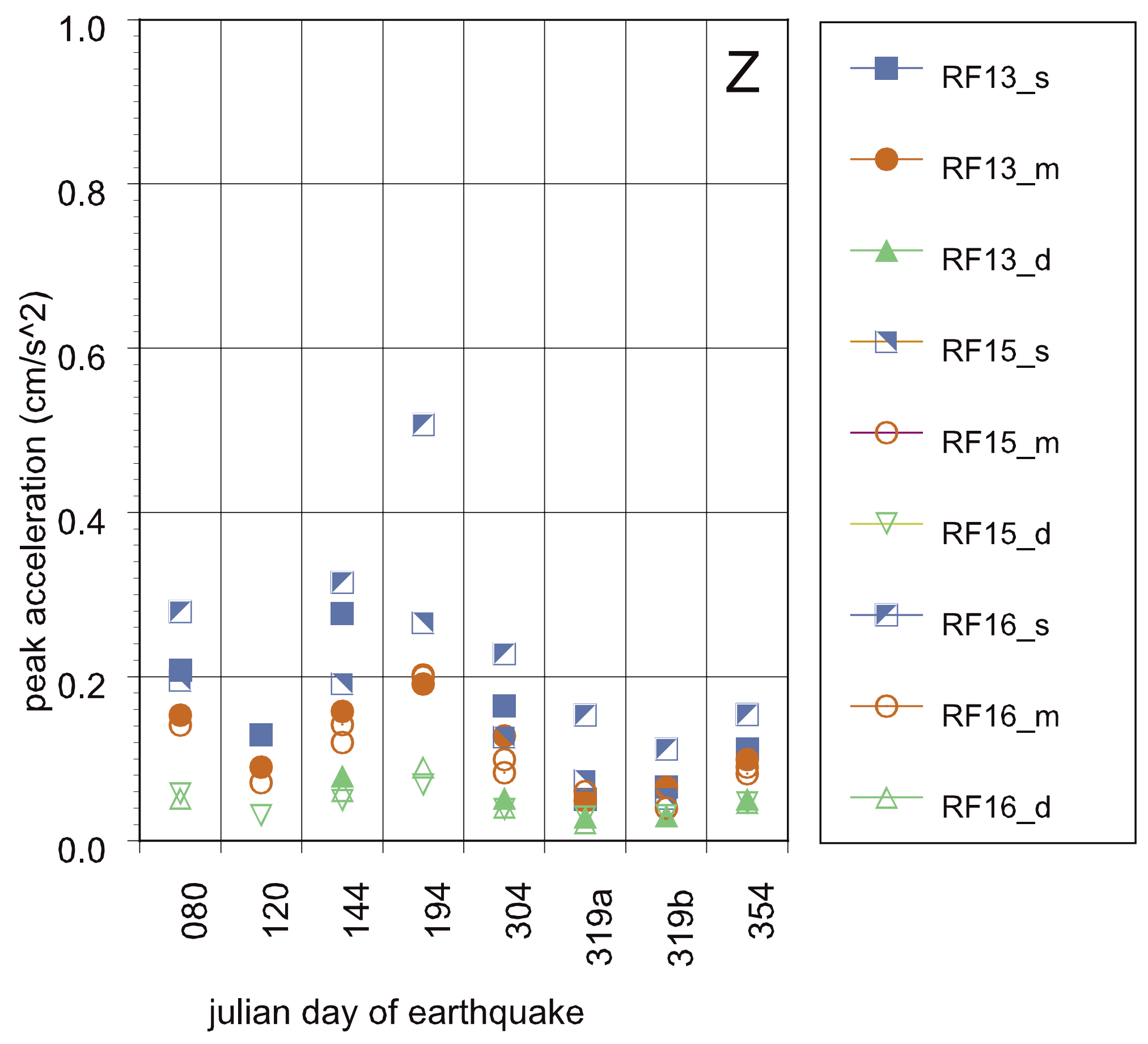

\footnotetext{
4a. PGA values for usable signals in 2003. Values are grouped by component $(\mathrm{Z}, \mathrm{N}, \mathrm{E})$ on three pages. (Q data in TDA \# 006DV.007 -- derived from TDA \# 006DV.003.)
} 


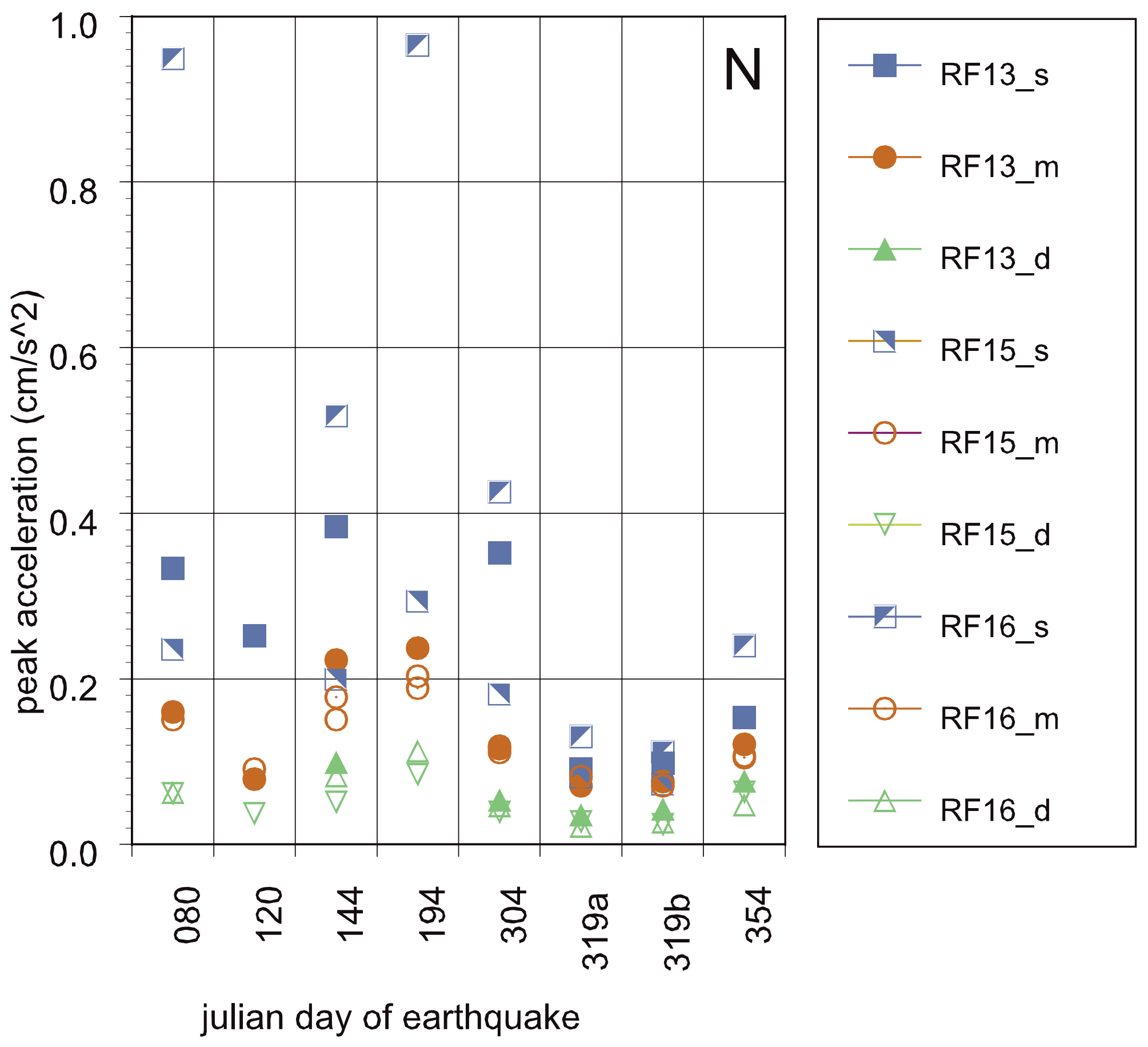

4b. PGA values for usable signals in 2003. Values are grouped by component (Z,N,E) on three pages. (Q data in TDA \# 006DV.007 -- derived from TDA \# 006DV.003.) 


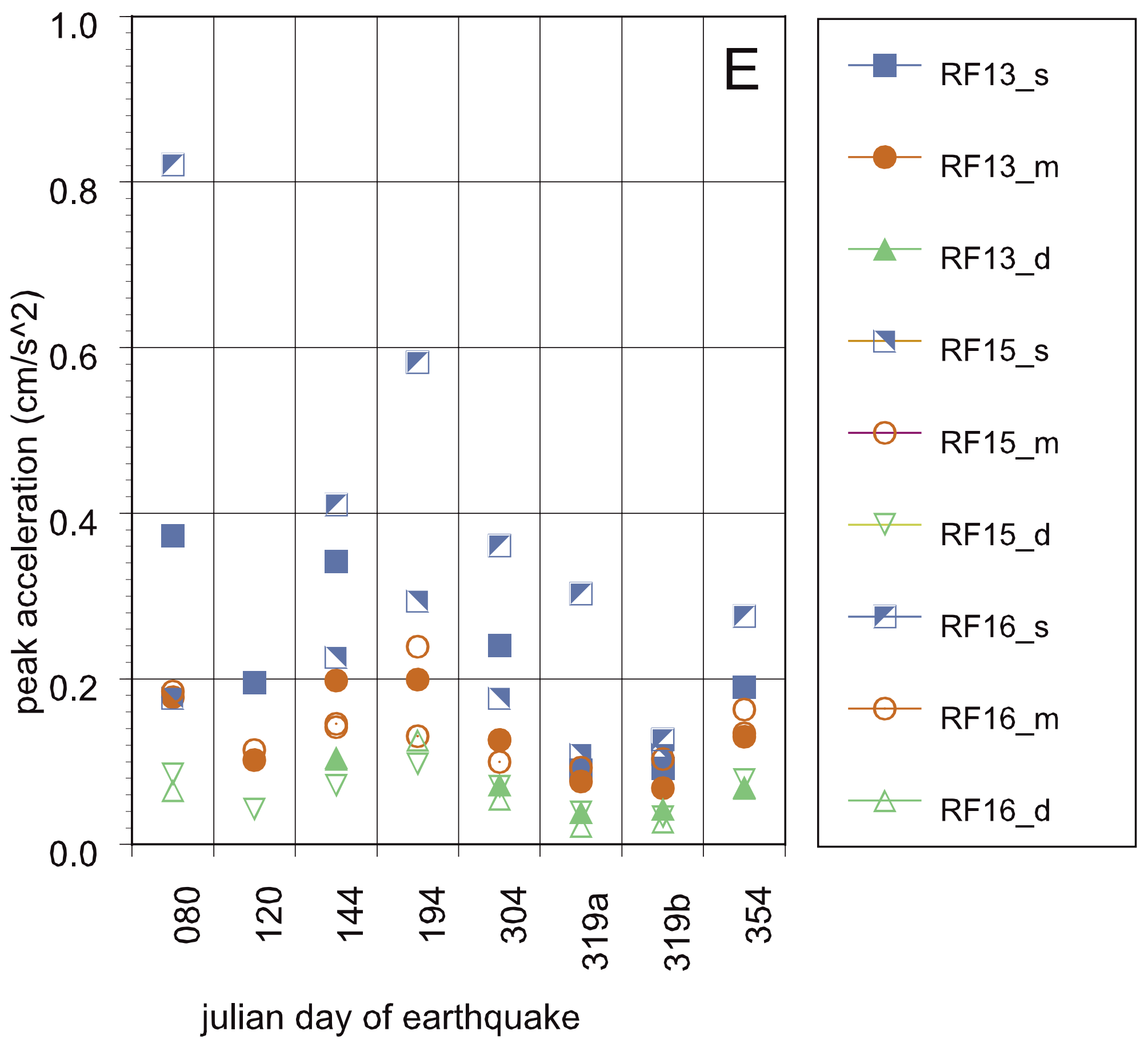

4c. PGA values for usable signals in 2003. Values are grouped by component (Z,N,E) on three pages. (Q data in TDA \# 006DV.007 -- derived from TDA \# 006DV.003.) 


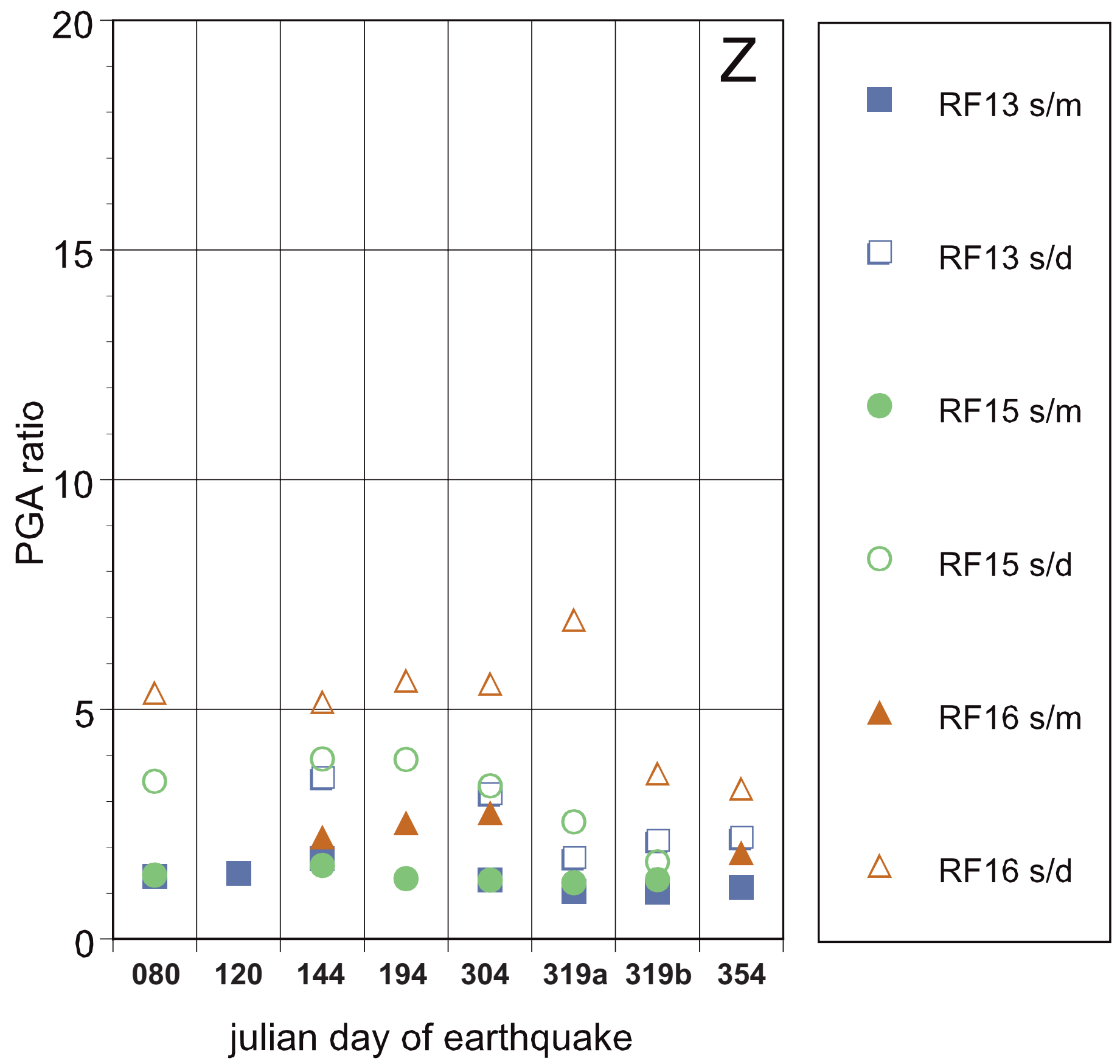

5a. PGA ratios (surface-to-midhole and surface-to-deep) for usable signals in 2003. Ratios are computed from the data displayed in Figure 4 and grouped by component (Z,N,E) on three pages. (Q data in TDA \# 006DV.007 -- derived from TDA \# 


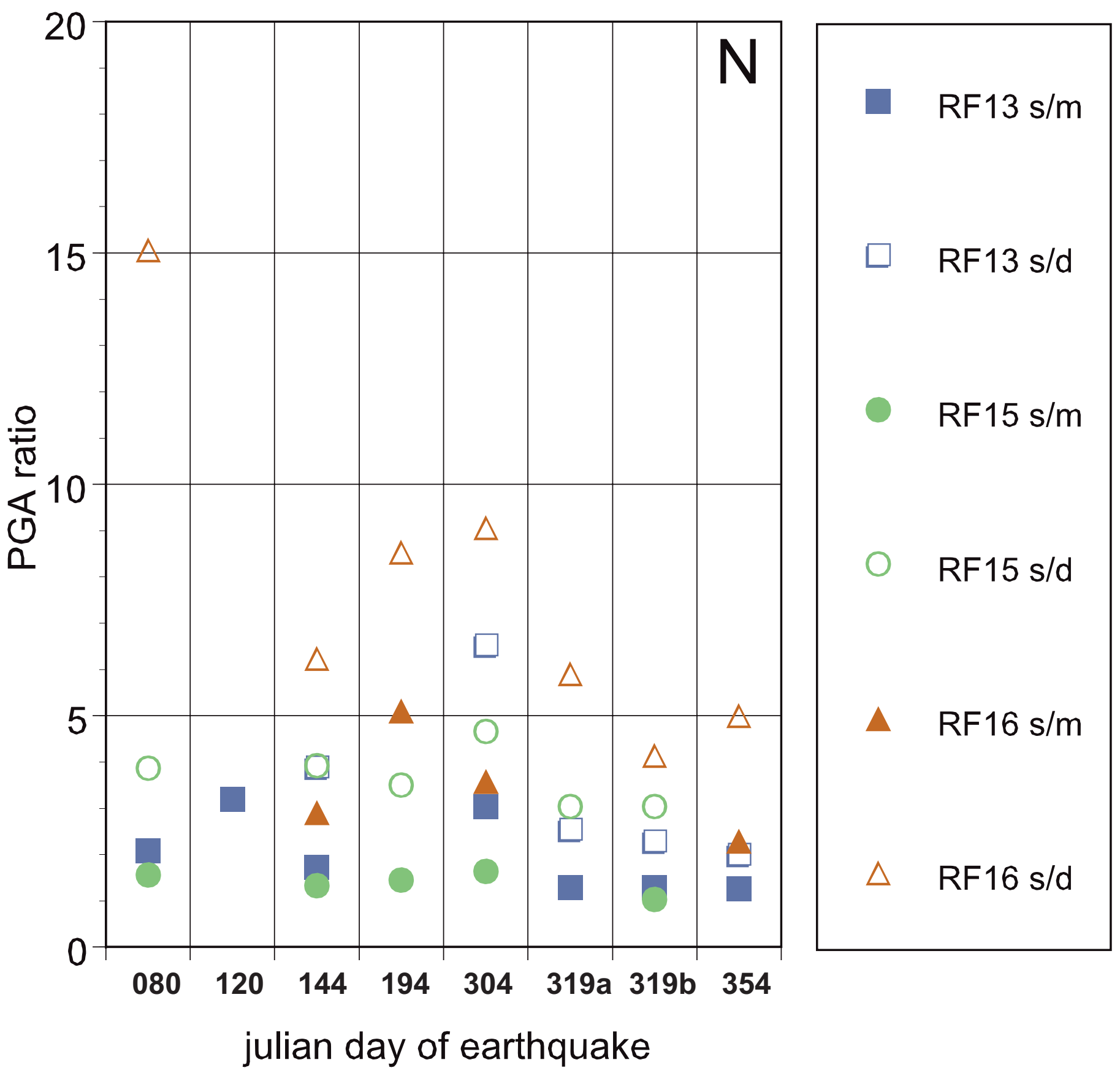

5b. PGA ratios (surface-to-midhole and surface-to-deep) for usable signals in 2003. Ratios are computed from the data displayed in Figure 4 and grouped by component $(\mathrm{Z}, \mathrm{N}, \mathrm{E})$ on three pages. (Q data in TDA \# 006DV.007 -- derived from TDA \# 006DV.003.) 


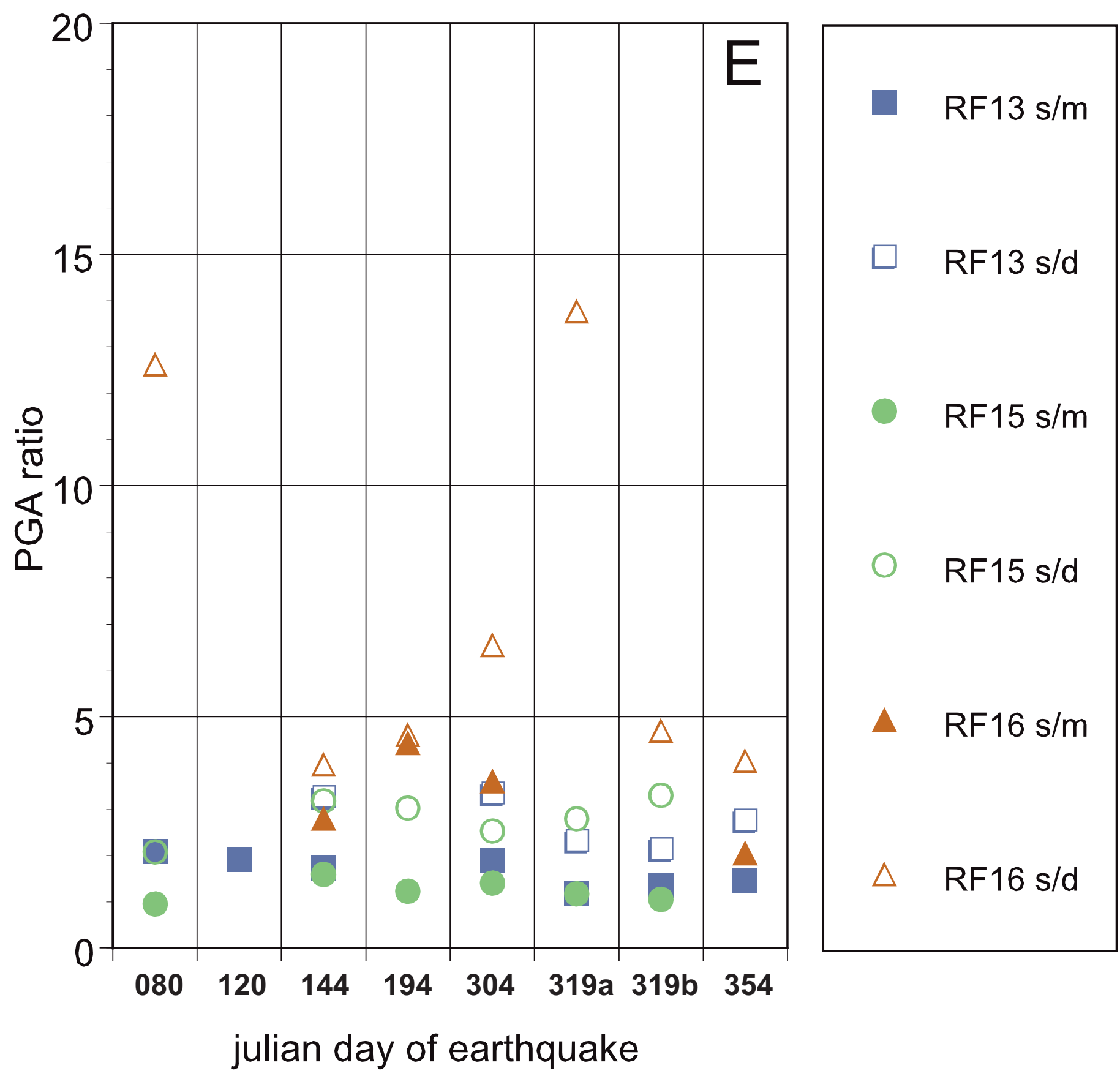

5c. PGA ratios (surface-to-midhole and surface-to-deep) for usable signals in 2003. Ratios are computed from the data displayed in Figure 4 and grouped by component (Z,N,E) on three pages. (Q data in TDA \# 006DV.007 -- derived from TDA \# 006DV.003.) 


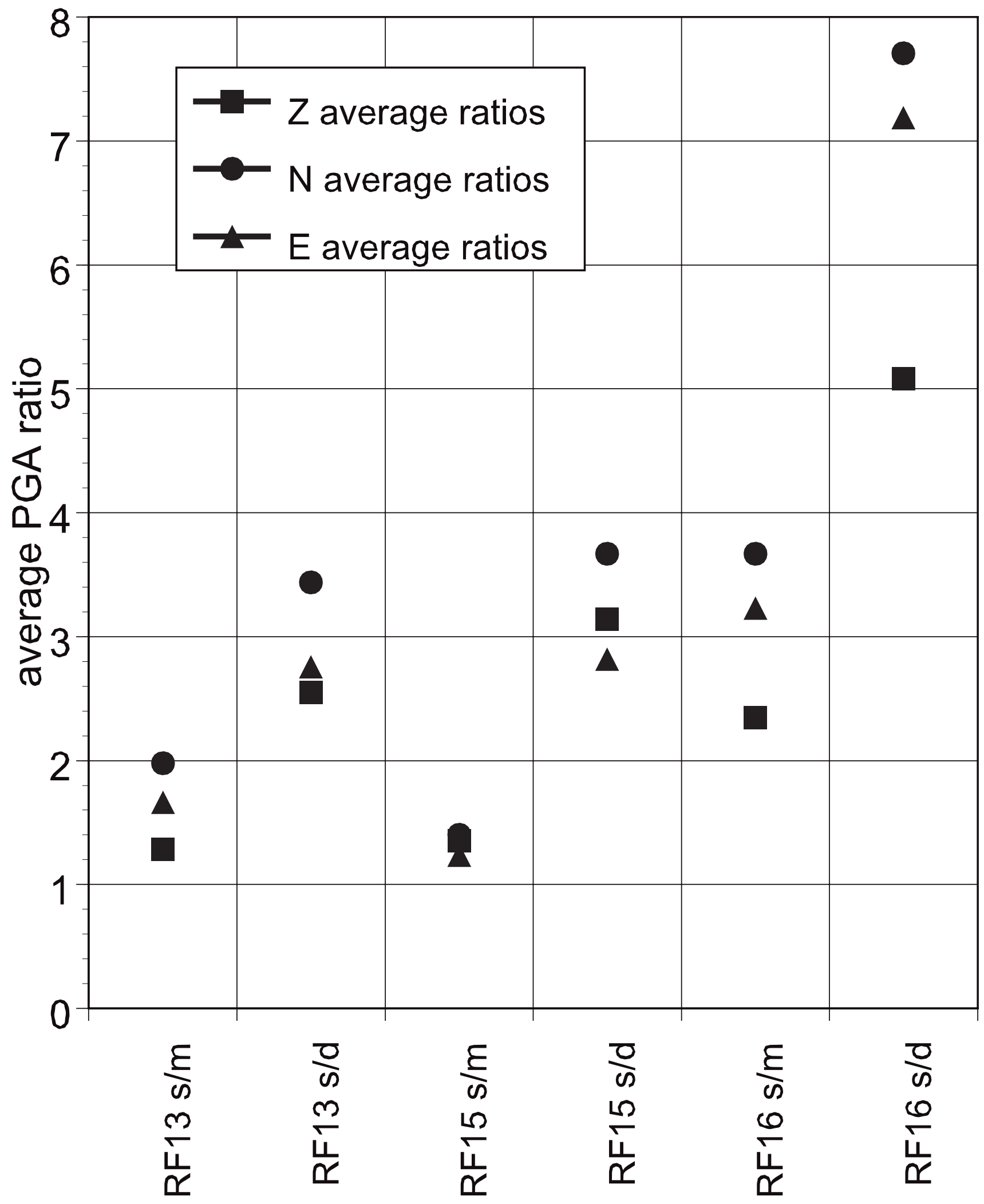

6. Averages of PGA ratios over available events ( $\mathrm{s}$ - surface, $\mathrm{m}=$ midhole, $\mathrm{d}=$ deep). Ratios are computed from the data displayed in Figure 4. (Q data in TDA \#006DV.007 -- derived from TDA \# 006DV.003.) 
Initial Borehole Accelerometer Array Obseryations Near the NorthPortal of the ESF
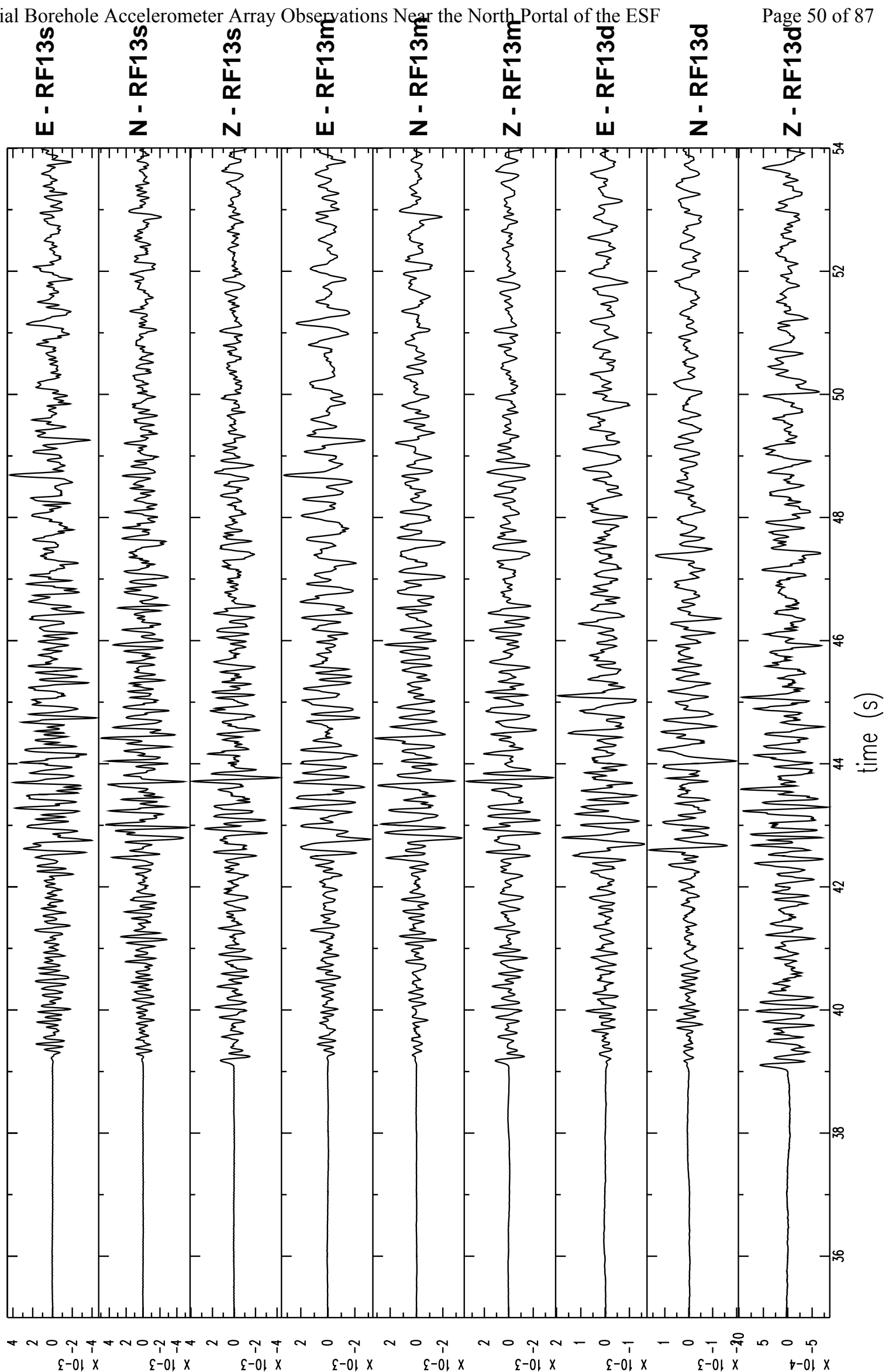

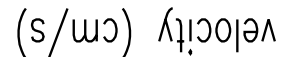

7a. Velocity traces of an M 2.5 earthquake on day 304 in Rock Valley (Table 3), integrated from the accelerometer recordings shown in Figure 3. The traces are grouped by borehole on three pages. (Q data in TDA \# 006DV.003.) 


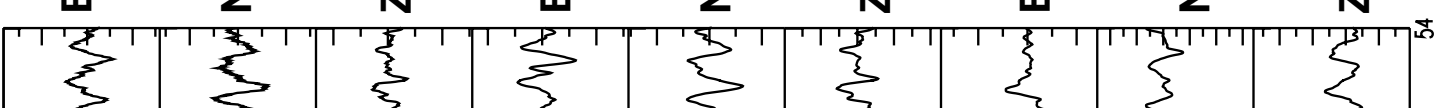

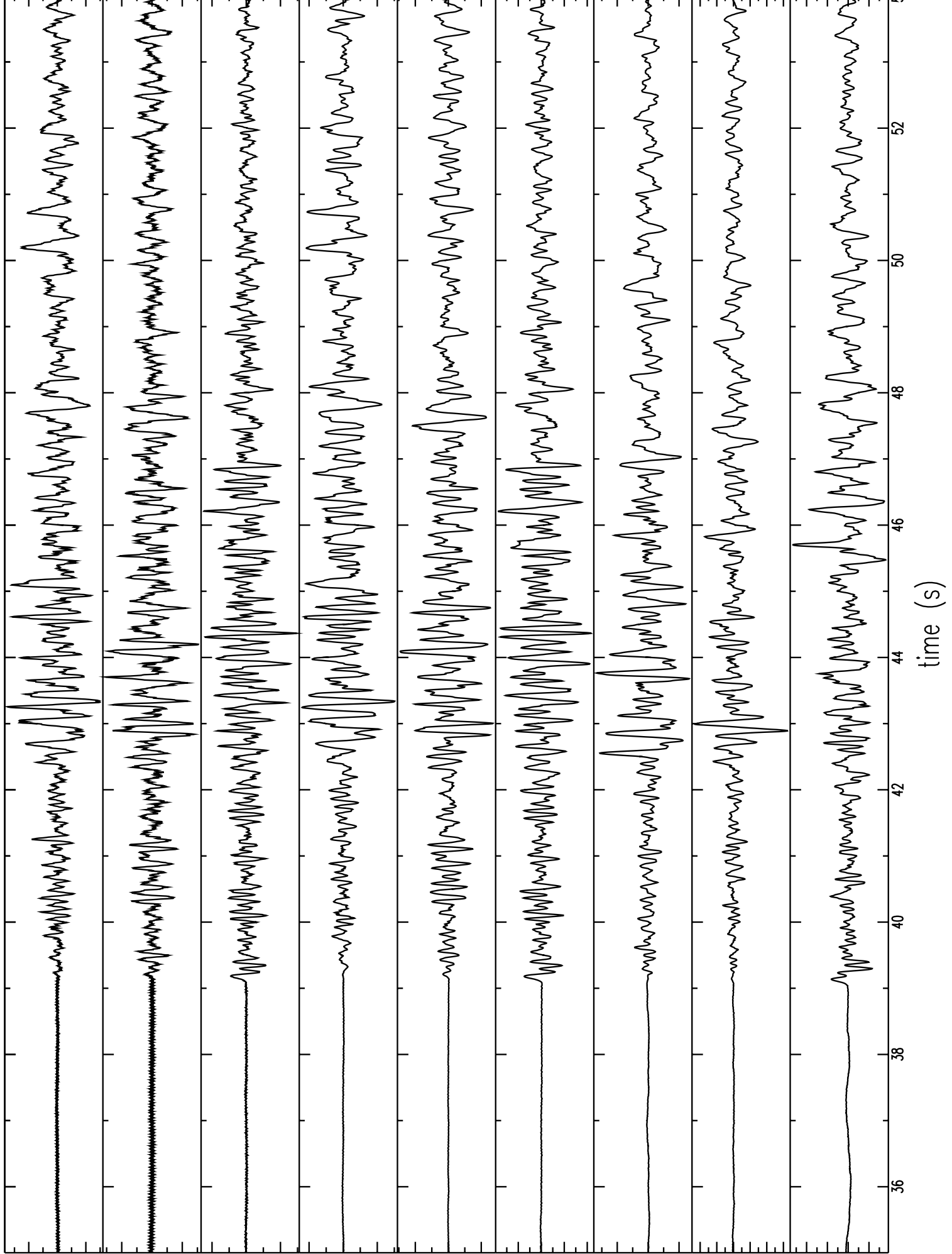

N O $N$ N

$\varepsilon-0|x \quad \varepsilon-0| x \quad \varepsilon-0|x \quad \varepsilon-0| x \quad \varepsilon-0|x \quad \varepsilon-0| x \quad \varepsilon-0|x \quad t-0| x \quad t-0 \mid x$

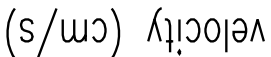

7b. Velocity traces of an M 2.5 earthquake on day 304 in Rock Valley (Table 3), integrated from the accelerometer recordings shown in Figure 3. The traces are grouped by borehole on three pages. 

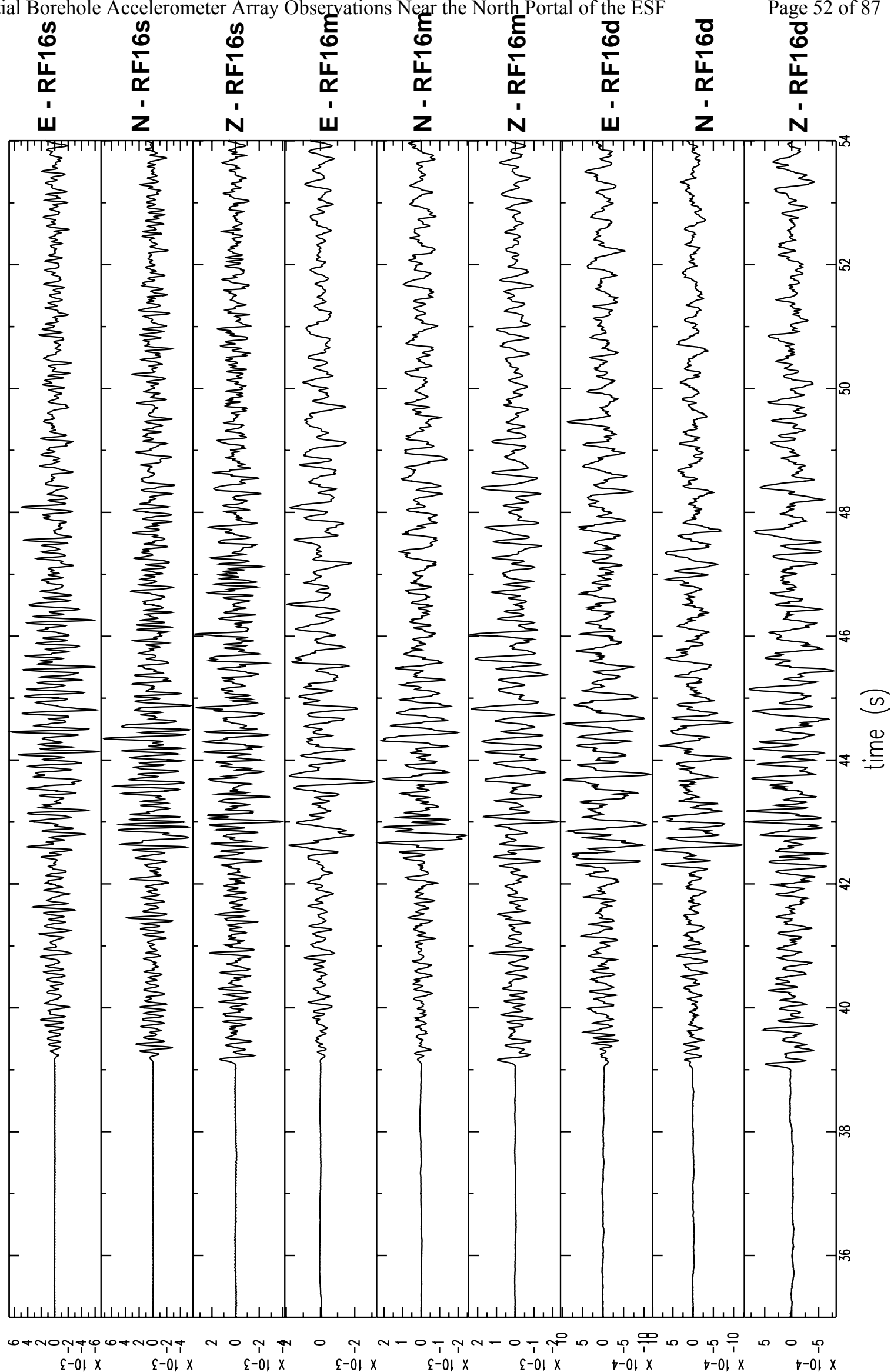

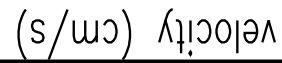

7c. Velocity traces of an M 2.5 earthquake on day 304 in Rock Valley (Table 3), integrated from the accelerometer recordings shown in Figure 3. The traces are grouped by borehole on three pages. 


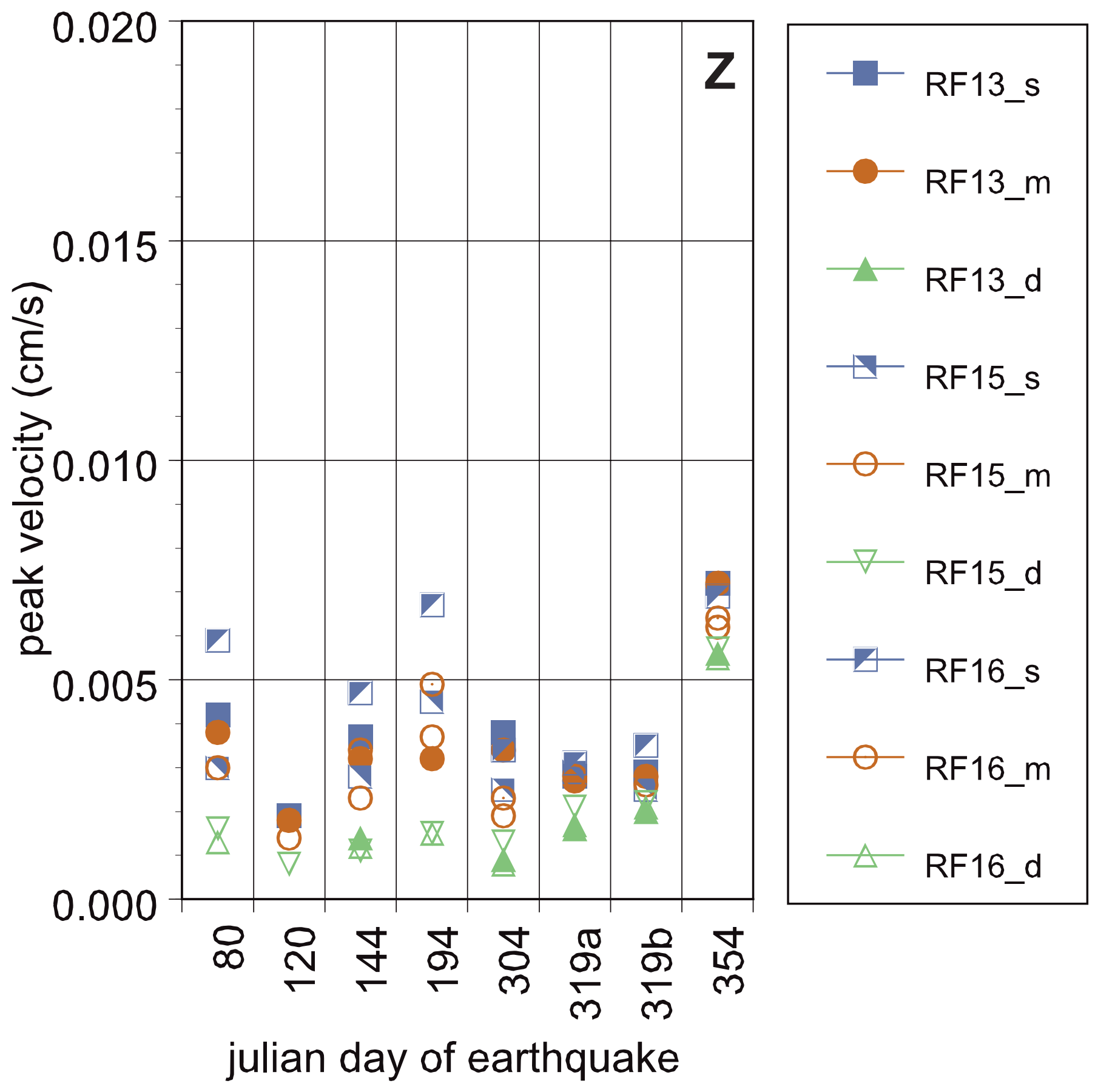

8a. PGV values for usable signals in 2003. Values are grouped by component (Z,N,E) on three pages. (Q data in 006DV.007 -- derived from TDA \# 006DV.003.) 


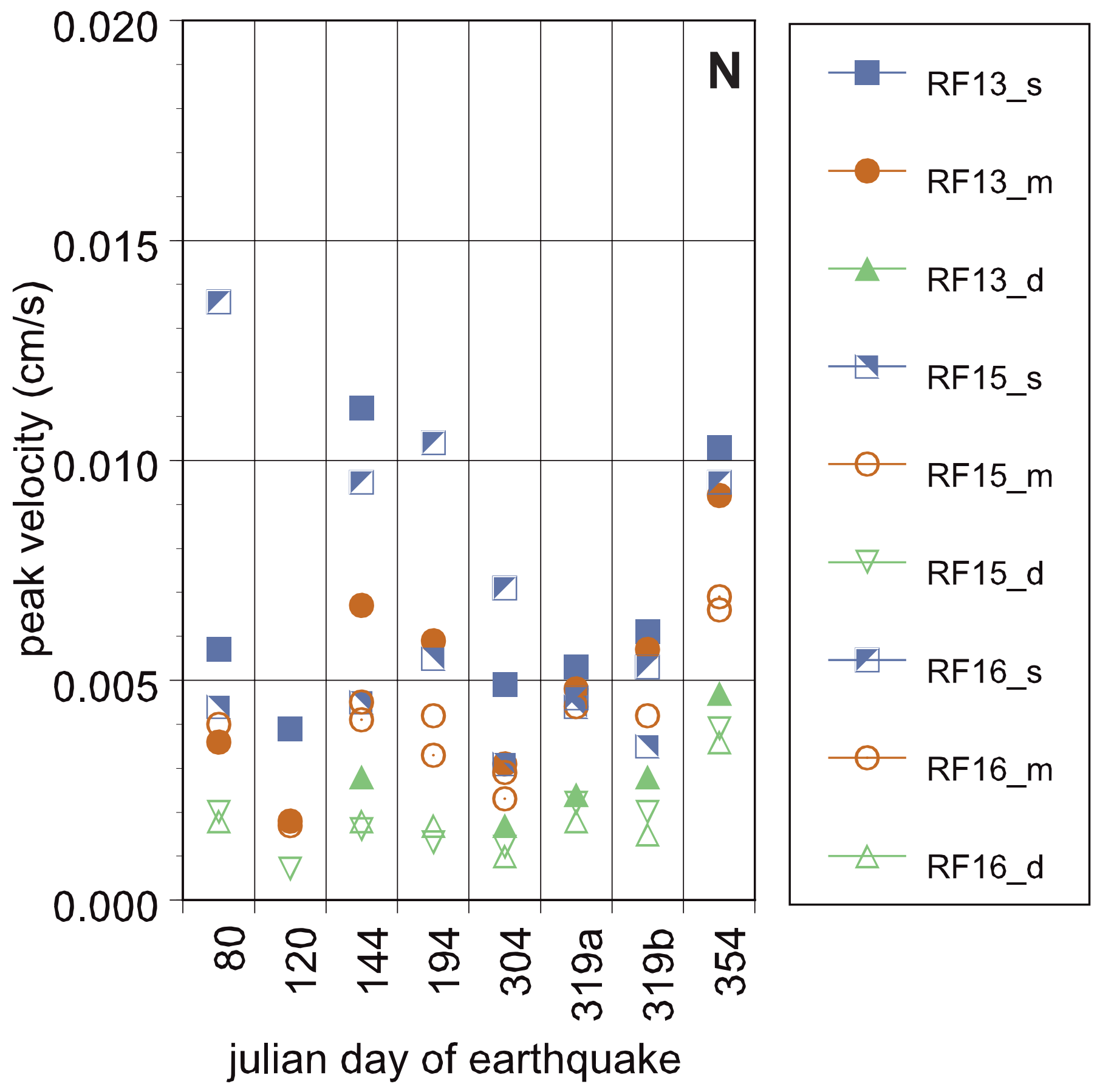

8b. PGV values for usable signals in 2003. Values are grouped by component (Z,N,E) on three pages. (Q data in 006DV.007 -- derived from TDA \# 006DV.003.) 


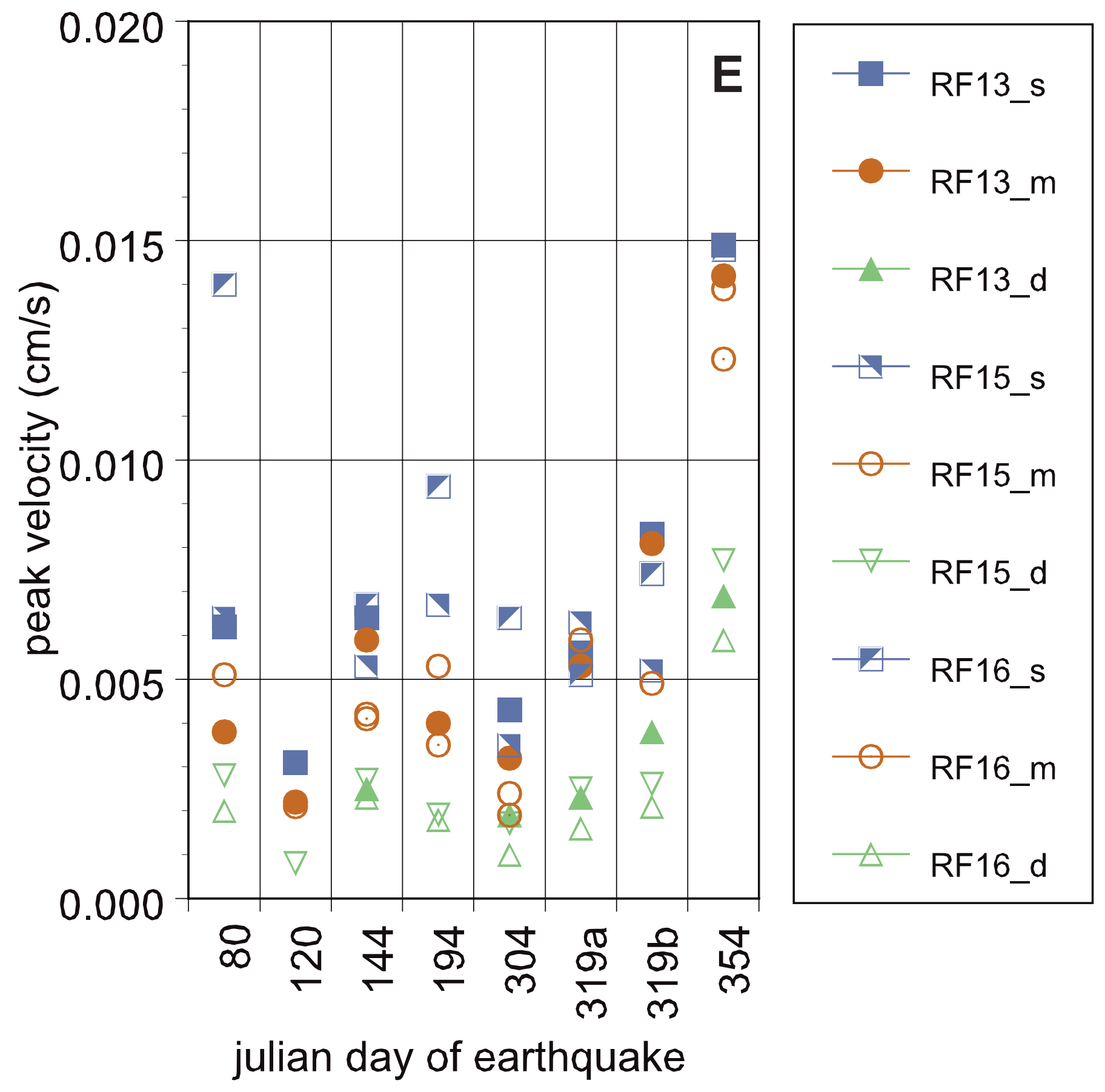

8c. PGV values for usable signals in 2003. Values are grouped by component (Z,N,E) on three pages. (Q data in 006DV.007 -- derived from TDA \# 006DV.003.) 
9a. Accelerometer spectra of the day 304 earthquake in Rock Valley (see Figure 3 for time series). The spectra are grouped by sensor on nine pages. (Q data derived from TDA \# 006DV.003 with program SAC.)

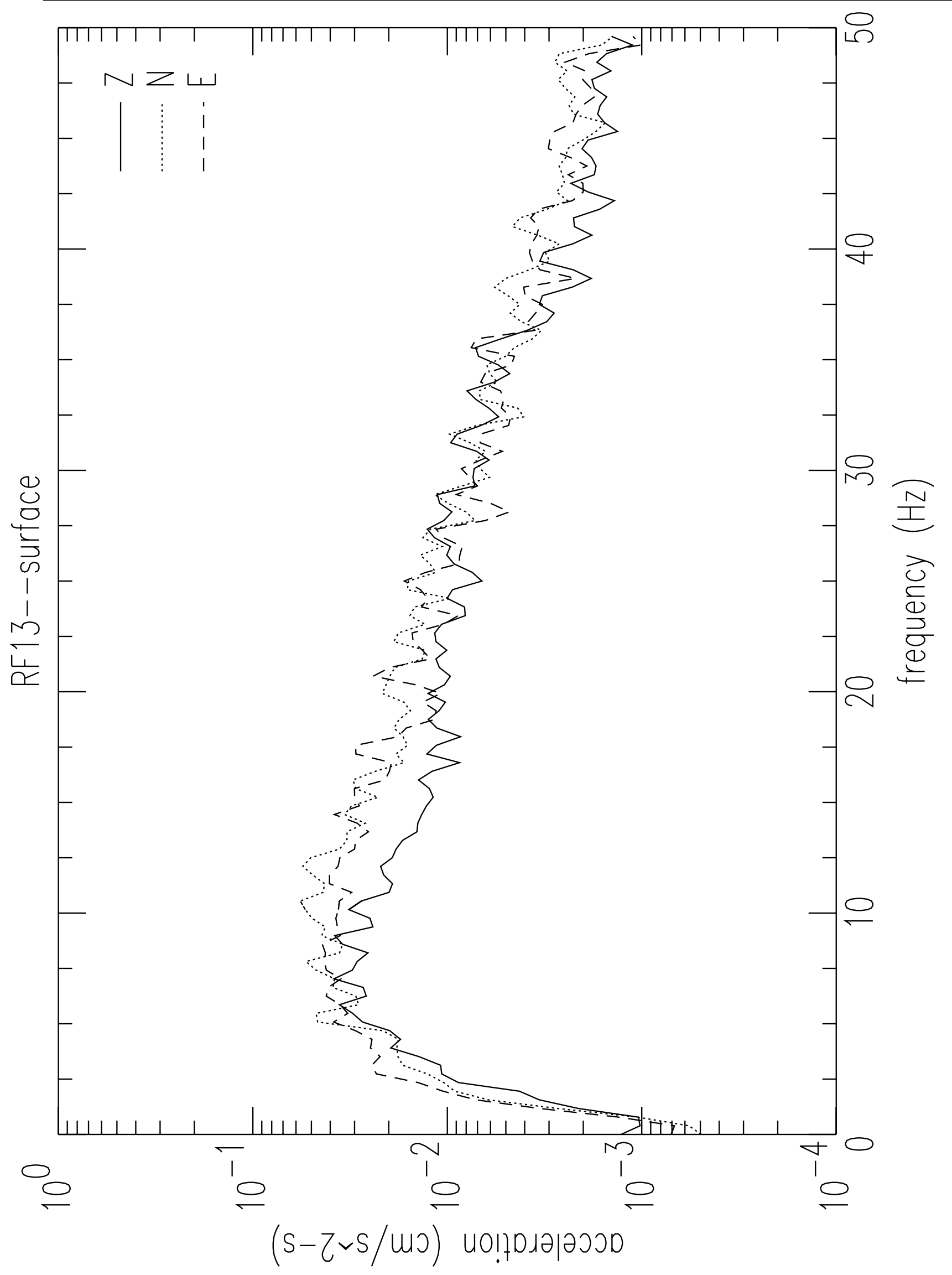


9b. Accelerometer spectra of the day 304 earthquake in Rock Valley (see Figure 3 for time series). The spectra are grouped by sensor on nine pages. (Q data derived from TDA \# 006DV.003 with program SAC.)

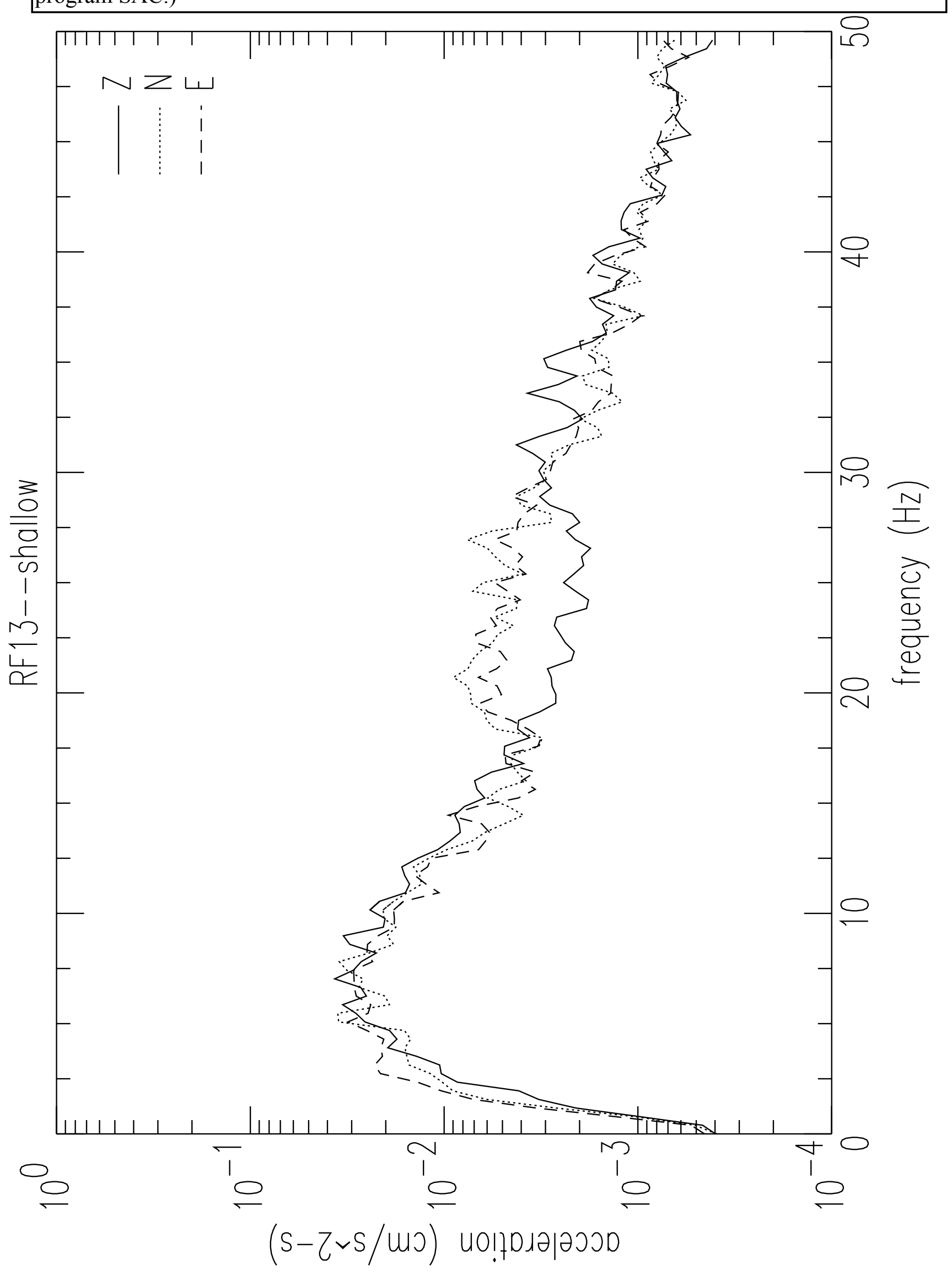


9c. Accelerometer spectra of the day 304 earthquake in Rock Valley (see Figure 3 for time series). The spectra are grouped by sensor on nine pages. (Q data derived from TDA \# 006DV.003 with program SAC.)

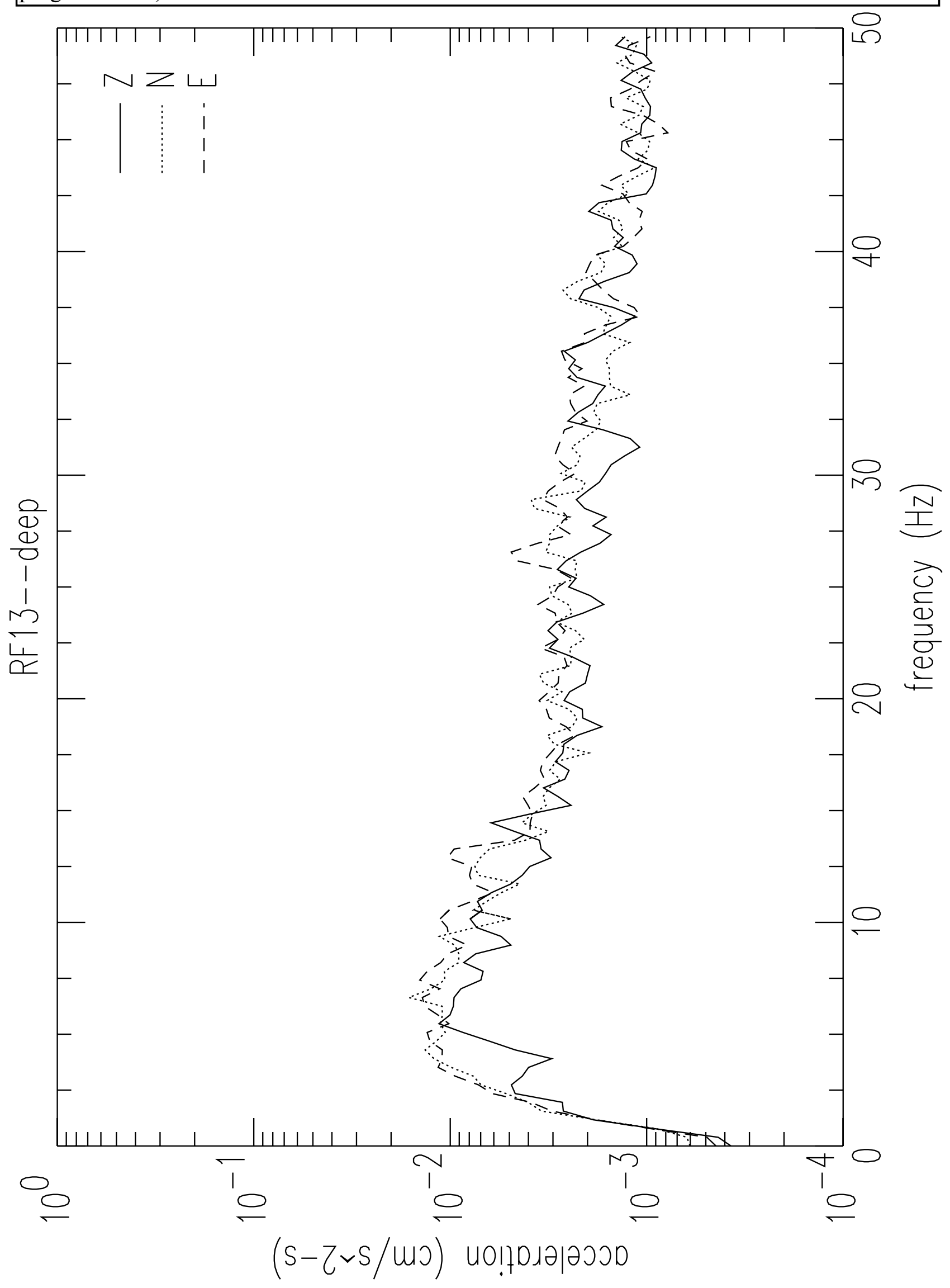


9d. Accelerometer spectra of the day 304 earthquake in Rock Valley (see Figure 3 for time series). The spectra are grouped by sensor on nine pages. (Q data derived from TDA \# 006DV.003 with program SAC.)

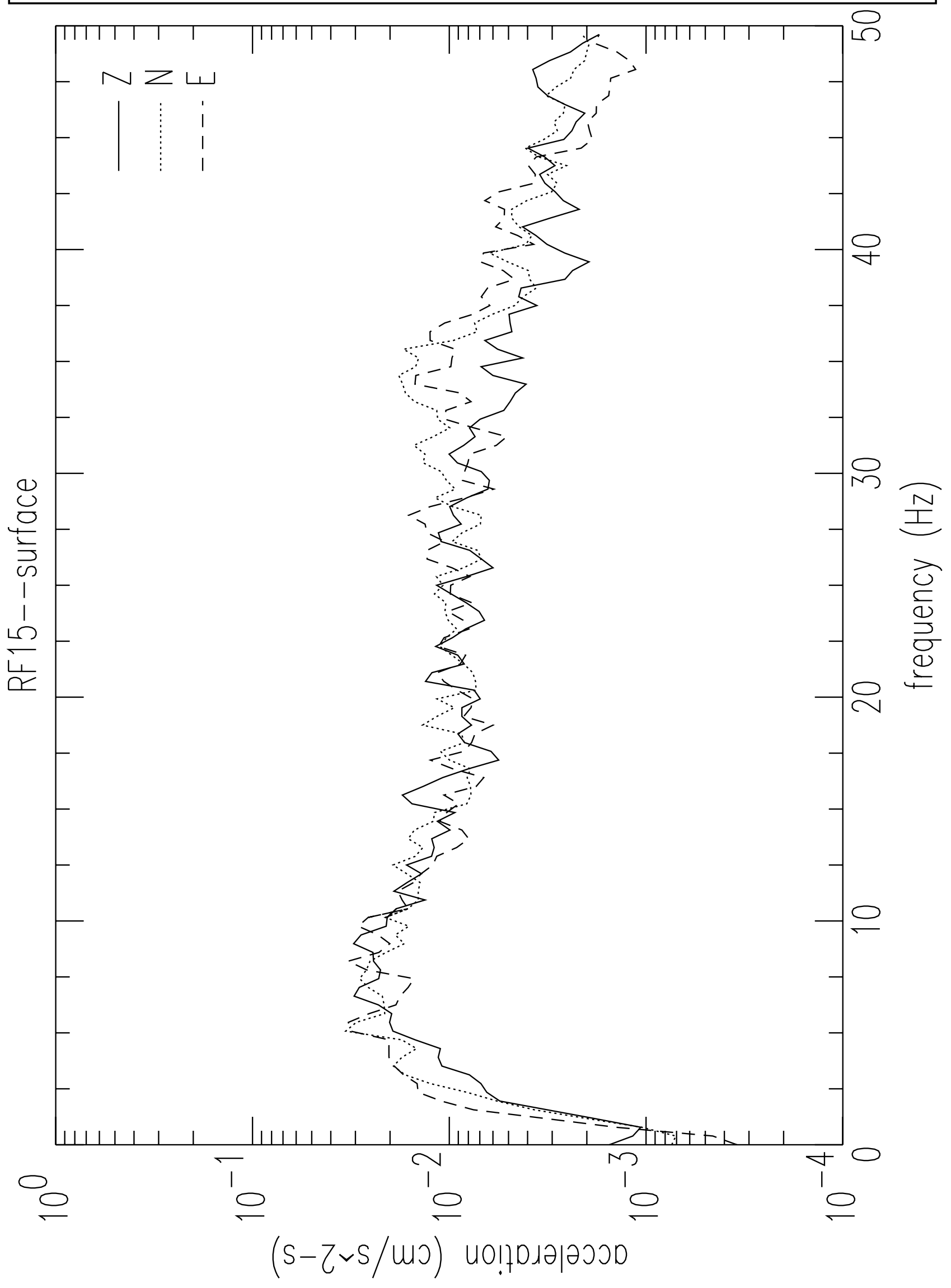


9e. Accelerometer spectra of the day 304 earthquake in Rock Valley (see Figure 3 for time series). The spectra are grouped by sensor on nine pages. (Q data derived from TDA \# 006DV.003 with program SAC.)

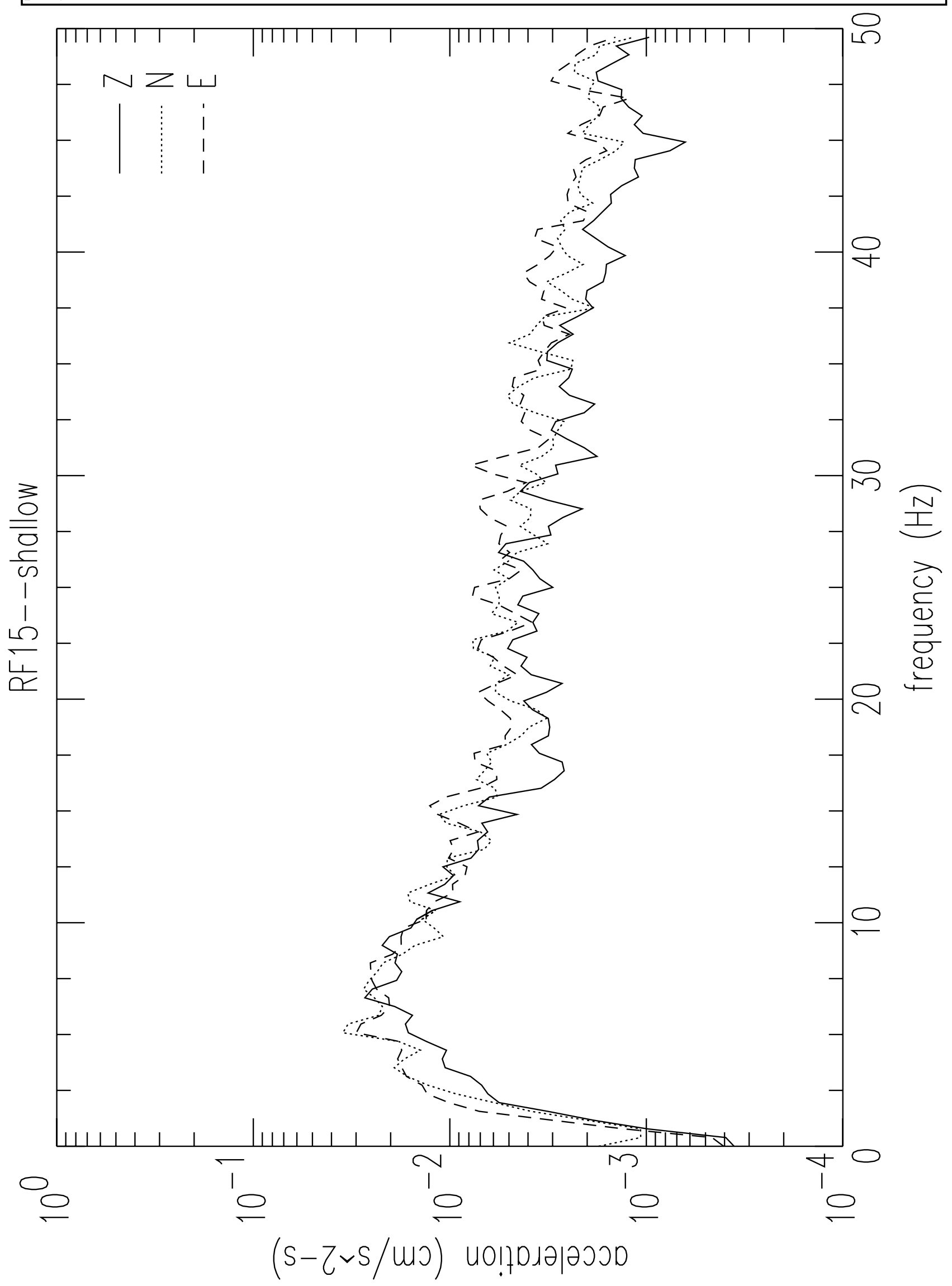


9f. Accelerometer spectra of the day 304 earthquake in Rock Valley (see Figure 3 for time series). The spectra are grouped by sensor on nine pages. (Q data derived from TDA \# 006DV.003 with program SAC.)

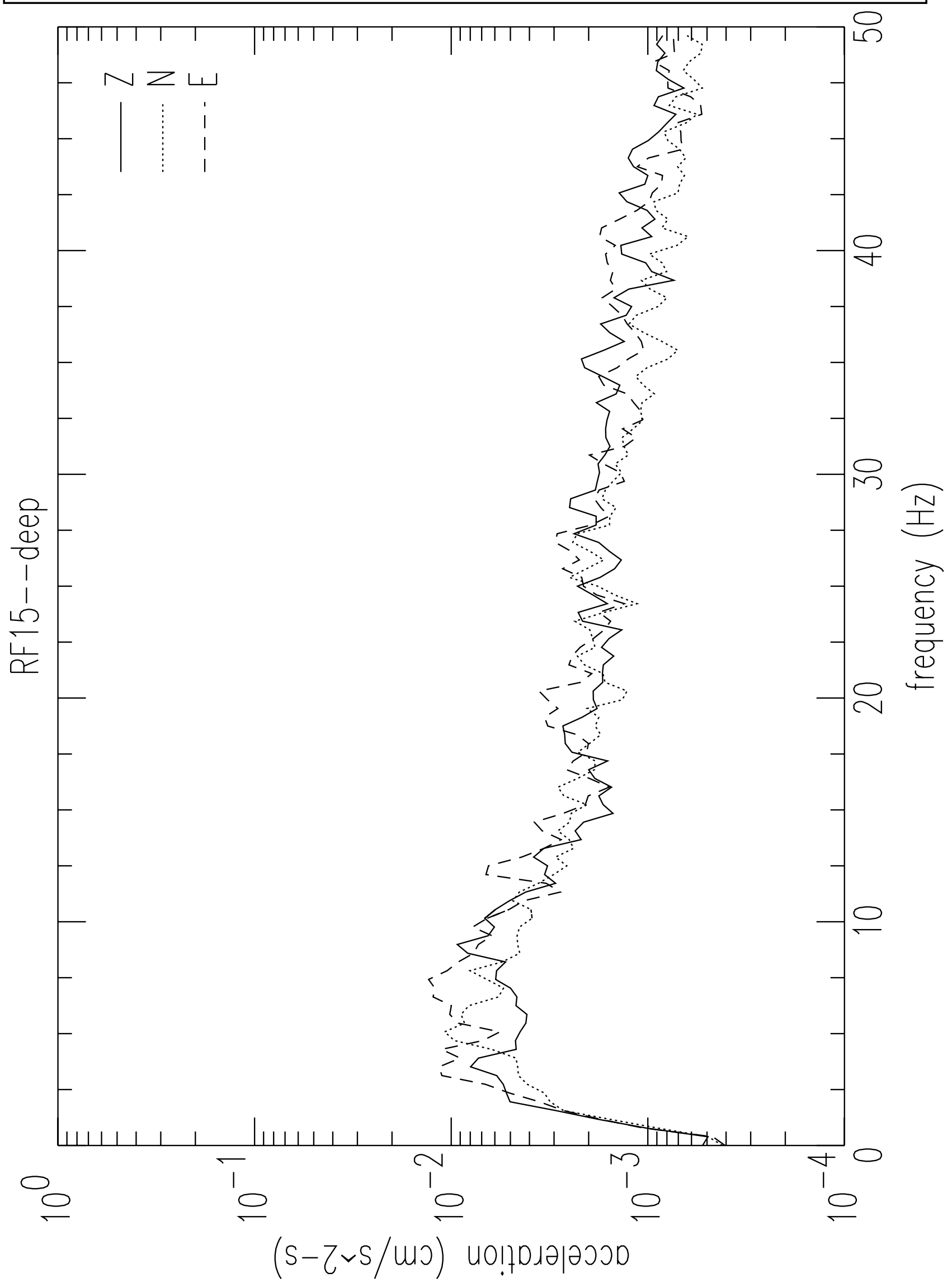




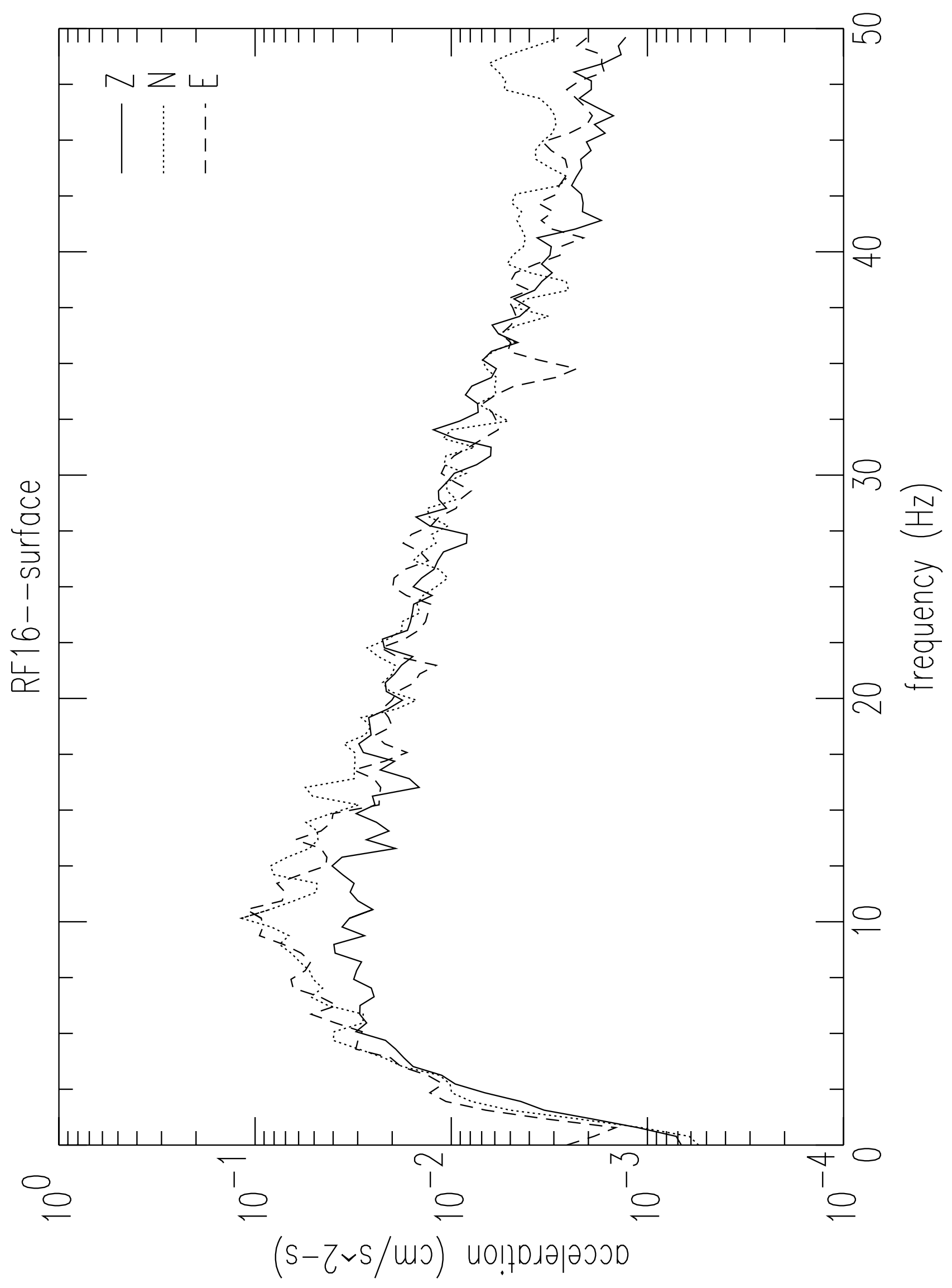




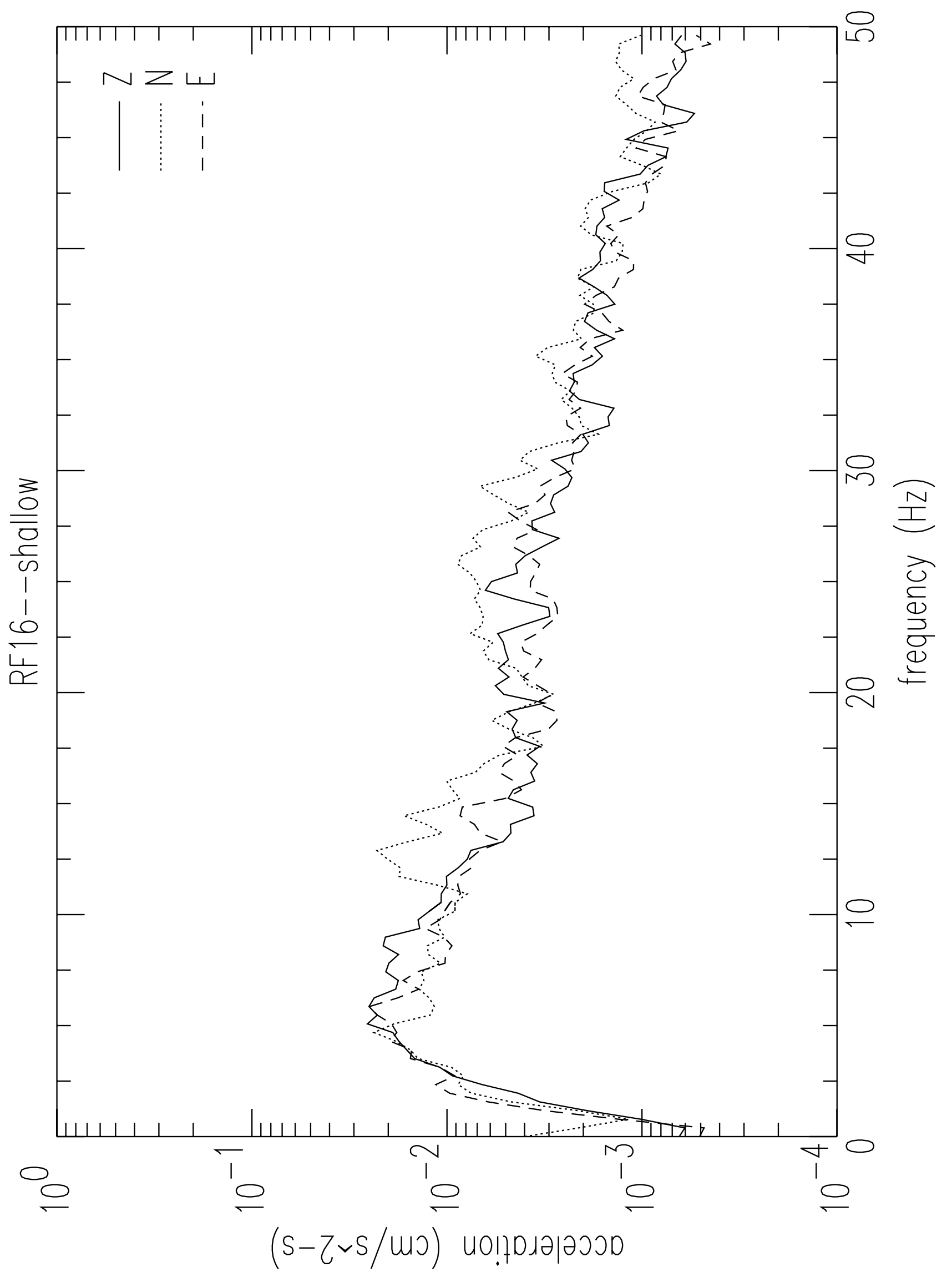


Initial Borehole Accelerometer Array Observations Near the North Portal of the ESF

Page 64 of 87

9i. Accelerometer spectra of the day 304 earthquake in Rock Valley (see Figure 3 for time series). The spectra are grouped by sensor on nine pages. (Q data derived from TDA \# 006DV.003 with program SAC.)

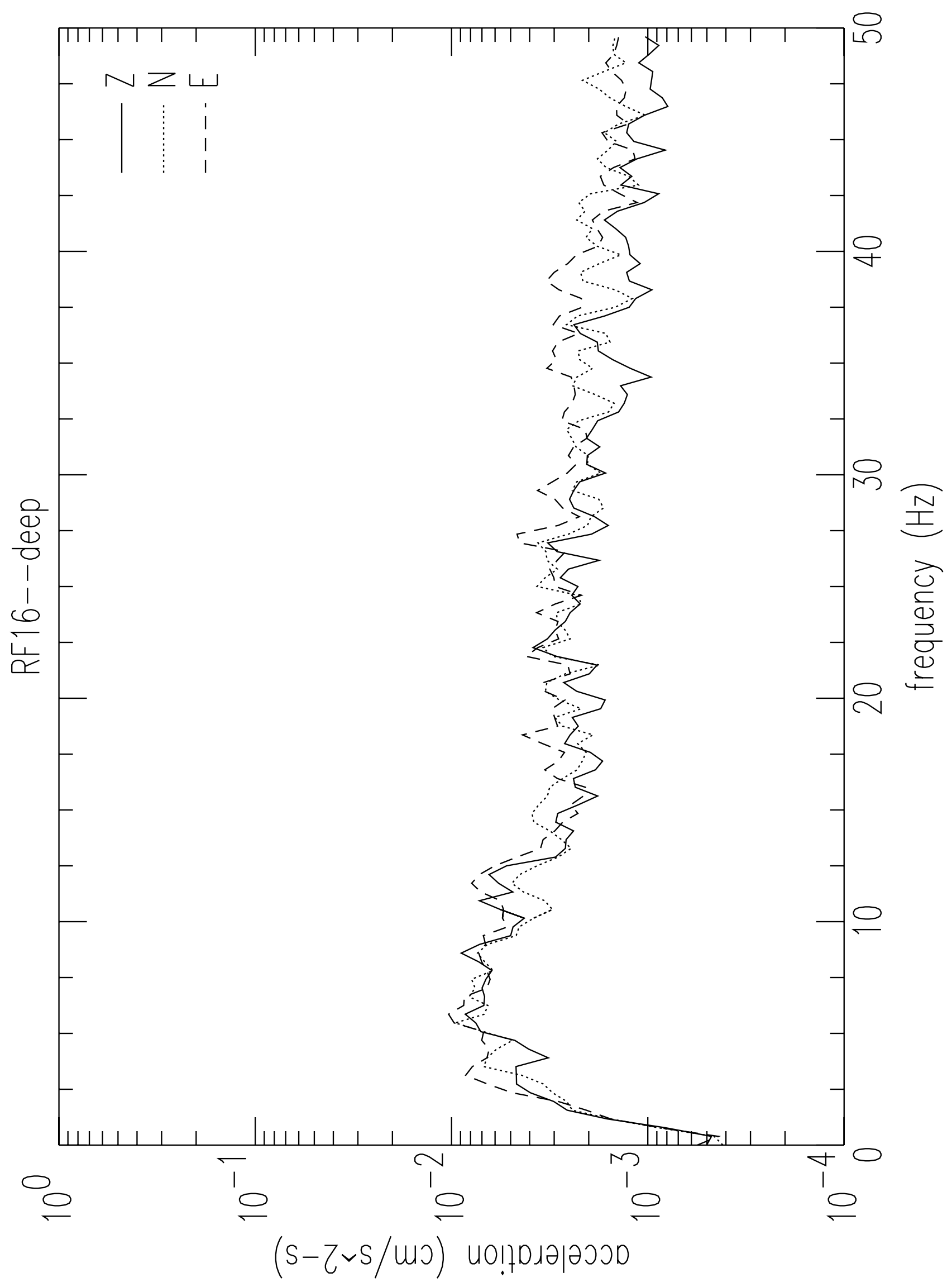




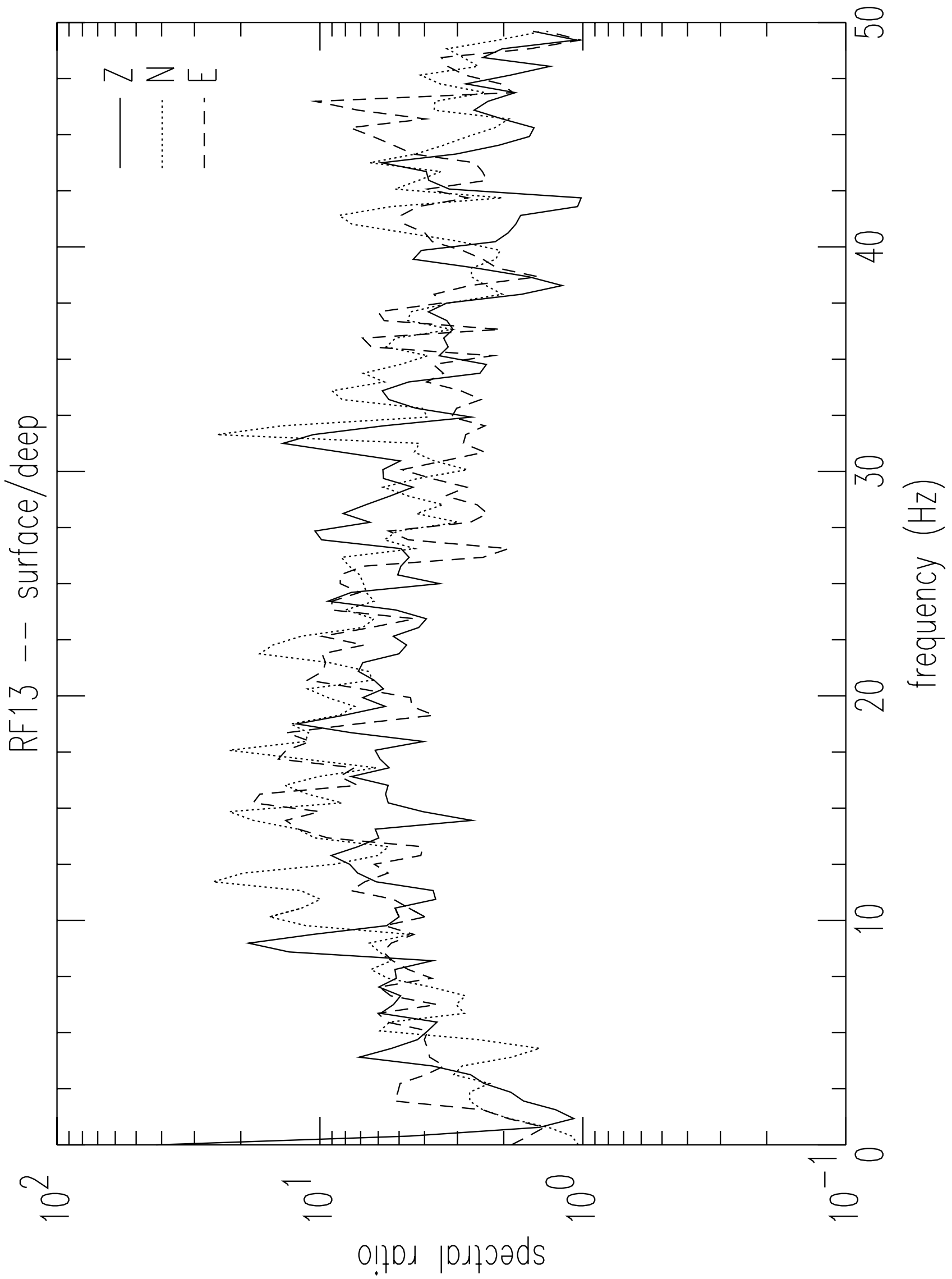




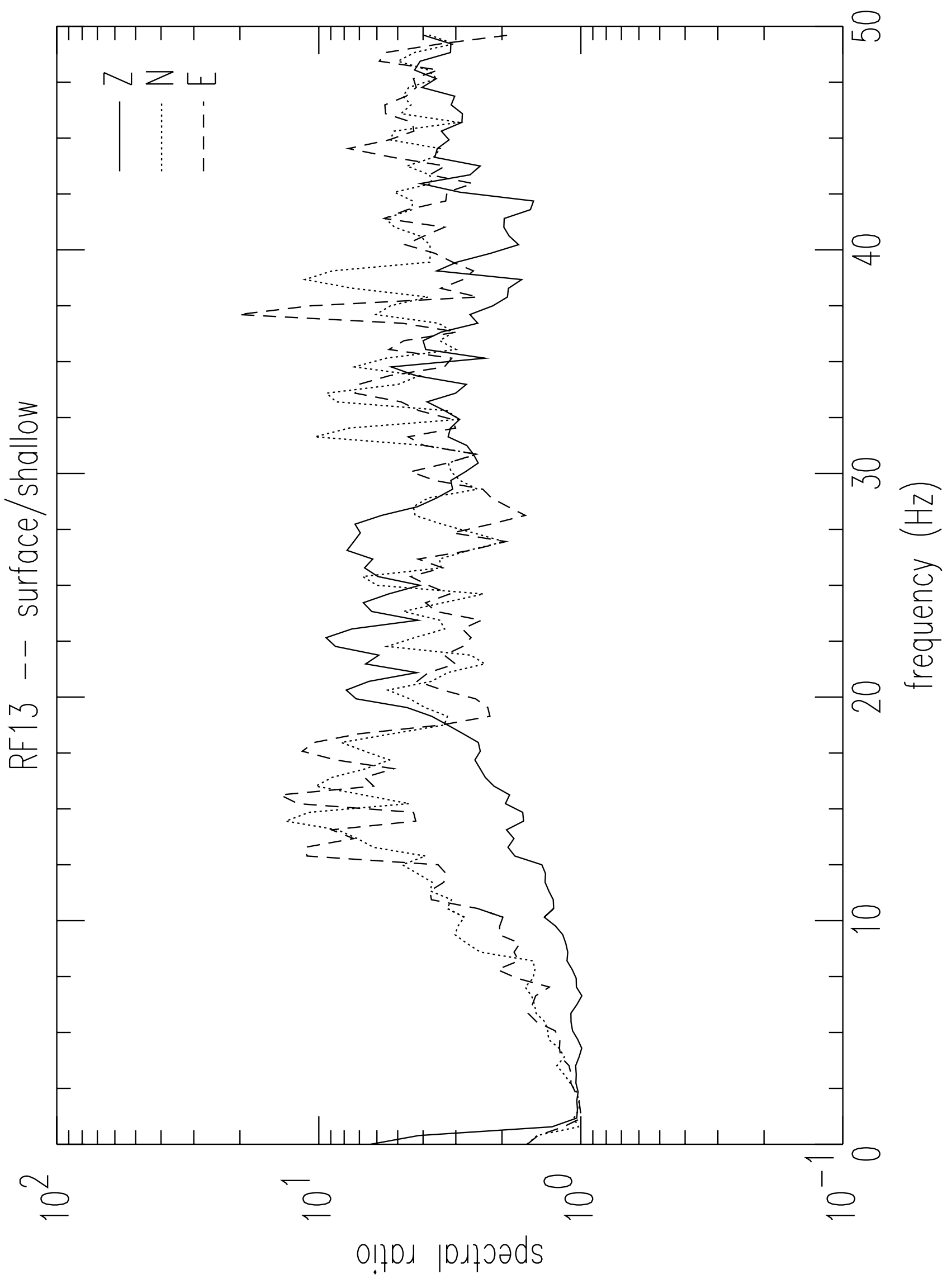




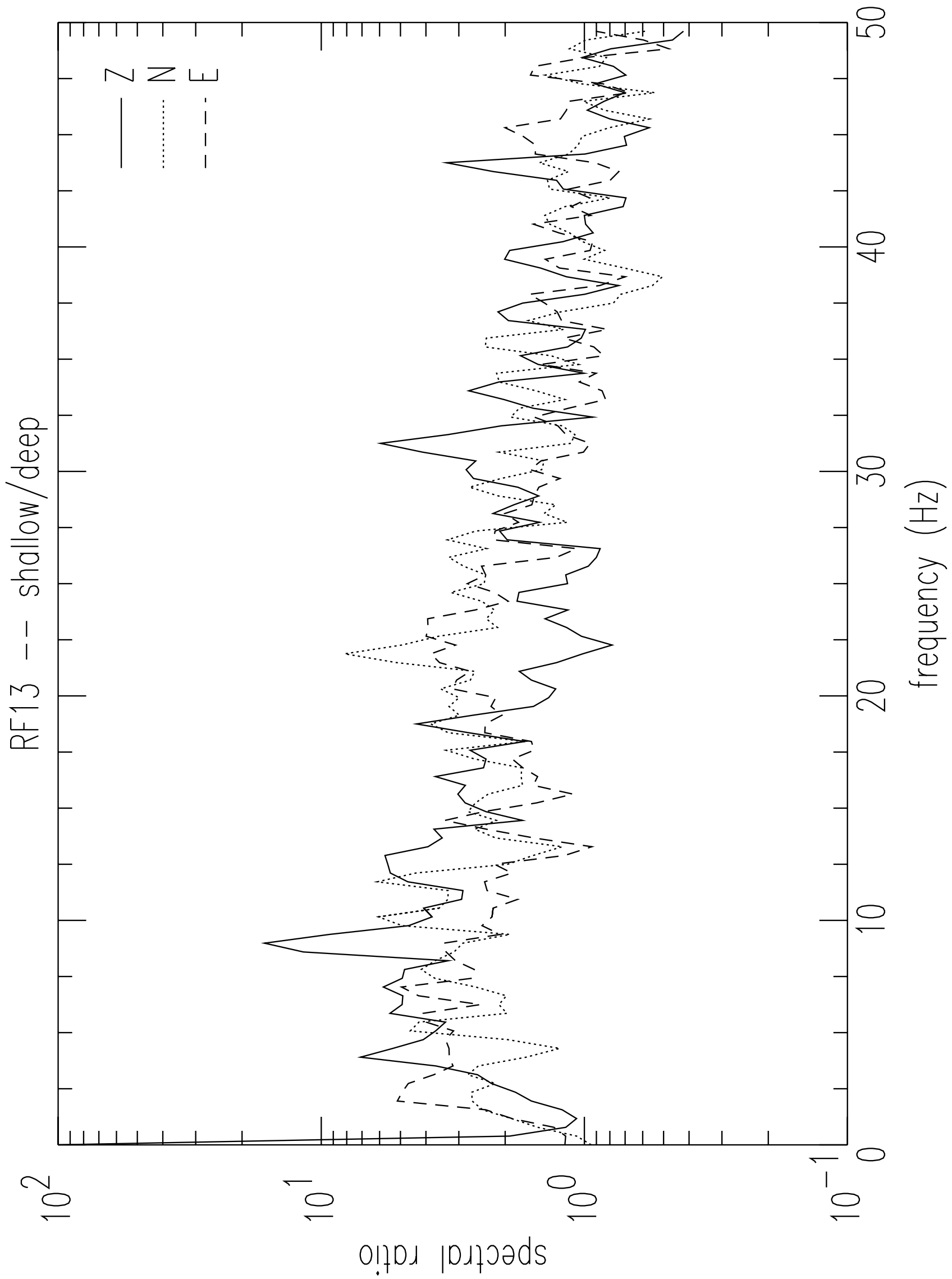




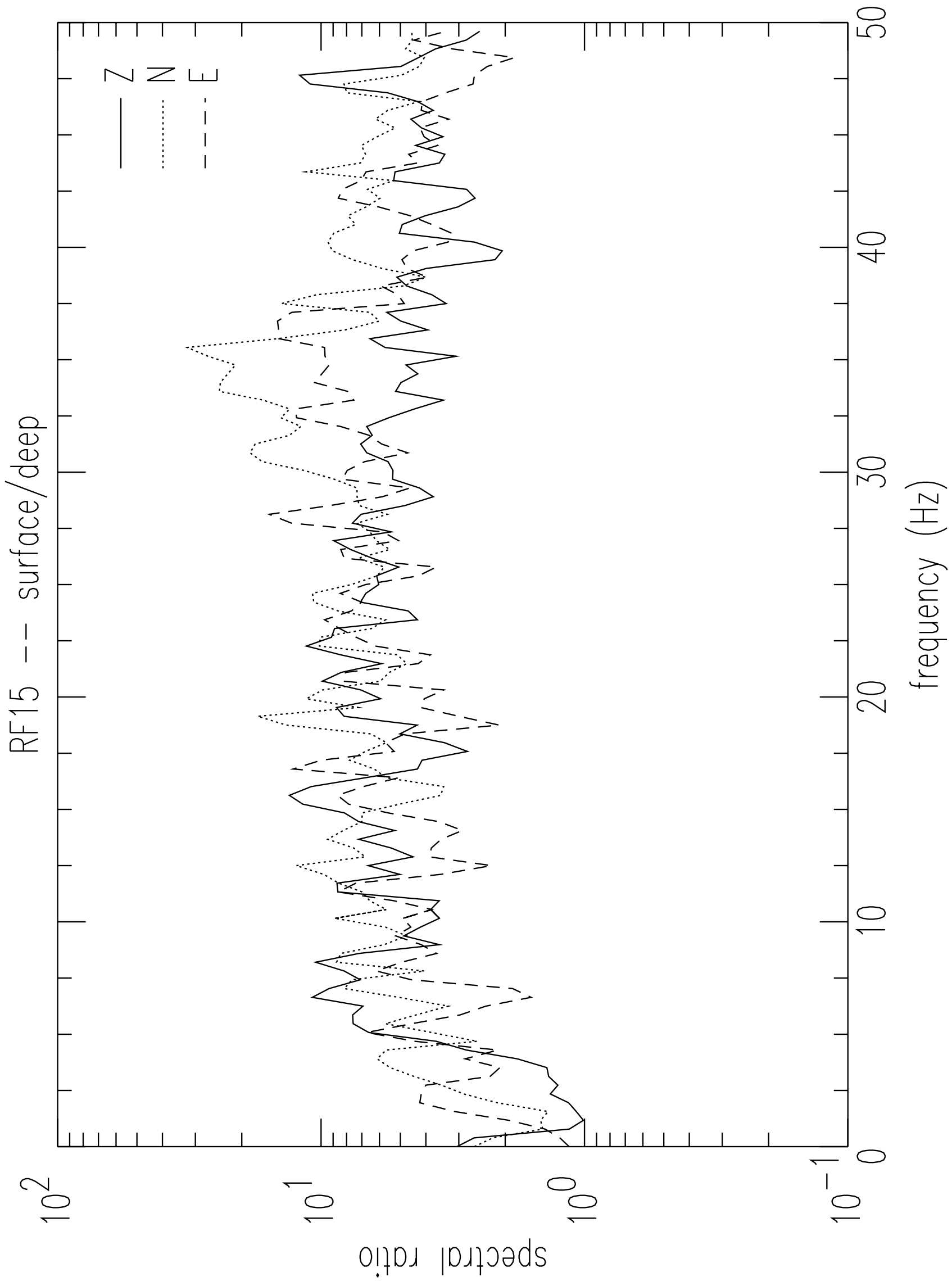


10e. Spectral ratios for spectra shown in Figure 9. The ratios are surface/deep, surface/midhole, and midhole/deep for each borehole. (Q data derived from TDA \# 006DV.003 with program SAC.)

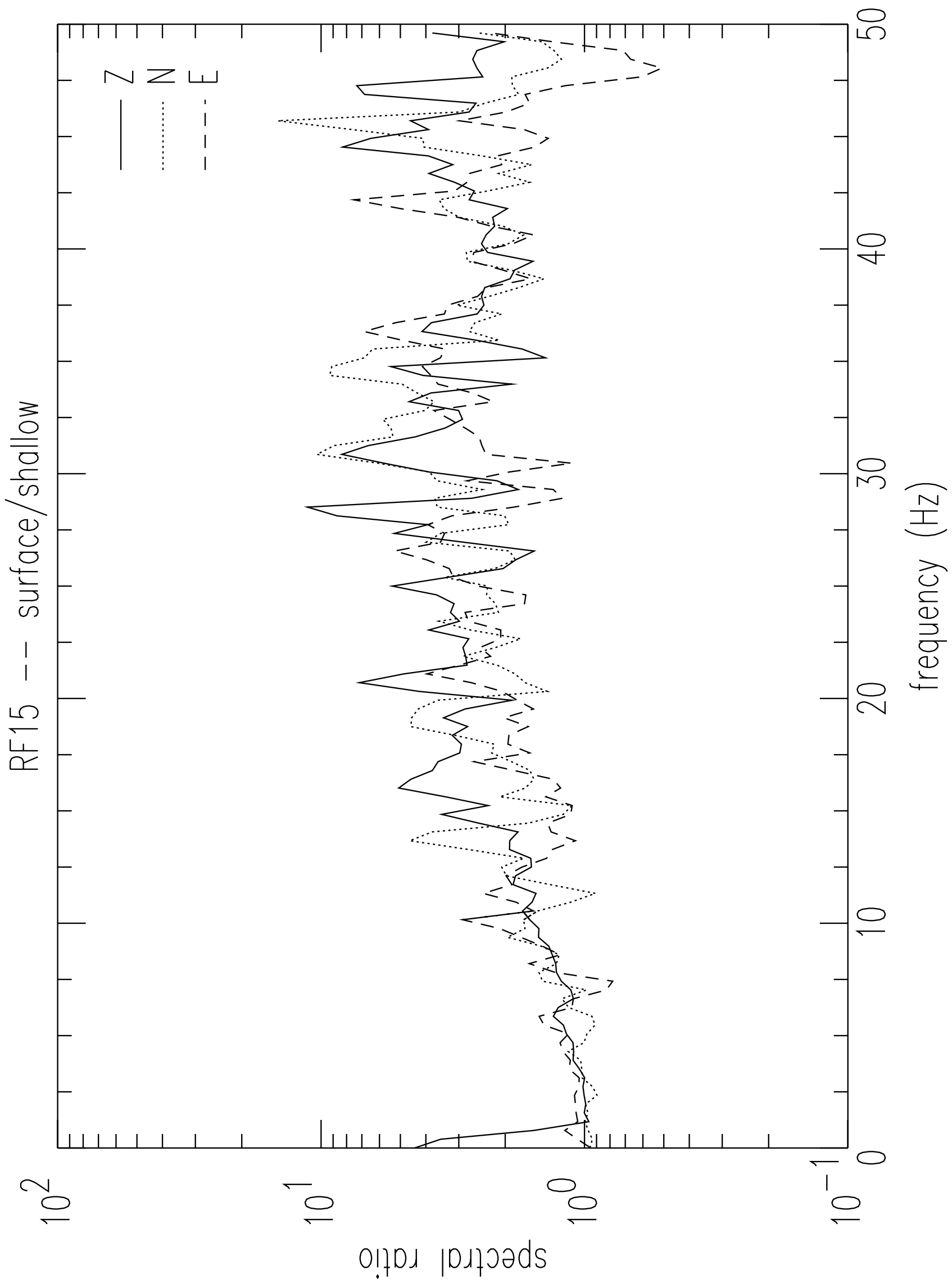




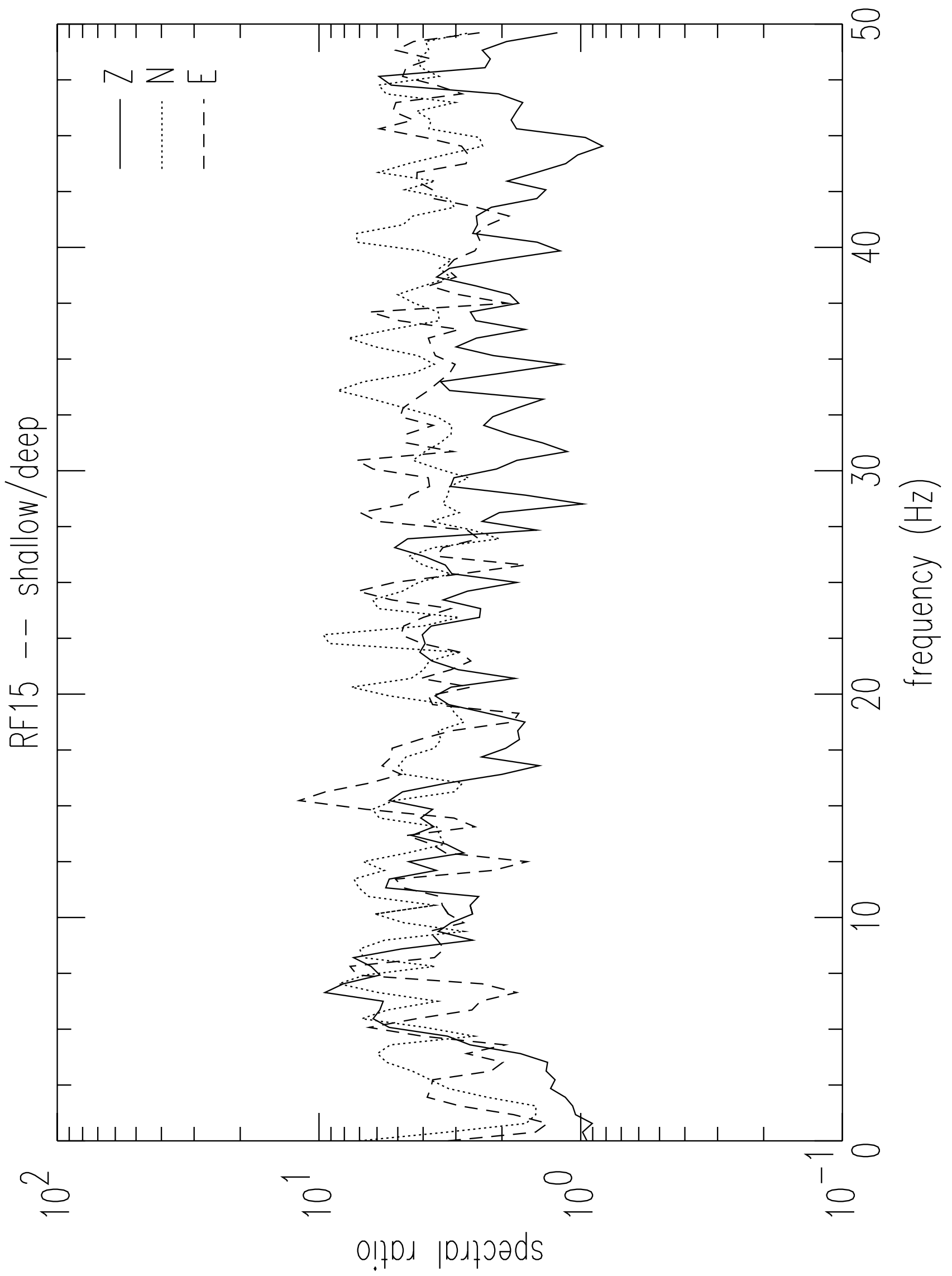


Initial Borehole Accelerometer Array Observations Near the North Portal of the ESF

Page 71 of 87

10g. Spectral ratios for spectra shown in Figure 9. The ratios are surface/deep, surface/midhole, and midhole/deep for each borehole. (Q data derived from TDA \# 006DV.003 with program SAC.)

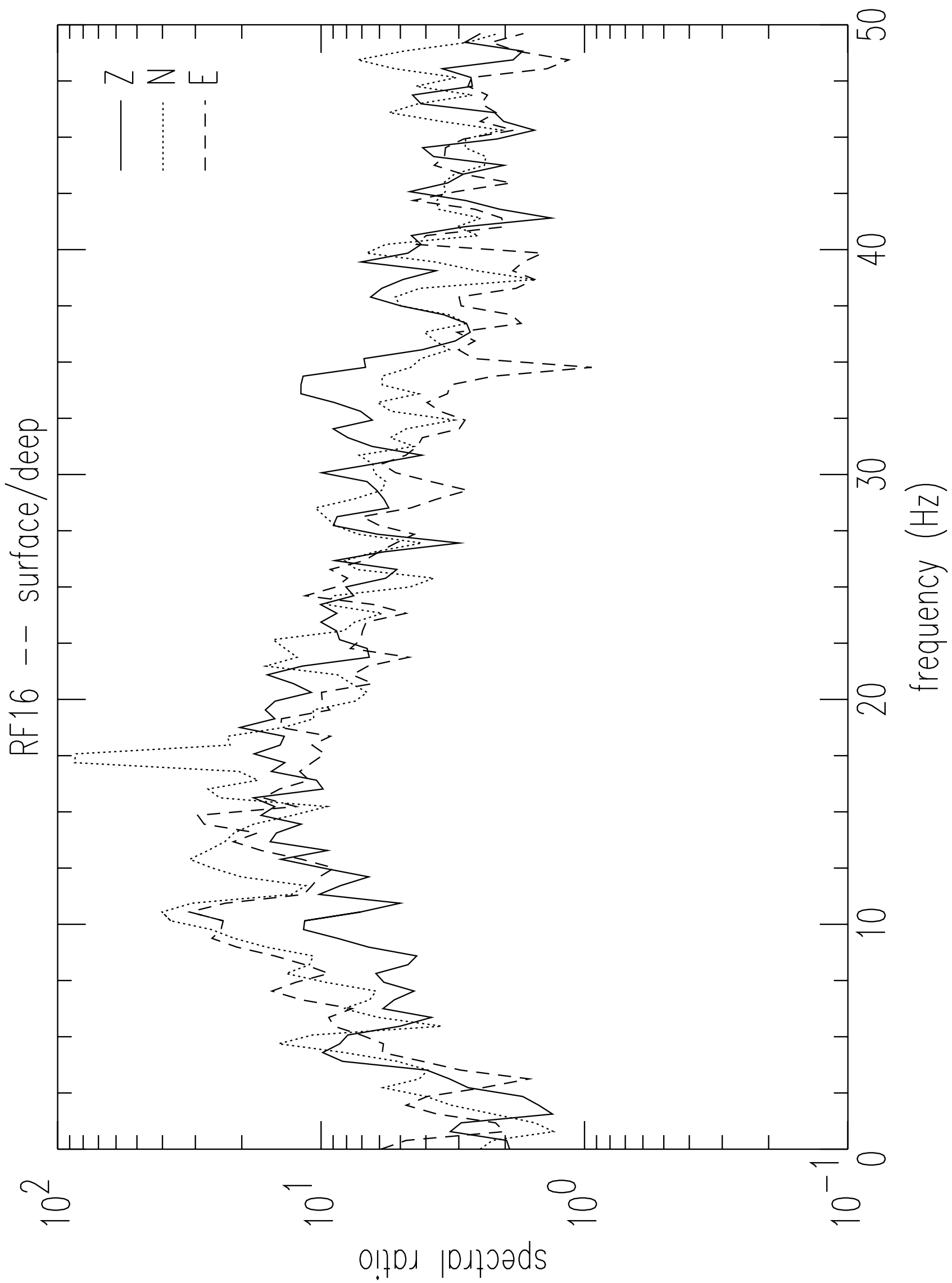




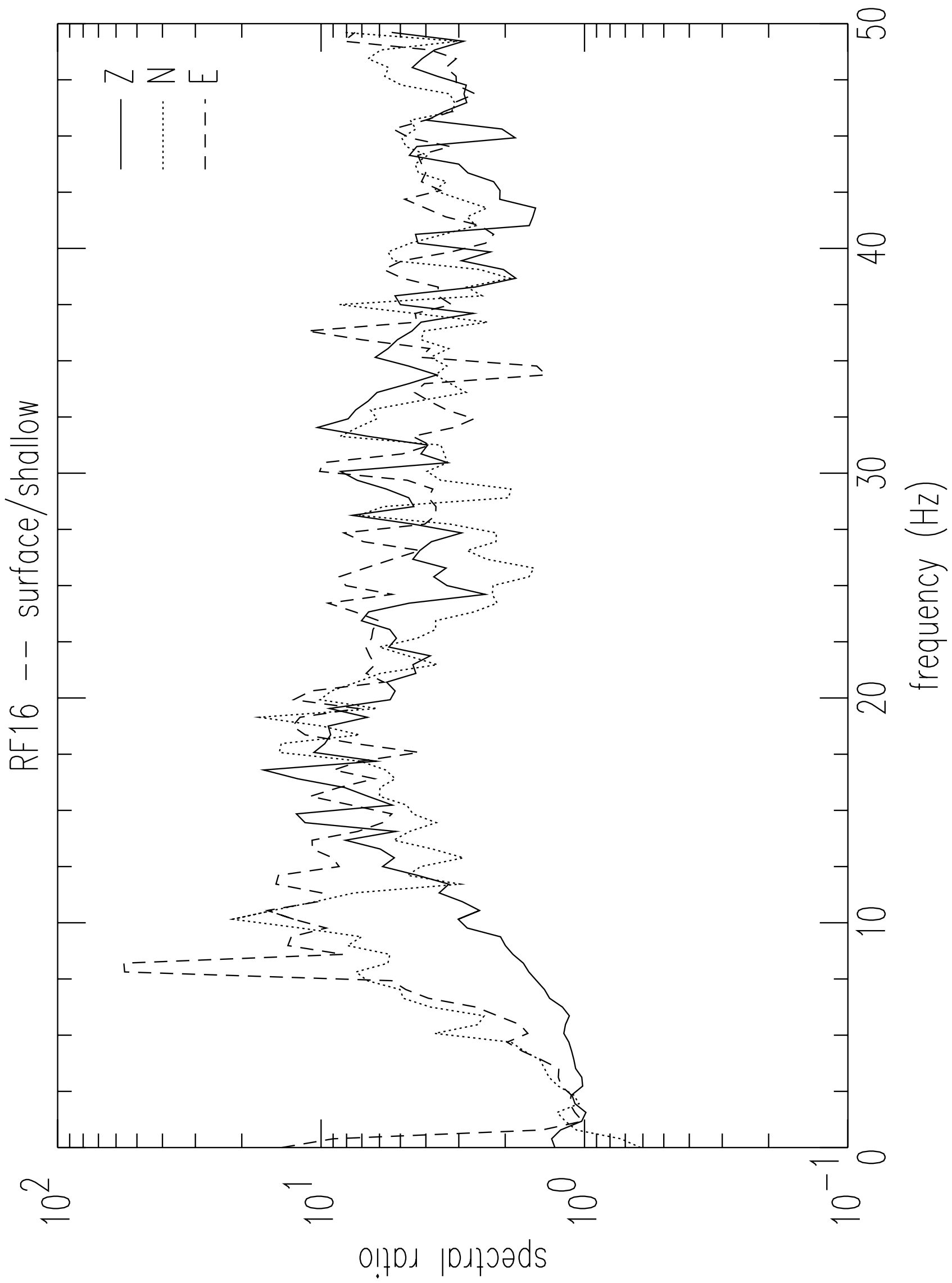




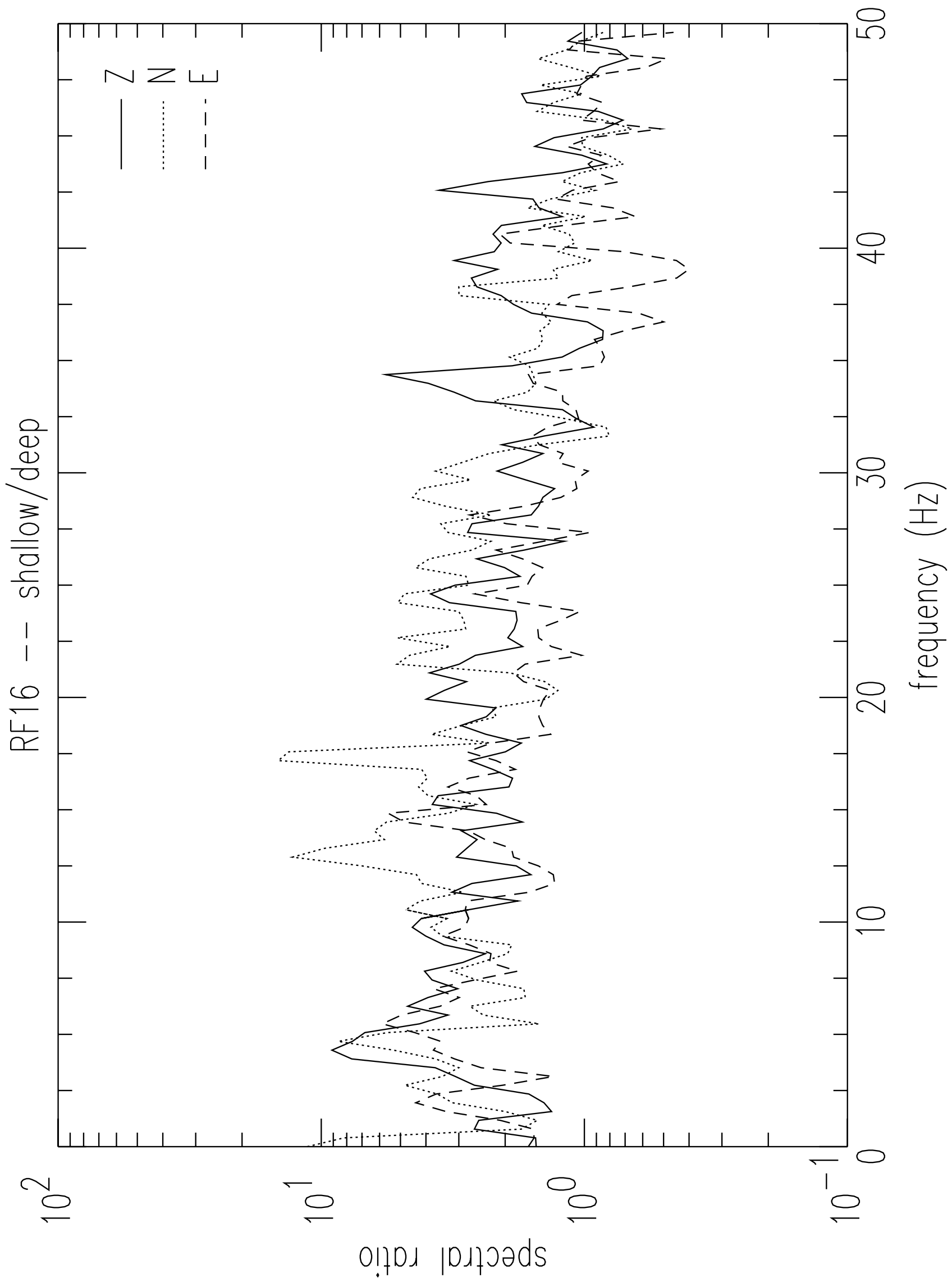




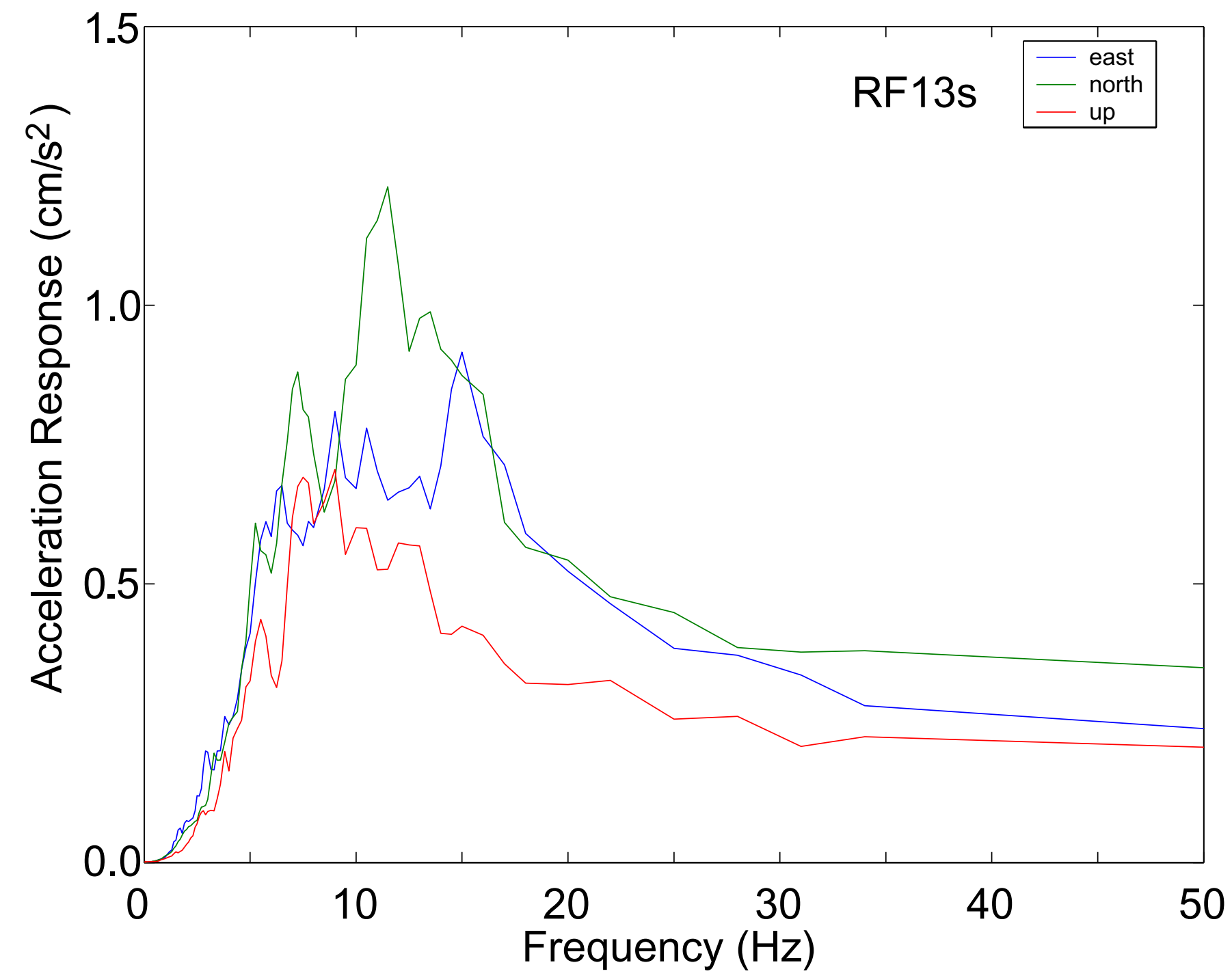

11a. Acceleration response spectra (Sa) for the surface accelerograms of the day 304 earthquake in Rock Valley (see Figure 3 for time series). A 5\% damping constant is assumed. The spectra are grouped by borehole on three pages. (non-Q: not to be used for quality-affecting work; source data from TDA \# 006DV.003.) 


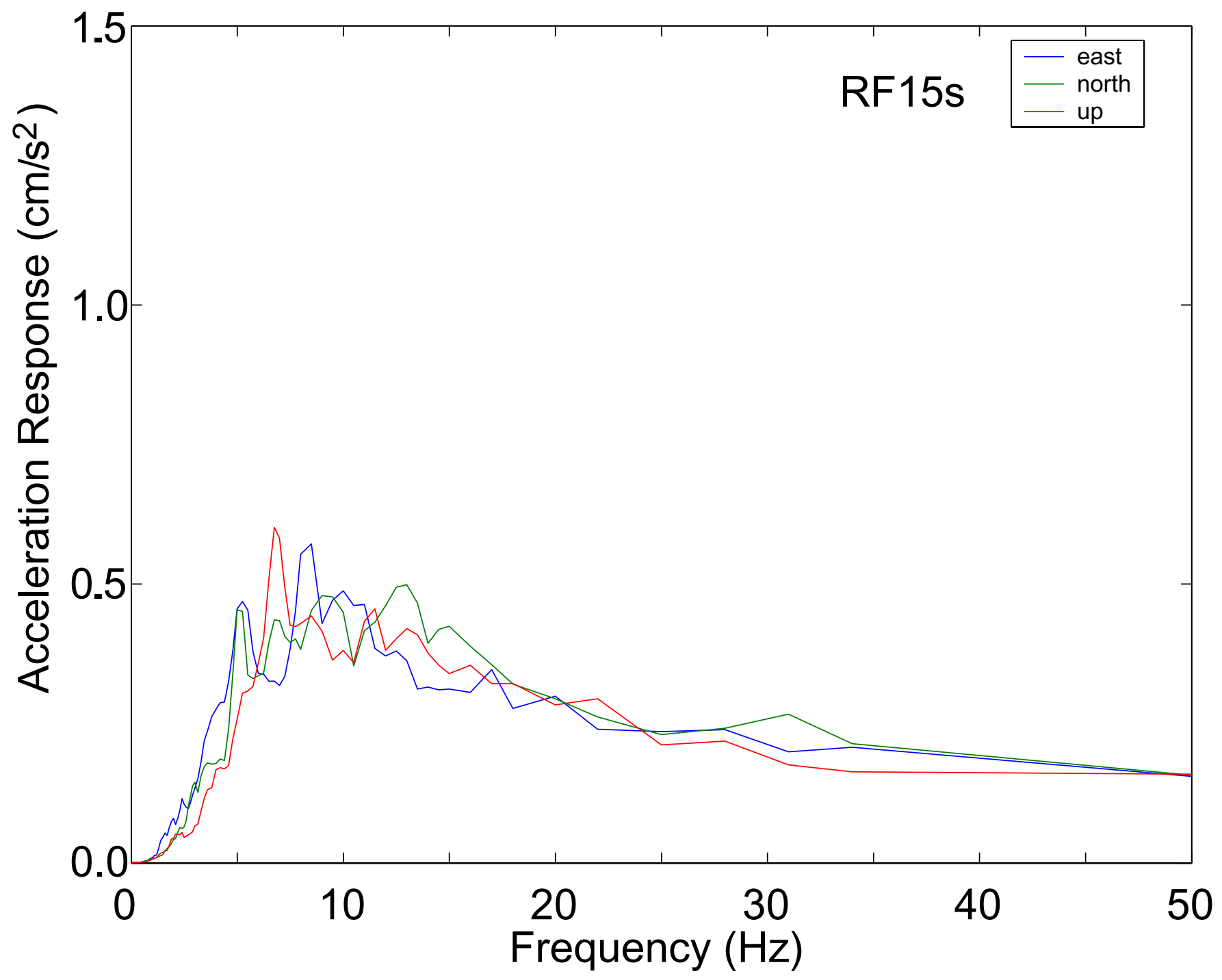

11b. Acceleration response spectra (Sa) for the surface accelerograms of the day 304 earthquake in Rock Valley (see Figure 3 for time series). A 5\% damping constant is assumed. The spectra are grouped by borehole on three pages. (non-Q: not to be used for quality-affecting work; source data from TDA \# 006DV.003.) 


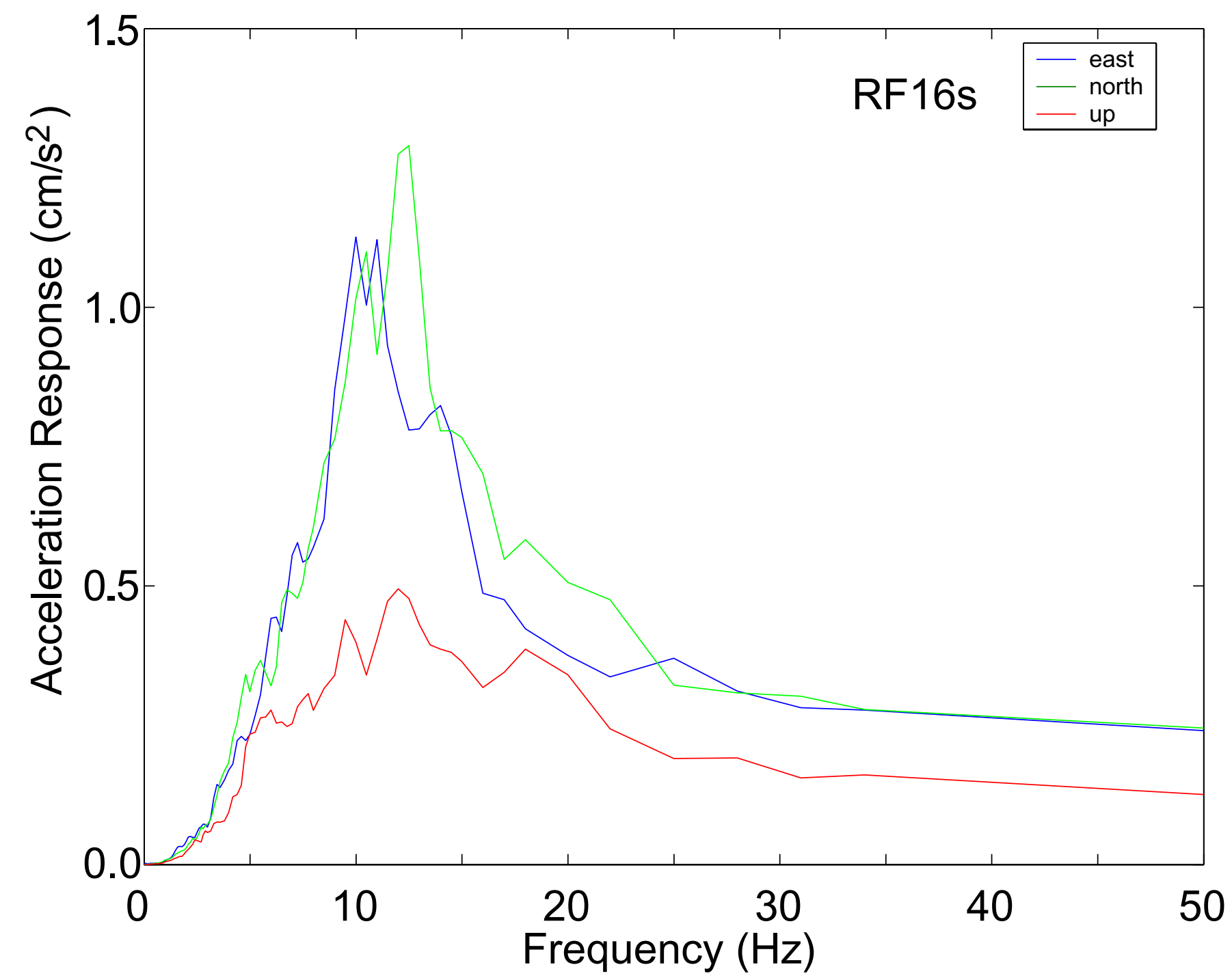

11c. Acceleration response spectra $(\mathrm{Sa})$ for the surface accelerograms of the day 304 earthquake in Rock Valley (see Figure 3 for time series). A 5\% damping constant is assumed. The spectra are grouped by borehole on three pages. (non-Q: not to be used for quality-affecting work; source data from TDA \# 006DV.003.) 


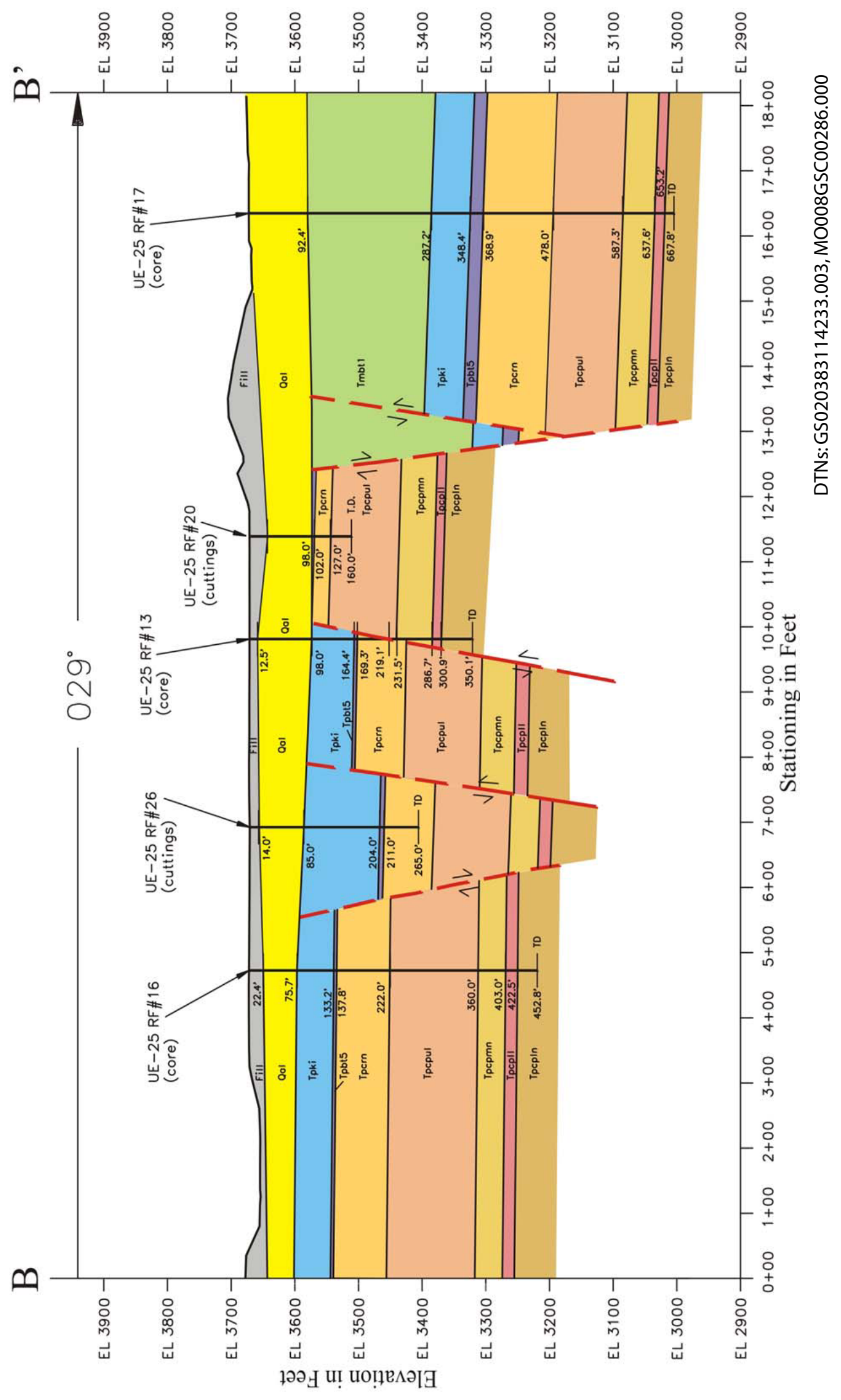

12. A geologic cross-section through boreholes RF16 and RF13. This figure is taken exactly from Luebbers et al. (2002), Figure 226. (DTN's GS020383114233.003, MO0008GSC00286.000.) 


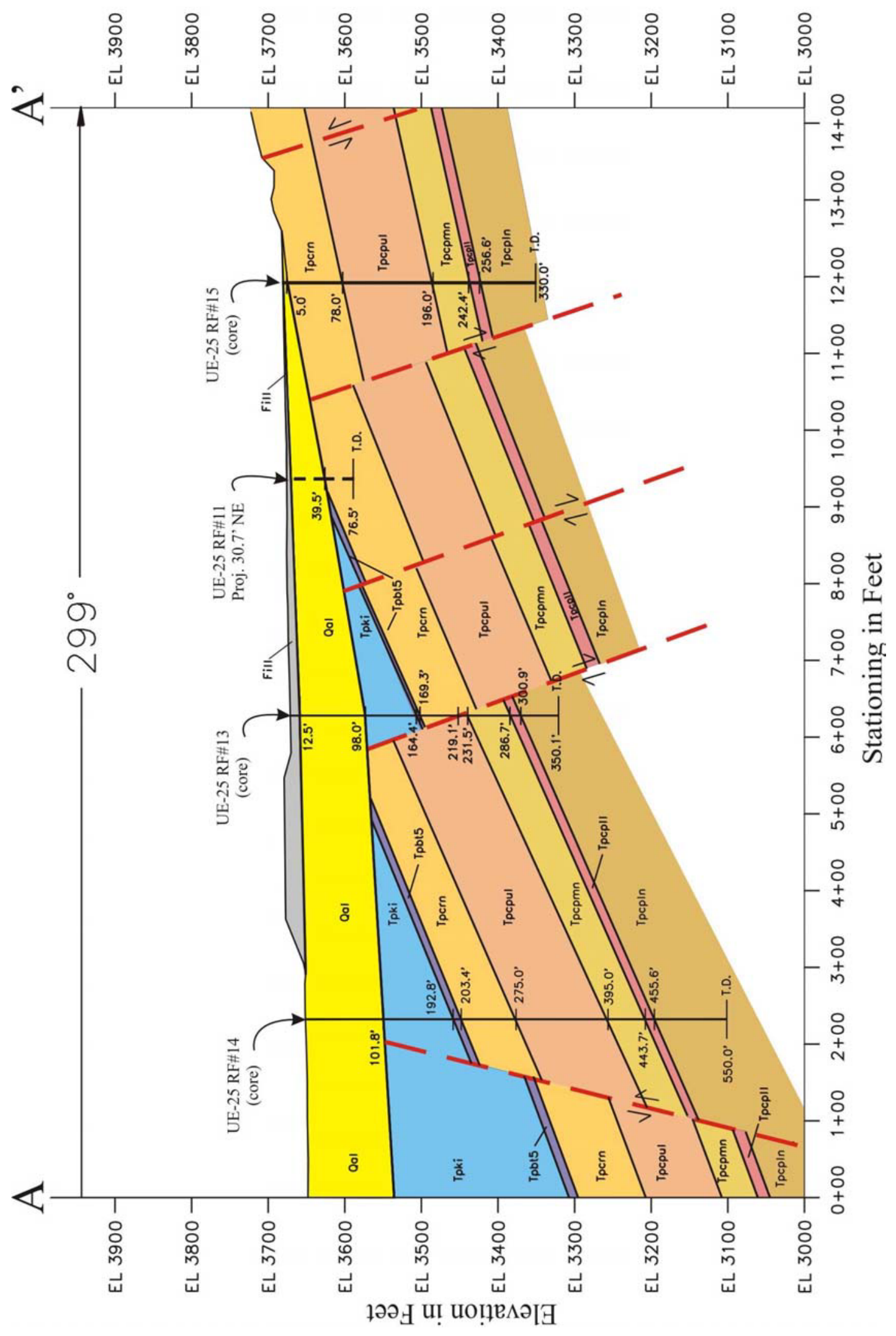

13. A geologic cross-section through boreholes RF13 and RF15. This figure is taken exactly from Luebbers et al. (2002), Figure 225. (DTN's GS020383114233.003, MO0008GSC00286.000.) 


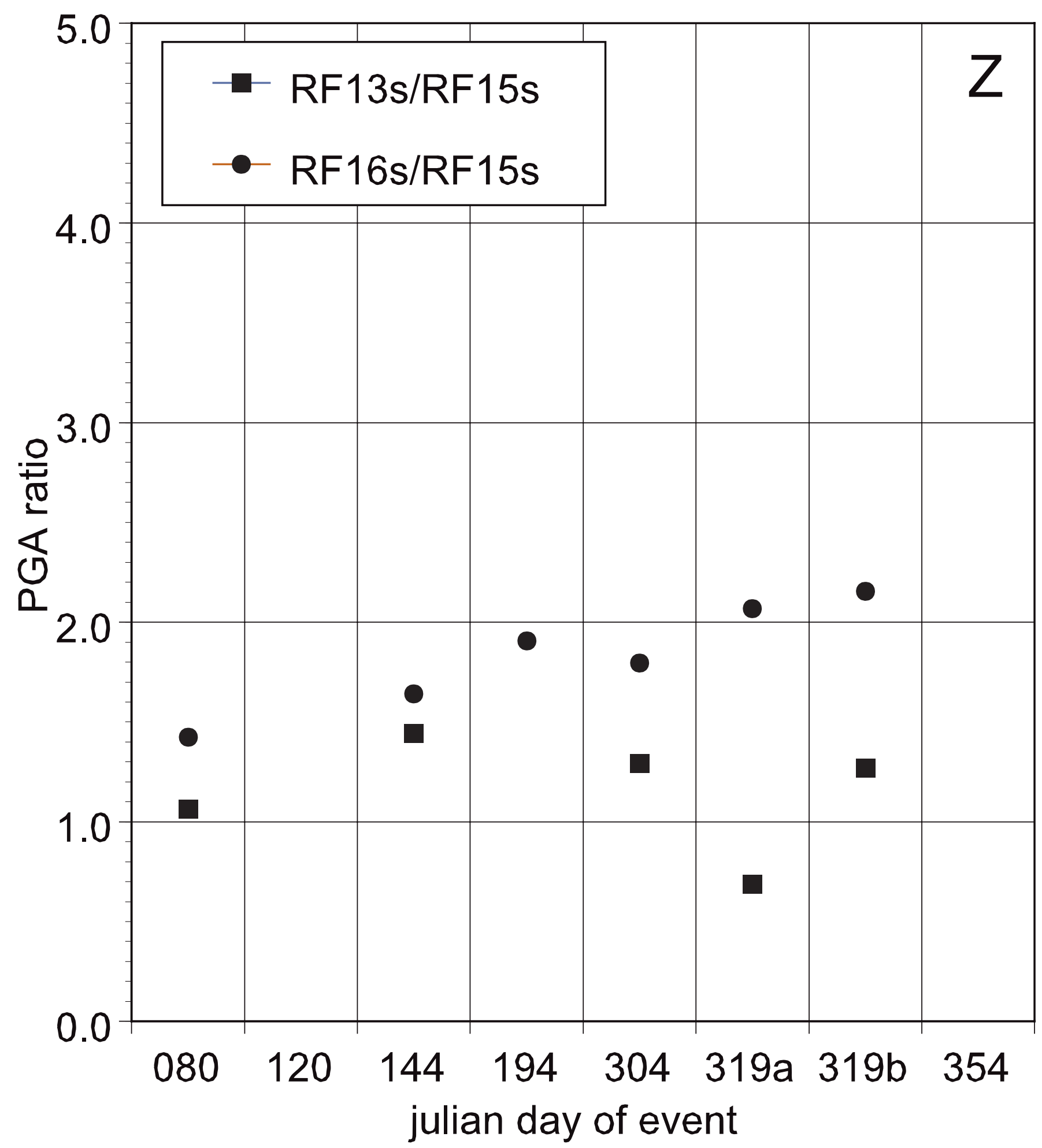

14a. Ratio of RF13 and RF16 PGA's to those of RF15, the reference site. Ratios are computed from the data displayed in Figure 4 and grouped by component $(\mathrm{Z}, \mathrm{N}, \mathrm{E})$ on three pages. (Q data in TDA \# 006.DV.007 -- derived from TDA \# 006DV.003.) 


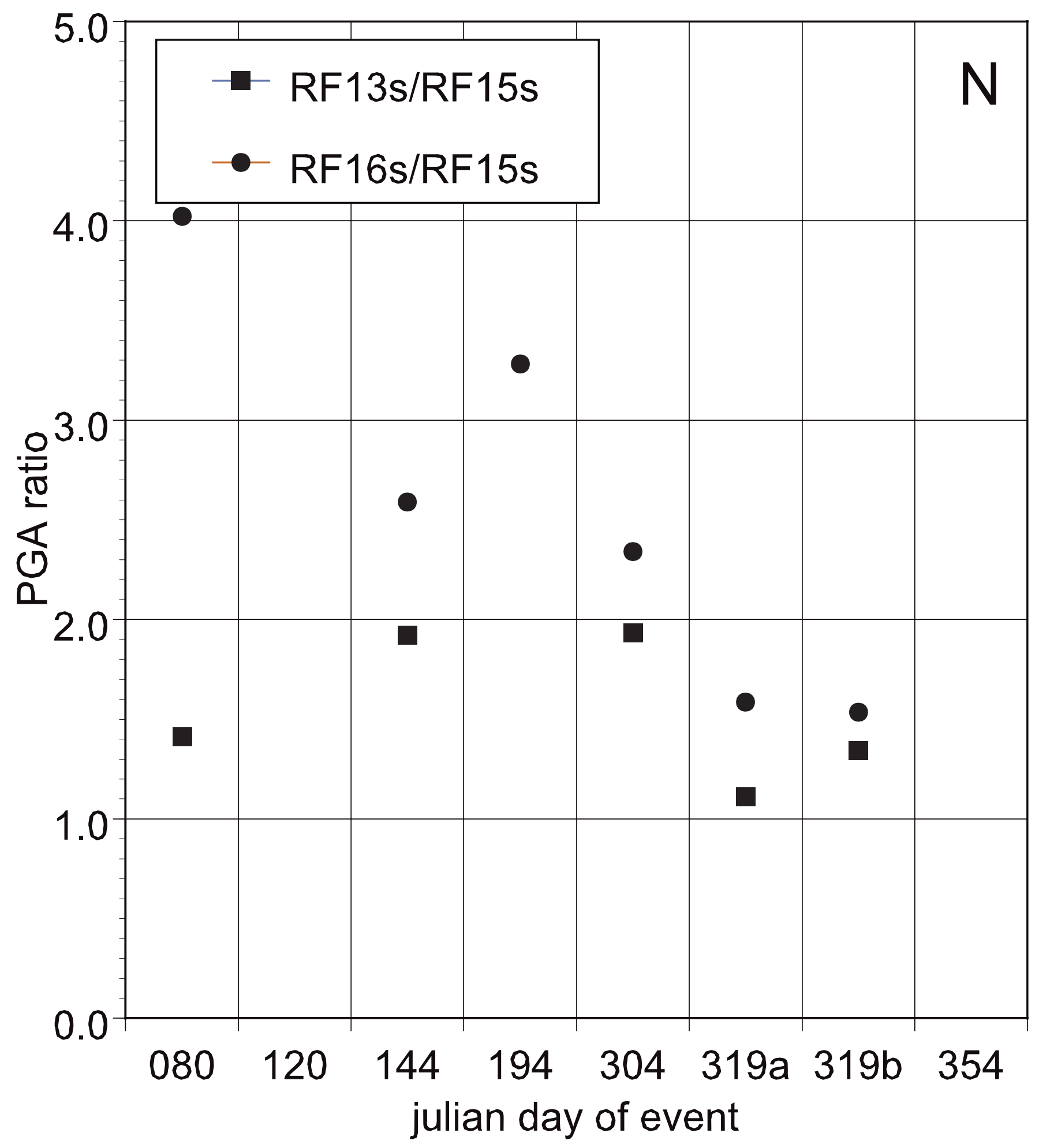

14b. Ratio of RF13 and RF16 PGA's to those of RF15, the reference site. Ratios are computed from the data displayed in Figure 4 and grouped by component $(\mathrm{Z}, \mathrm{N}, \mathrm{E})$ on three pages. (Q data in TDA \# 006.DV.007 -- derived from TDA \# 006DV.003.) 


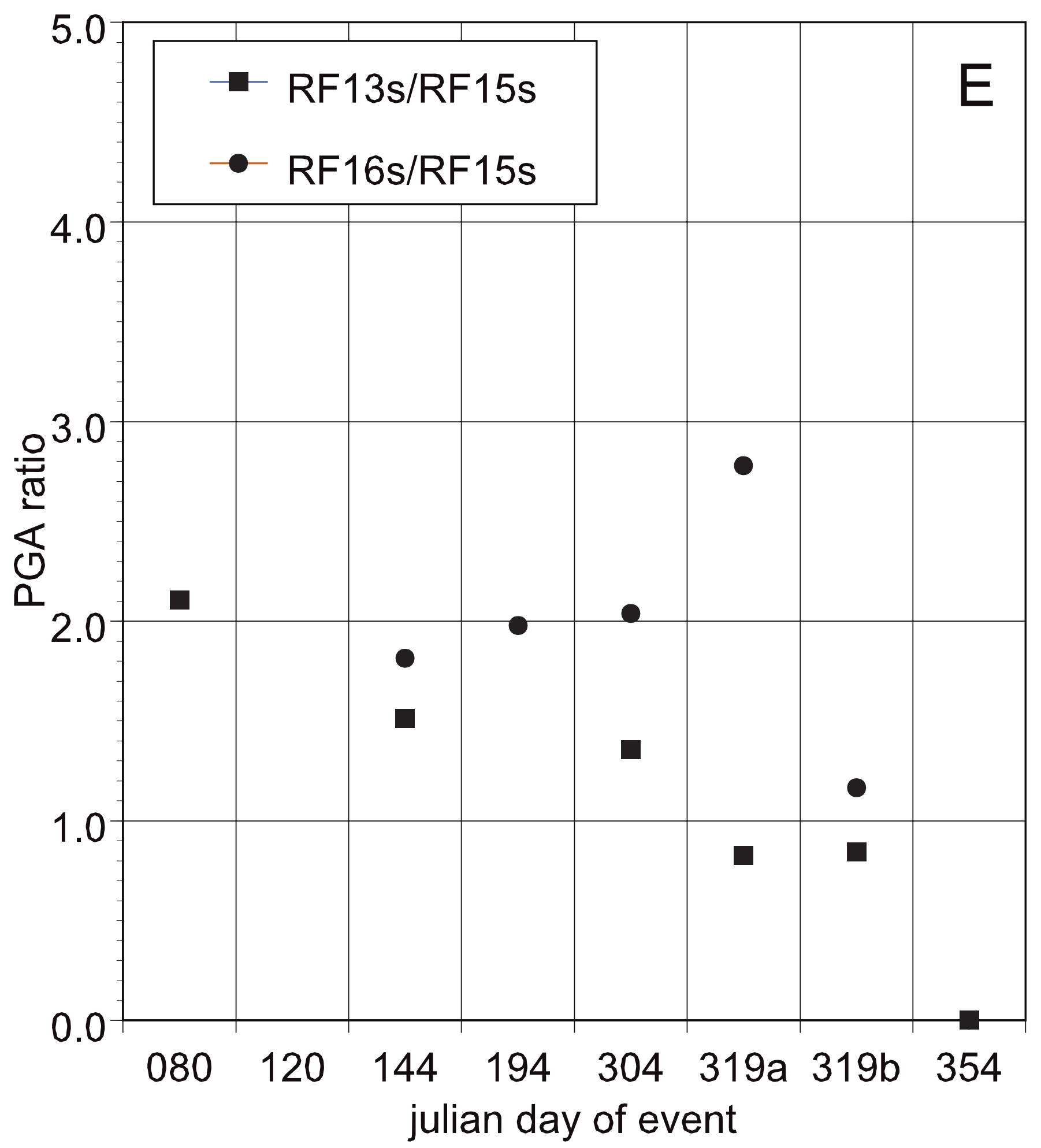

14c. Ratio of RF13 and RF16 PGA's to those of RF15, the reference site. Ratios are computed from the data displayed in Figure 4 and grouped by component $(\mathrm{Z}, \mathrm{N}, \mathrm{E})$ on three pages. (Q data in TDA \# 006.DV.007 -- derived from TDA \# 006DV.003.) 

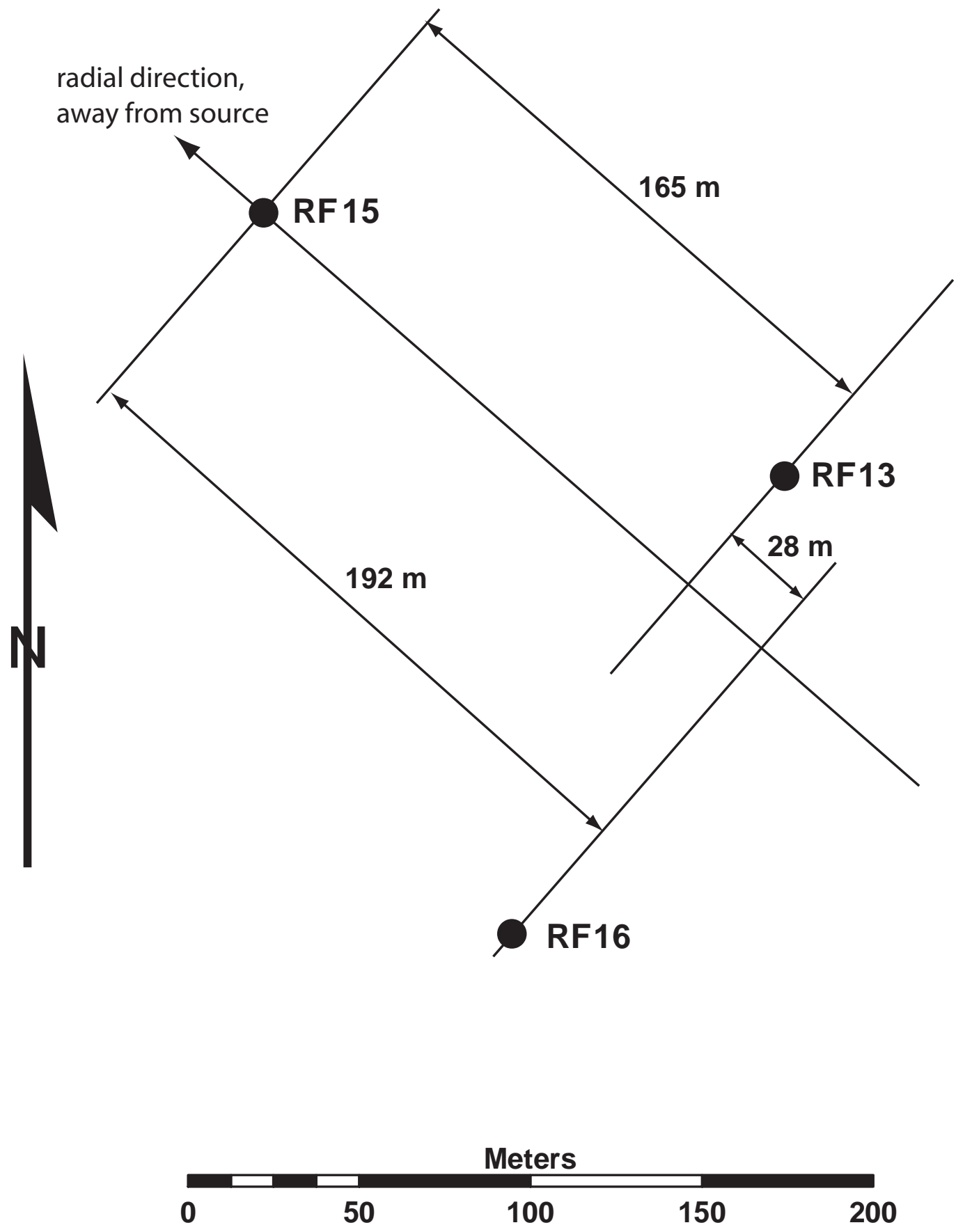

15. Geometry of signal propagation across the ESF pad for the Rock Valley earthquake on day 304. The projection is UTM. 
Initial Borehole Accelerometer Array Observations Near the North Portal of the ESF
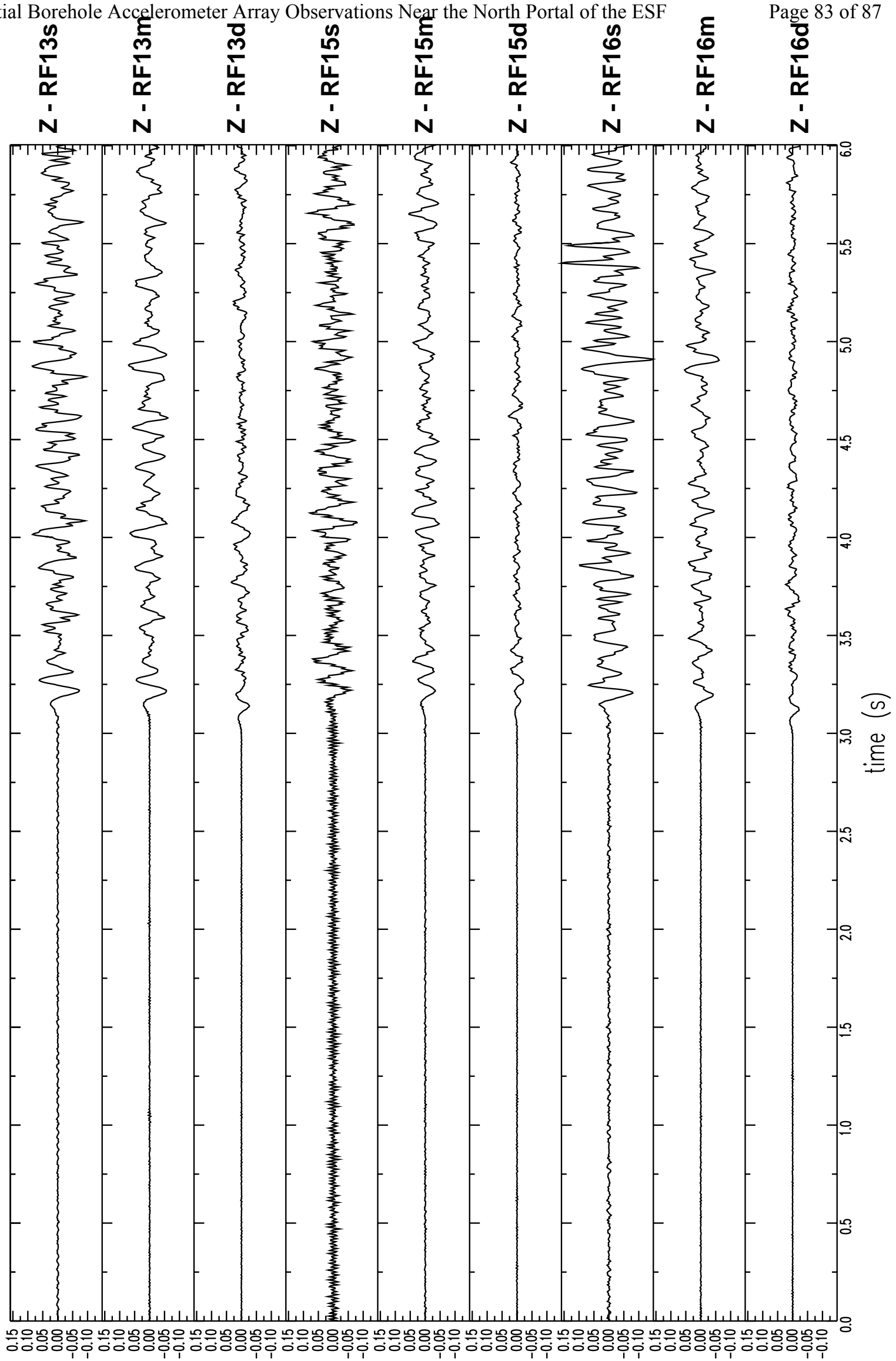

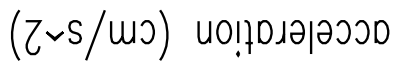

16. P waves of the earthquake on day 304 in Rock Valley (Table 3). The recordings are at $200 \mathrm{sps}$; 60-cycle noise is clear on the surface accelerometer recordings. (Q data in TDA \# 006DV.003.) 


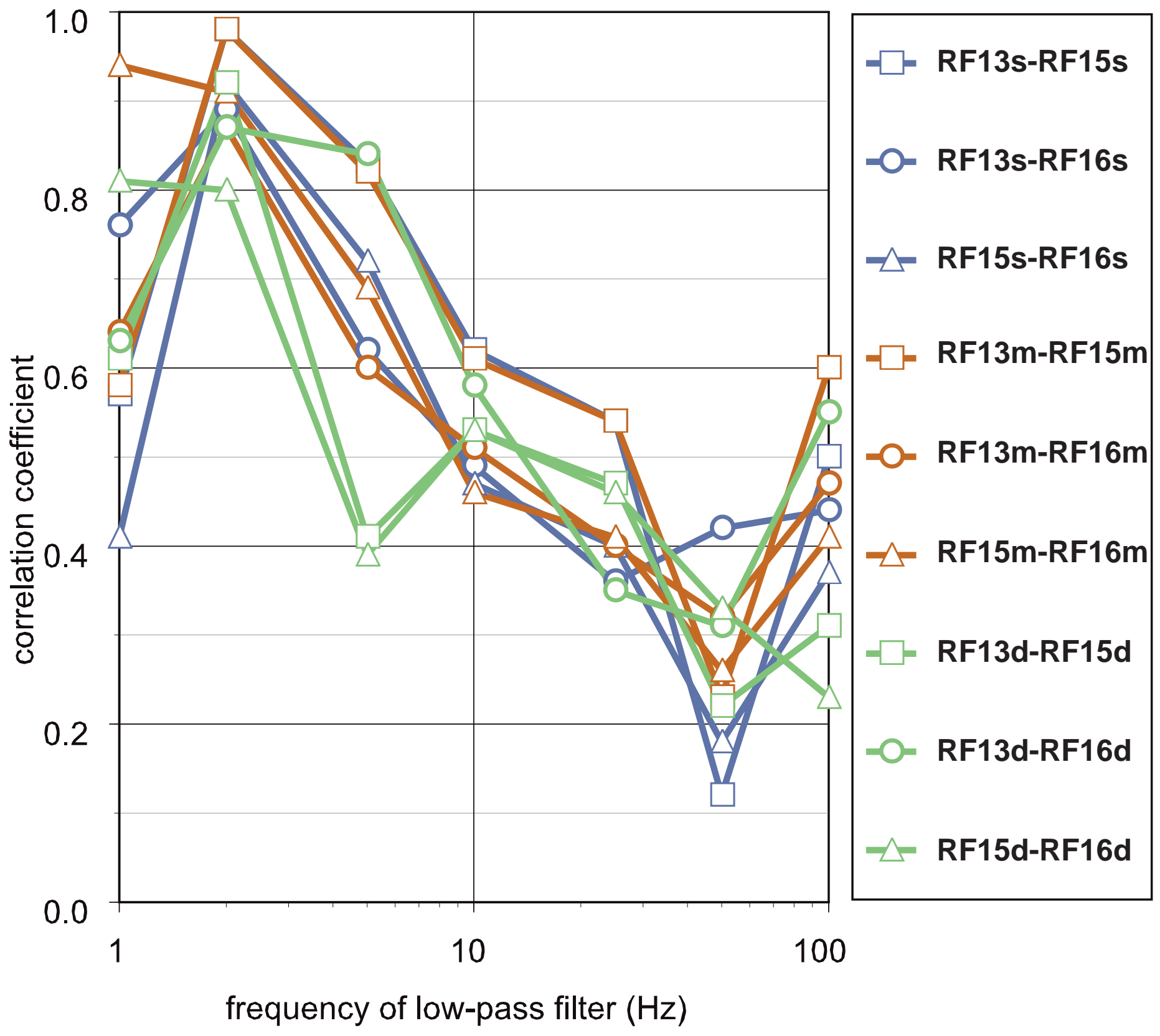

17. Correlation coefficients of the $\mathrm{P}$ waves among the three boreholes for different lowpass cutoff frequencies. "s" = surface, " $\mathrm{m} "=$ midhole, and "d" = deep. Only coefficients among recordings at similar depth (s,m,d) were computed. (Q data derived from TDA \# 006DV.003 with program SAC.) 

on day 304 in Rock Valley (Table 3). The transfer functions are the ratios of surface to deep spectra. (Q data derived from TDA \# 006DV.003 with program SAC.)

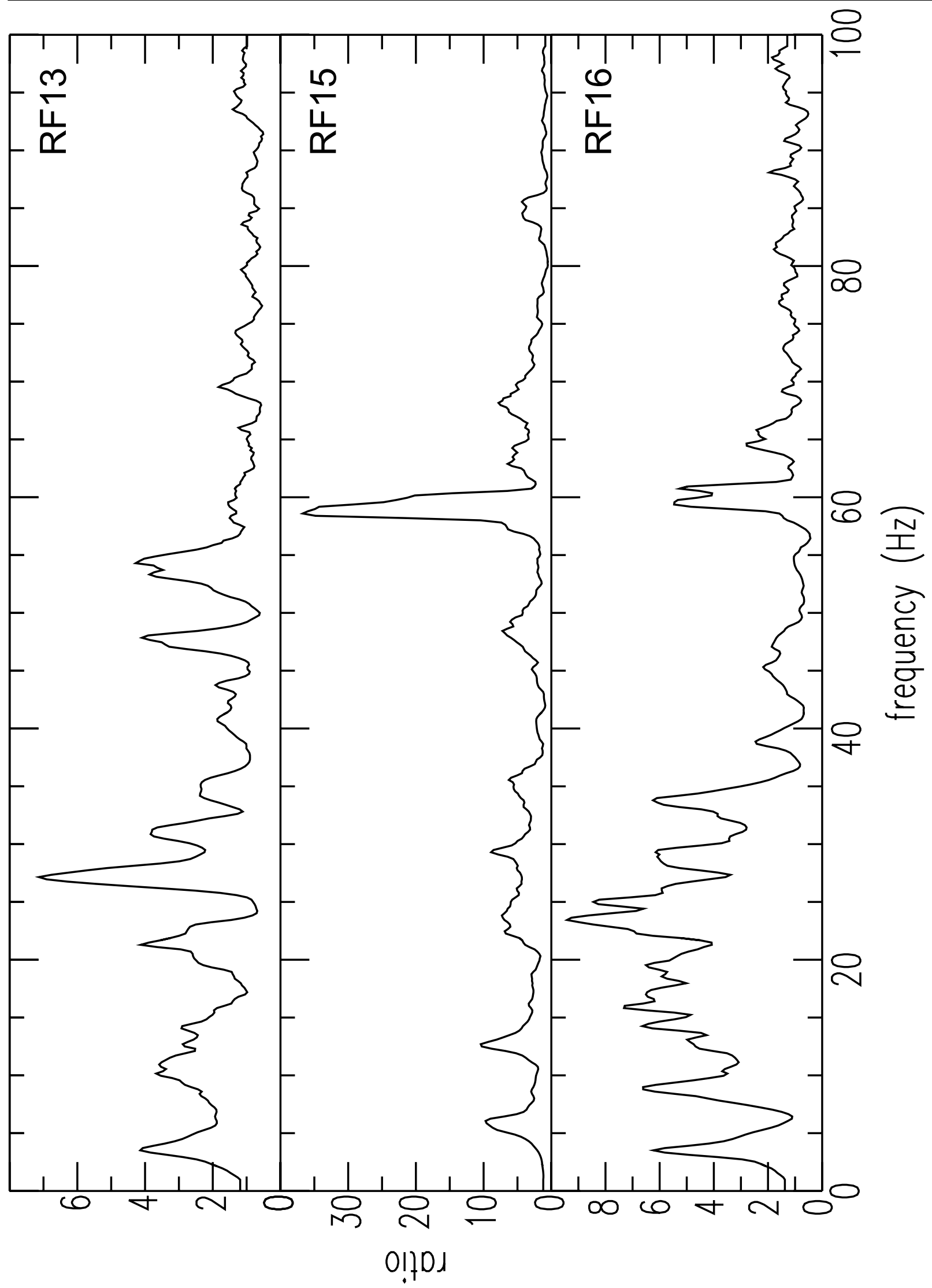



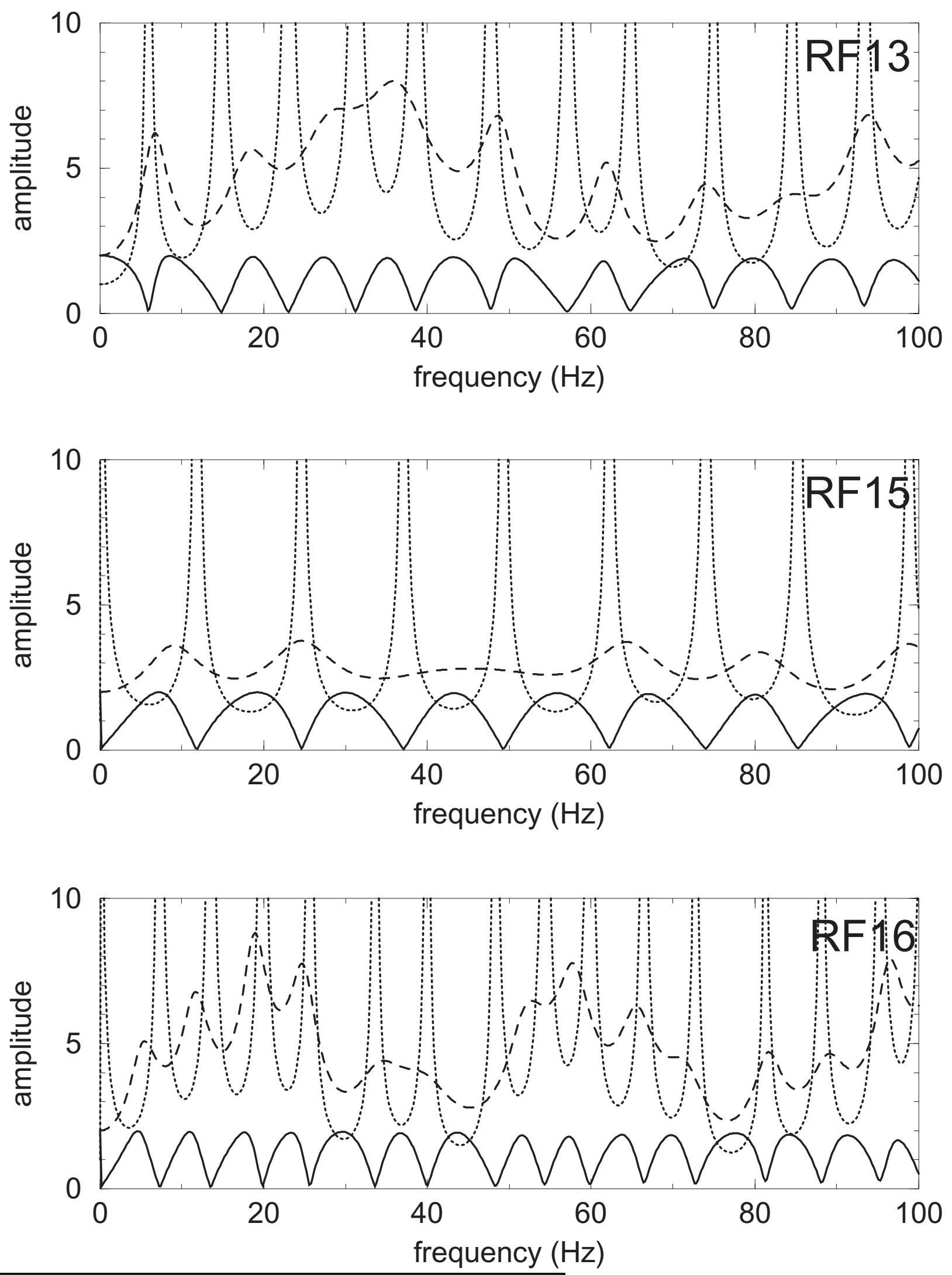

19. Computed P-wave transfer functions at the three boreholes. A simple 1-D model with vertically propagating waves was assumed at each borehole. (non-Q: not to be used for quality-affecting work; source data from 006DV.003.)

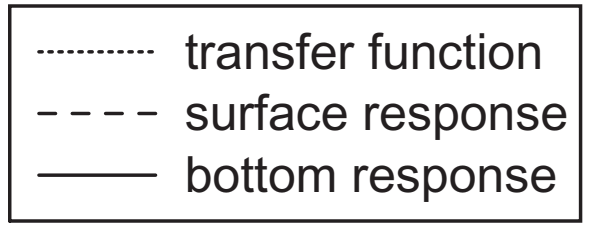




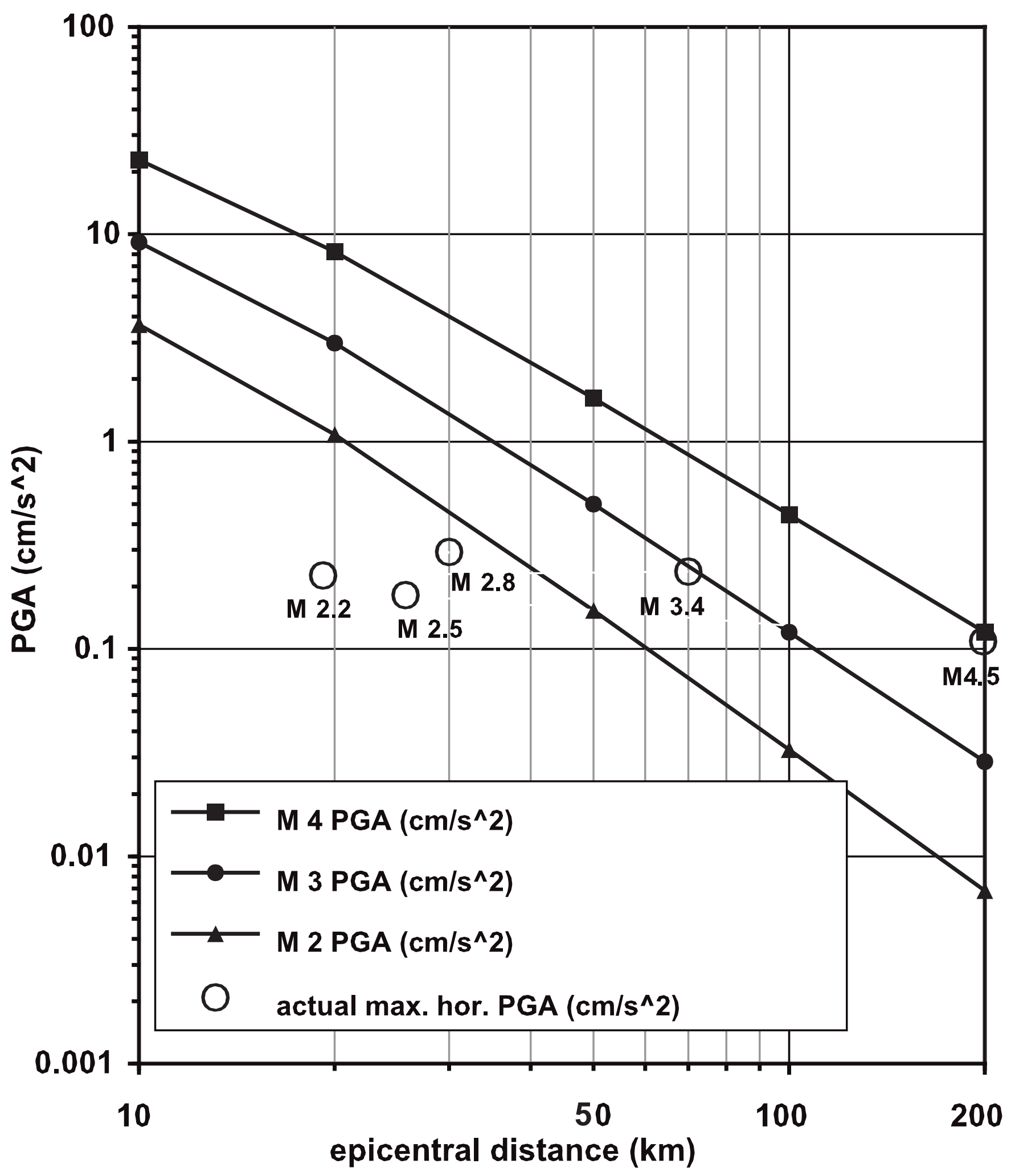

20. Observed peak horizontal accelerations recorded at the surface accelerometer at borehole RF15 (the "reference" site) versus extrapolations of the PSHA equations (CRWMS M\&O, 1998). (Observed data points are Q data in TDA \# 006.DV.007 -- derived from TDA \# 006DV.003; PSHA extrapolations are non-QA. Not to be used for quality-affecting work.) 